\title{
Review
}

\section{Formulation in Surfactant Systems: From-Winsor-to-HLDN}

\author{
Jean-Louis Salager *, Ronald Marquez *, Johnny Bullon *, Ana Forgiarini *
}

Laboratorio FIRP, Universidad de Los Andes, Mérida 5101, Venezuela

*Correspondence: jl.salager@gmail.com; marquezronald.ula.ve@gmail.com; jbullontorr@gmail.com; anafor.ula@gmail.com

\begin{abstract}
Formulation is an ancient concept, although the word has been used only recently. The first formulations made our civilization advance by inventing bronze, steel, and gunpowder; then, it was used in medieval alchemy. When chemistry became a science and with the golden age of organic synthesis, the second formulation period began. This made it possible to create new chemical species and new combinations "à la carte." However, the research and developments were still carried out by trial and error. Finally, the third period of formulation history began after World War II, when the properties of a system were associated with its ingredients and the way they were assembled or combined. Therefore, the formulation and the systems' phenomenology were related to the generation of some synergy to obtain a commercial product. Winsor's formulation studies in the 1950s were enlightening for academy and industries that were studying empirically surfactant-oil-water (SOW) systems. One of its key characteristics was how the interfacial interaction of the adsorbed surfactant with oil and water phases could be equal by varying the physicochemical formulation of the system. Then, Hansen's solubility parameter in the 1960s helped to reach a further understanding of the affinity of some substances to make them suitable to oil and water phases. In the 1970s, researchers such as Shinoda and Kunieda, and different groups working in Enhanced Oil Recovery (EOR), among them Schechter and Wade's group at the University of Texas, made formulation become a science by using semiquantitative correlations to attain specific characteristics in a system (e.g., low oil-water interfacial tension, formulation of a stable $\mathrm{O} / \mathrm{W}$ or W/O emulsion, or high-performance solubilization in a bicontinuous microemulsion system at the so-called optimum formulation). Nowadays, over 40 years of studies with the hydrophilic-lipophilic deviation equation (HLD) have made it feasible for formulators to improve products in many different applications using surfactants to attain a target system using HLD in its original or its normalized form, i.e., HLDN. Thus, it can be said that there is still current progress being made towards an interdisciplinary applied science with numerical guidelines. In the present work, the state-of-the-art of formulation in multiphase systems containing two immiscible phases like oil and water, and therefore systems with heterogeneous or micro-heterogeneous interfaces, is discussed. Surfactants, from simple to complex or polymeric, are generally present in such systems to solve a wide variety of problems in many areas. Some significant cases are presented here as examples dealing with petroleum, foods, pharmaceutics, cosmetics, detergency, and other products occurring as dispersions, emulsions, or foams, that we find in our everyday lives.
\end{abstract}

Keywords: colloids; interface; formulation; surfactant; cosmetics; petroleum; food; paint; pharmaceutics; emulsions; foams; dispersions; HLDN

\section{Definition of formulation}

Physicochemical formulation [1-3] has been used by humanity to attain products with tailored properties to meet particular needs [4-7]. The properties of the formulated product can be its stability or instability over time, its reactivity with the environment or with a particular substance, its safety of use, its conditioning and presentation, its thermal or electrical conductivity, its viscosity or rheology, its wettability, its appearance, texture, color, smell, etc. [8-22].

Formulation combines two aspects: First, the knowledge that relates the product content with the desired effects and properties, which are associated in general with chemistry, physics, and physical chemistry [23-27]. Equilibrated systems are essential in this case, and their behavior has been studied by thermodynamics at a high scientific level. Second, formulation includes the operations used to 
manufacture the product that involves the association of the ingredients and the final conditioning of the product $[9,28-30]$. This often has to do with temporary, out-of-equilibrium, and irreversible phenomena, the outcome of which usually depends on the history of manufacture [31-36]. These aspects are superficially studied in classical university education in Science and Engineering because their scientific management requires the use of non-continuous or derivable functions. It is the case of nonequilibrium phenomena, including hysteresis, and although they are currently used in practice, they are sometimes difficult to explain and, eventually, contrary to elementary logic. In any case, formulation is intended to obtain a product (usually commercial) with a well-defined objective, and capable of satisfying a list of diverse requirements that imply, in many cases, a multidisciplinary collaboration $[1,37,38]$.

In general, the industrial sectors that deal with formulation are highly specialized and associated with know-how representing a high percentage of the product's commercial value. This is either because they are complicated (requiring a high scientific level) or unique, confidential, and often protected by patents.

Industries that manufacture commodities (caustic soda, fuels, iron, and non-ferrous metals, etc.), or "fine" specialties, but common chemicals (acetyl salicylic acid, sodium hydroxide, trichloroethylene, vinyl chloride, soaps, etc.), are inserted into a competitive market. Thus, their value depends on production operations (raw material, extraction, chemical synthesis) and not on formulation [39].

On the contrary, industries that make products whose value does not depend on the availability of ingredients, but on their association and combination to produce synergies, with a lot of confidential know-how and long experience, require the use of formulation fundamentals and applications. When there are several levels of quality for a product, such as in paints, foods, detergents, household and hygiene products, perfumes, etc., basic or ordinary products are economical. On the other hand, products with high performance and a high price belong to the formulation industry. This section should provide a detailed account of the development history, including the origin, key breakthroughs and current status of formulation in colloids and interface science phenomena [40-44].

\section{Formulation with surfactants in human history}

Formulation of the first soaps proposed in Babylon almost 4,500 years ago consisted of cooking vegetable oils and fats neutralized or saponified with alkaline ashes [45]. This type of soap-like material has been found in clay cylinders excavations. They were used to clean wool and then found to help as a healthcare measure by Pharaohs for therapeutic procedures and skin diseases. Results of interest in food, medicine, and other subjects were achieved, all by trial and error, often being random. Year after year, the human species was organized into groups, countries, and civilizations and developed formulations to change their life, such as processing metals, making alloys like bronze and then steel, inventing gunpowder, etc. After the Middle Ages, many formulations emerged, sometimes even though as magical, being its main representative Paracelsus, a physician and toxicologist who used elemental chemicals in low quantities (as colloidal gold) to heal people [21]. When chemistry became a science with Lavoisier 300 years ago, the second stage of the formulation was reached, particularly with the starting golden period of organic synthesis in the mid-1800s, with the availability of new substances for a specific use. However, only in the last 75 years did the relationship between formulation and the properties achieved in a product, considered a complex system, were understood from the physicochemical point of view [46]. As a result, a phenomenological inference has been reached that allows the invention of new materials according to precise needs, including ecofriendly considerations, among others. Therefore, elaborating formulations is now a truly scientific creative work, based on knowledge and practical know-how accumulated over centuries $[8,43,46]$.

Today, formulation is defined as the knowledge and the experiences build-up during the selection, mixing, association, and conditioning of ingredients to obtain a well-defined commercial product capable of satisfying a pre-established list of requirements [1]. With this definition, it is easy to understand that formulation is an interdisciplinary science that requires exceptional collaboration between professionals with diverse competencies in various fields of knowledge, from academic to industry.

This presentation will be limited to formulation cases in heterogeneous systems that are the most important in practice. They are products with an interface between liquid(s), gas, and solid, such as emulsions, foams, suspensions, single or multiple, and of course, surfactants. In order to produce the 
required properties, these molecules adsorb at the interfaces and are involved in many association phenomena in the bulk.

\section{Formulation of a complex product}

A formulated product contains, in general, several ingredients. On the one hand, the active materials that fulfill most of the main functions sought and, on the other hand, the auxiliaries or additives that improve the use and performance during the different stages of its handling [1].

Active substances are the essential ingredients because they determine the desired primary function in most cases. In general, formulation aids are indispensable for various reasons, particularly as a vehicle of active matter. They are of different types and are classified according to their main role in the product. Other aids, which are generally called additives, promote additional properties that facilitate the use of products. Finally, aids or process additives make it possible to improve the effectiveness of the active material or facilitate its use in real conditions, particularly from the economic and ecological points of view. They are often the ingredients found in the most significant quantity. Water is, of course, the most common liquid product. Still, there are solvents or oily liquids and, sometimes, homogeneous mixtures or heterogeneous dispersions with properties of interest such as emulsions, foams, and suspensions. The knowledge on these aspects has changed considerably in the last halfcentury with the development of thermodynamics and physical chemistry applied to mixed systems.

On the other hand, in the last period of the formulation, after the Second World War, a new category of ingredients appeared that produced an important effect despite being present in small quantities. They are sometimes called optimization agents, whose role is based on complex, innovative properties and sometimes unique molecular interactions, such as surfactants and polymers.

Surfactants and polymers were initially used as:

- Interfacial agents to lower tension, adsorb in monolayers, change the wettability, form various types of dispersions (emulsions, foams, suspensions), stabilize them, or on the contrary, break them.

- Rheology modifying agents or gel-forming agents, used to reduce fluid friction, fluidify a powder, produce a pseudoplastic or viscoelastic non-Newtonian rheology, or even attain a particular texture.

In addition to the above properties, which can be described as direct, since they have to do with the basic effects of these molecules, surfactants and polymers have more complex effects that have been understood thanks to the advanced scientific level attained. Among the main properties products obtain are their protection from thermal, physical, or biological degradation, which are essential. Examples of mechanisms to achieve this are the following properties:

- Stabilizing agents to prevent separations, e.g., avoiding sedimentation, coagulation, flocculation, coalescence, precipitation, etc.

- Stabilizing agents that form new stable structures, e.g., producing micelles or more complex aggregations such as liquid crystals, vesicles, liposomes, etc.

- Destabilizing agents, e.g., destroying association, sometimes using surfactants to attain the socalled optimal formulation.

- Compatible agents that allow very complex effects, e.g., to change the wettability of a solid surface or make compatible components that usually would separate.

\section{Mono and multiphase formulations}

In the case of homogeneous systems, i.e., single-phase, significant scientific advancement came from the development of Hildebrand and Scott's theory of regular solutions based on the concept of solubility parameter introduced in 1950. Charles Hansen, a scientist working on paints, which are formulated systems containing many ingredients of different sources, proposed a decomposition of the solubility parameter into several terms that correspond to three separate interactions, qualified as non-polar, dipole, and hydrogen bond [47,48].

Heterogeneous systems are, in general, complex and their persistence or stability is a critical problem that must be controlled. These systems contain two or more immiscible phases and will separate in a timeframe from seconds to centuries. In general, one of these phases of the heterogeneous system is a continuous liquid phase, and the other phase is in dispersed form in fragments that tend to separate. The most common case is a system composed of two immiscible liquids, referred to as water 
and oil. In general, one polar phase, such as an aqueous solution and one non-polar phase, such as an oil, thus, separating sooner or later.

Heterogeneous systems with small fragments are very common in practice. If these fragments are relatively small, so small as not to be visible to the naked eye $(<200 \mu \mathrm{m})$, they may have similar or even better properties than a single-phase system. They are classified as micro-heterogeneous systems and, depending on the type of fragments, are called emulsions (liquid-liquid), foams (gas-liquid), suspensions (solid-liquid), and sometimes with other terms such as suspo-emulsions (oil/water emulsion containing solid particles, as is the case with paints and various foods).

The presence of at least one dispersed phase with small fragments implies a large interfacial area. Therefore, the system requires, in many cases, an agent with interfacial properties to remain kinetically stable. These are usually called surfactants with a small molecular size (molecular weight 200-500 $\mathrm{Da}$ ) or polymeric surfactant when it is a large molecule (molecular weight up to hundreds of thousands of Da). Another type of droplet or bubble stabilization can occur with solid nanoparticles that go to the interface of form an encapsulation layer around the fragments, in which case we speak of Pickering emulsions or foams [49-54].

The presence of several phases in micro-heterogeneous systems (2 phases or more) makes phenomena much more complex, in particular in terms of persistence over time since, sooner or later, the phases will be separated. However, while it is true that the persistence of a few minutes or a few hours can be an inconvenience in some cases, it is likely that in other cases, the absence of change in months or years is essentially equivalent to thermodynamically stable systems. That is why stability is reported as the time during which an identifiable change occurs in the product, such as a $50 \%$ separation of a phase.

It will be noted that, in some instances, a micro-heterogeneous system in the form of a fine dispersion allows exceptional and attractive solutions to problems. These solutions are even extraordinary when they eliminate conflicting effects to achieve what is wanted of rheology, texture, persistence, tension, wettability, fluidity, robustness, etc. [55-64].

\section{What is formulating?}

Formulating consists essentially of three aspects. The first is choosing the ingredients and putting them together properly to manufacture the product with the desired properties. The second is to use the product according to the properties it must present. The third has to do with how the product looks, stays, or disappears after use.

As a first step, this implies assembling groups of people capable of handling scientific, technological, economic, ecological, and even legal problems. Given the requirements of varied competencies, it is not possible to find a person specialized in all aspects. Chemists, physicists, biologists, and various engineers are necessary even in the non-scientific technical sector. In other words, an efficient group of formulators must be relatively large to create a global knowledge of a team and know-how about formulation's practical use. This is based on the experience accumulated by individuals who work in multidisciplinary teams. It also requires the group to learn to work systematically to be time effective and make the business economically feasible.

Thus, it means that know-how has to be attained quickly in a university research center, where knowledge generation generally happens without much time restriction. On the other hand, in an industrial sector research development center, what matters is to have fast and significant results, worrying less about the cost. This type of combination involves conflicts and is not often spontaneously successful. Therefore, it is essential to manage it in a scientific-technical-economic way, taking into consideration: the risk, cost, and interest that are estimated or determined according to the knowledge, know-how, and experience of the research team.

Risk has to do with the likelihood that organized work will achieve the purpose. The cost of time and financial resources depends on the staff's investigative efficiency. The interest has to do with the benefit that would be achieved by reaching the goal and is closely related to both scientific and technological innovation.

In the particular case of micro-heterogeneous systems, the knowledge attained after many years of research has allowed understanding better the systems' behavior, leading to predictive tools' development that permits ingredient selection to achieve products for specific needs. This has been done by introducing scientific-technical tools in the practical use of surfactant-water-oil systems such 
as the well-known numerical concept HLD (Hydrophilic-Lipophilic Deviation) and its normalized form HLDN, much more helpful than the previously presented HLB concept $[2,38,62,65-67]$.

Once the known antecedents have been assimilated, the basic scientific studies will be carried out to verify the possibilities of associating the active materials with the auxiliaries and additives, as indicated in the left part of Figure 1.

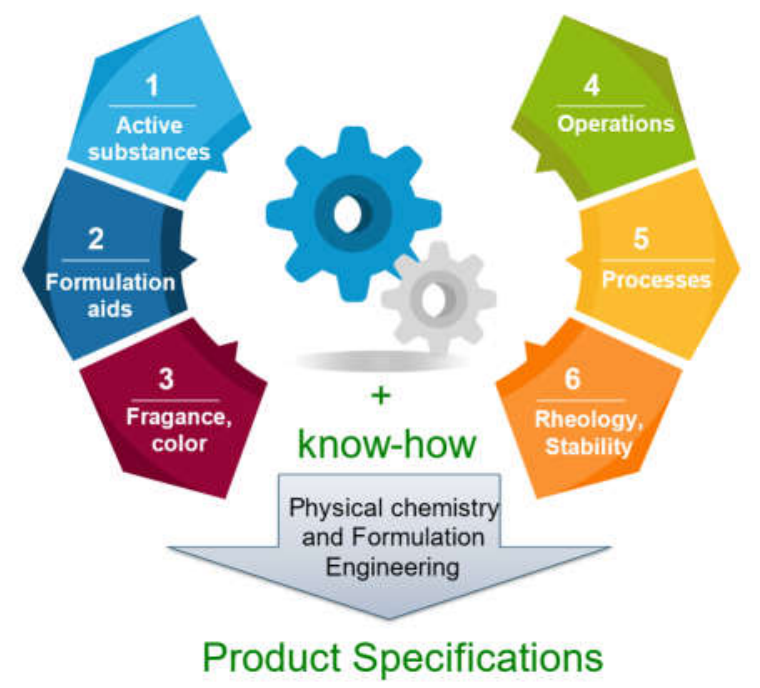

Figure 1. Requirements and steps in the formulation of a product

This type of work requires, in general, several types of equipment to study surfactants and polymers. It involves having an expensive inventory of devices (unless analytical services can be hired) in UV-VIS and FTIR spectroscopy, HPLC, $\zeta$-potential, NMR, granulometry, rheology, etc. This is what is often used in basic studies at the beginning of the formulation project.

Then, the operational variables must be manipulated by people who have scientific competence and technological experience. In heterogeneous systems, particularly micro-heterogeneous, there are many possibilities indicated in Figure 2, both in terms of knowledge about the phenomena involved and practical know-how.

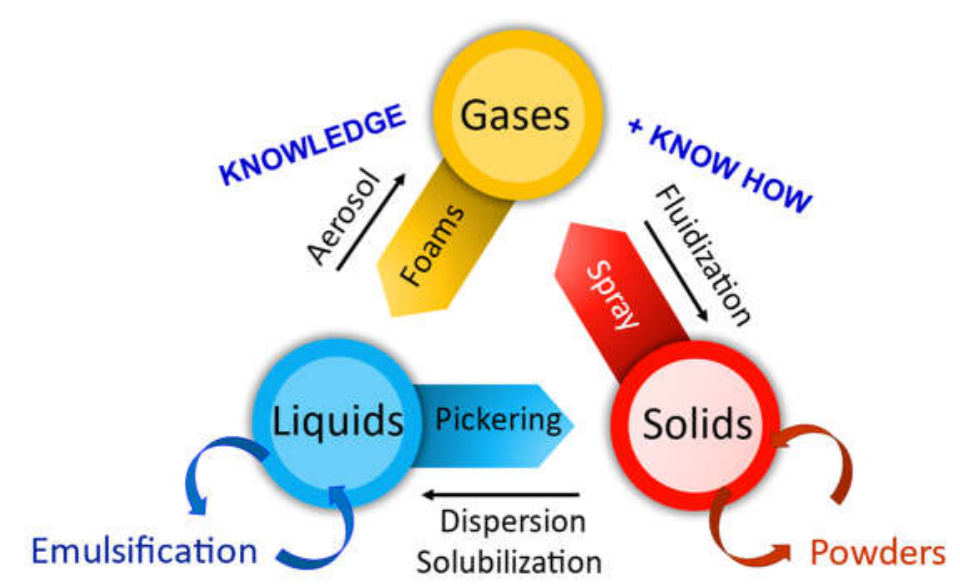

Figure 2. Phenomena involved in the formulation of micro-heterogeneous systems

These aspects necessary to deploy suitable industry solutions by formulating a product are generally limiting and often involve innovations in methods and the construction of new devices. Nevertheless, it is common for the formulation of a new product to be associated with the development of new instruments or an unprecedented combination never realized before. Successful examples can be found in several industries. 
Historically, soaps were used to clean wool to make fabrics in ancient times by the Sumerians, who reported the processes in cuneiform text tablets [68]. Then they were used by the pharaohs, the Romans, and later in the Middle ages as a healthcare measure to treat skin diseases, without knowing the basic principles of bactericide action of soaps that destroy the microorganisms membrane layers [45].

The works of Bancroft and other researchers in the years 1900-1920 on emulsions and applications were performed with various soaps [69,70]. However, only in 1920, synthetic chemical processes were implemented in Germany to produce new amphiphiles. Later, in 1932 alcohol sulfates production started (used in detergents Dreft ${ }^{\circledR}$ in 1933 and later Tide ${ }^{\circledR}$ in 1947), up to the mass production of branched alkylbenzene sulfonates for detergent applications in the 1930-40s, which were finally called surface-active-agents or surfactants in 1950 [71]. After 1960 new considerations related to sustainability (surfactants biodegradability) and performance issues (hard water, detergency, $\mathrm{pH}$ ), were developed by the industry [71-74].

Some unexpected episodes occurred in specific situations, like the case associated with the son (Patrick) of John F. Kennedy, who died from the so-called hyaline membrane disease (HMD), two days after his birth in 1963, just three months before the president assassination. This medical problem was killing about 25,000 premature infants each year in the USA at that time. Due to the currently known infant respiratory distress syndrome (IRDS), this death motivated more medical investigation and increased public awareness. It also inspired further research on the role of surfactants to avoid the collapse of lung alveoli when the newborn is starting to breathe. However, despite many original studies showing the complex role of surfactants, proteins, and potential inhibitors in the alveoli, it can be said that it was only since 2000, that there is a fairly effective treatment. The latter consists of injecting natural surfactants from lung lavages mammals, thus providing a medical solution in most cases [75].

The following non-exhaustive summary of surfactants applications includes a selection of different topics, which are listed with some personal criteria of the authors. It deals with the importance, historical occurrence, puzzling science, practical difficulty to understand, curiosity of use, understood mechanisms, solutions attainment, and urgent necessity. A plethora of more than 300 review books, from basic knowledge to specific applications and products containing surfactants, are available from many authors or editors, a dozen of them with several books, all that with a lot of repetition and sometimes misleading approaches. A famous surfactant science book series was started in 1967 by Marcel Dekker and was continued since 2003 by the CRC subsidiary from Taylor and Francis, and it is now at book numbers over 160. At least a third of these books deal with surfactants' domestic and industrial applications, an area that exploded in the past 30 years.

Thus, there is a vast quantity of published information with different knowledge and know-how between the academy and industry researchers, creating confusion, mainly because their priorities and motivations are in conflict. On the one hand, for academics, rigorous principles must be applied with strict mathematics or physics, sometimes with a fictitious model, a limited range, or an uncertain assumption. On the other hand, for industrials, a problem's solution has to be relevant, pertinently reached in a short time and with low spending, and eventually within some specific limits whatever the scientific strength on which it is based.

As Milton Rosen indicated, not in his famous general book in interfacial science [76], but in his concise practical opinion survey [77], the basic principles involved in surfactant science include many variables and many phenomena, and the real-life applications are too-far away from the available, often simplified, scientific models. Consequently, a relationship between the surfactant system and the application performance is often missing because of the limited scientific-technical experience of authors in both universities and industries. Therefore, we strongly recommend to the reader to assimilate Rosen's thorough description of the discrepancy between the academic and industrial R\&D approaches, which appears in the preface of his book [77], as some mismatching between the priorities of the scientist rigor and the technologist relevance.

Formulation with surfactants has been a subject of research for over 100 years. There is a vast body of knowledge on formulation with surfactants, including well-known authors or editors in interfacial sciences who have presented thorough review books, such as M. Bourrel [78], G. Broze [79], G. Cutler [80], S. Friberg [81], K. Holmberg [82], D. Langevin [12], C. Miller [83], K. Mittal [84], D. Myers [85], J. Sjoblom [86], T. Tadros [21], R. Zana [87] (listed in alphabetic order) and many others, which 
are not listed because it would require a dozen of years to be read. Thus, some bibliographic listings with hundreds of titles can be found in the literature. For example, by entering the term "surfactant" and "formulation" in Dimensions, Scopus, or Google Scholar databases.

An analysis of the keywords "surfactant" + " formulation" in the title and abstract in the databases Dimensions [88] and Scopus [89] indicates that there are today 12,000 to 17,000 publications related to the subject. Nevertheless, at the end of the 1970s (as depicted in Figure 3), an exponential increase in research in the field has generated multiple advances in universities and industries. In table 1, a list of the researchers with the most publications on the field is shown (Source: Dimensions and Scopus).

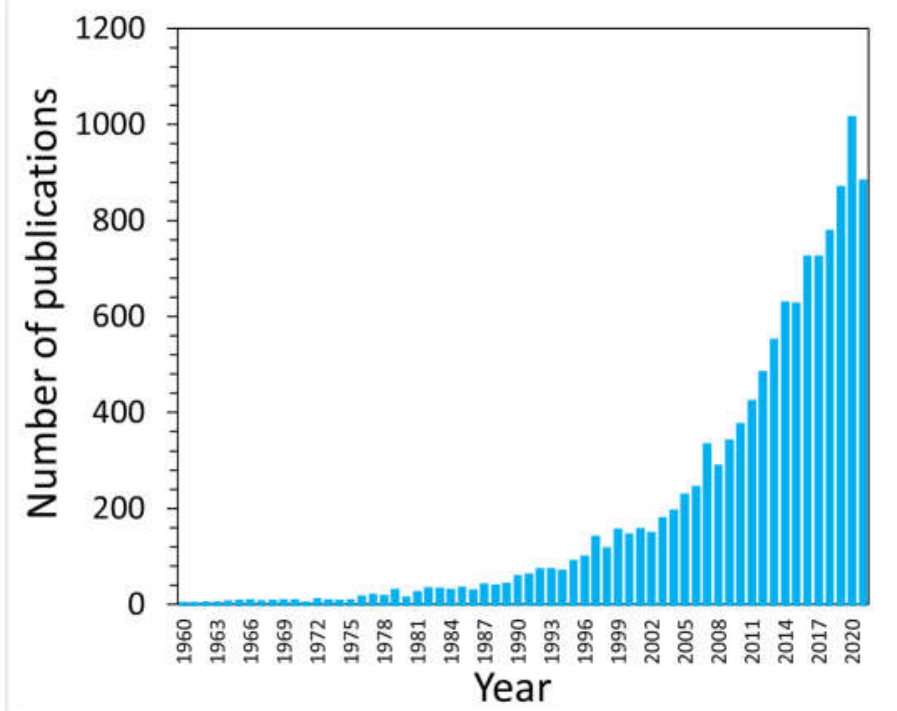

Figure 3. Number of publications per year with the keywords "surfactant" and "formulation" in the title and abstract since 1960. Source: Dimensions [88].

Table 1. Ranking of researchers with the greatest number of publications with the keywords "surfactant" and "formulation" in the title and abstract. Source: Dimensions [88] and Scopus [89].

\begin{tabular}{lcl}
\hline Author & $\begin{array}{c}\text { No of Publications } \\
\text { Dimensions (Scopus) }\end{array}$ & University \\
\hline Jean-Louis Salager & $78(94)$ & University of the Andes, Venezuela \\
Gary Arnold Pope & $64(64)$ & The University of Texas at Austin, U.S. \\
Edgar Joel Acosta & $45(49)$ & University of Toronto, Canada \\
David A Sabatini & $43(46)$ & University of Oklahoma, U.S. \\
Kishore Kumar Mohanty & $43(44)$ & The University of Texas at Austin, U.S. \\
Javed Ali & $36(49)$ & Jamia Hamdard, New Delhi, India \\
Jeffrey H Harwell & $35(34)$ & University of Oklahoma, U.S. \\
Mojdeh Delshad & $31(31)$ & The University of Texas at Austin, U.S. \\
Sanjula Baboota & $30(39)$ & Jamia Hamdard, New Delhi, India \\
Eliana Barbosa Souto & $29($ N.R.) & University of Coimbra, Spain \\
Farhan Jalees Ahmad & $27(17)$ & Jamia Hamdard, New Delhi, India \\
\hline
\end{tabular}

Additionally, a concept map was generated with VoSViewer text analytics module for keywords appearing at least 160 times, presented in Figure 4. It indicates the interconnection of three clusters of research, which can be classified in surfactant properties (green), macro- to nano- and microemulsions properties (yellow), and formulation of high-performance systems (blue). 


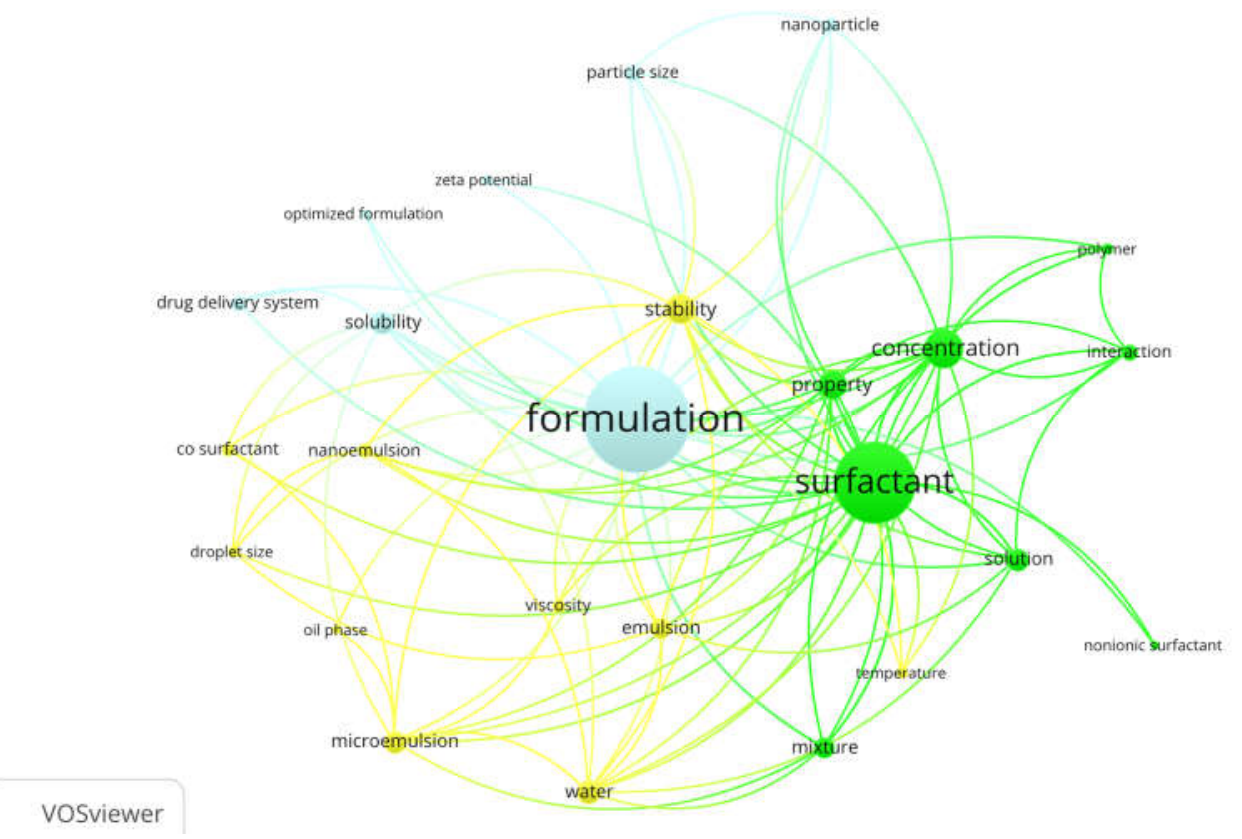

Figure 4. Concept map of publications related to the keyword search "surfactant" and "formulation" in Dimensions Database. Three clusters of research are shown: surfactant properties (green), emulsions and microemulsion properties (yellow), and formulation of high-performance systems (blue).

In order to illustrate such excess of information, particularly with its variety, the following paragraph contains a listing of only a dozen selected surfactant applications. There are only some references of a few publications to keep some moderation in the corresponding bibliography, in particular, those introducing an empirical but practical numerical approach with the so-called HLDN physicochemical description of the formulation of a surfactant-oil-water system with typically 6-7 different variables, with their advantages but also their limits.

1. Household products: washing machine detergents $[63,79,90-92]$, domestic cleaners, shampoo and hair conditioning products, etc. [93]. [62,94-97]

2. Griffin's hydrophilic Lipophilic Balance (HLB) historical proposal $[98,99]$ was probably somehow related to handling explosives safely with emulsions [100], although his company (Atlas Powder) patented the corresponding technology only a few years later.

3. The search of surfactant candidates to fairly resolve the enhanced oil recovery (EOR) during the crisis in the mid-1970s [101]. The basis is to change the interfacial phenomena effects using the R ratio theory proposed by Winsor at the Shell Research Center around 1950 [102]. Some empirical equations, so-called the Hydrophilic Lipophilic Deviation or Difference (HLD), with up to 6 variables $[103,104]$, considerably improved the prediction of optimum formulation for ultralow tension systems [62,105-108].

4. Ore flotation, i.e., separation of hydrophobized particles (ore) from hydrophilic ground, was a strong application of the wettability adjustment by introducing a proper surfactant $[109,110]$.

5. Surfactants already used in biology functions, e.g., eye wetting, lung surfactant behavior, medical and cosmetic attention, and for that often called biosurfactants, have a promising future [111,112], but currently, there are considerable difficulties and limitations.

6. Surfactants in emulsion breaking, particularly in crude oil dehydration, which is a complex but rather crucial application. In the last 20 years, intensive research has been performed on the subject, attaining specialized know-how in different aspects [113-122]. Mainly, the optimization of the formulation to attain performance and robustness in the formulation, strategies to minimize chemical dehydrant (demulsifier) dosification, and even the relationship between dilational interfacial rheology and the stability of emulsions in the vicinity and at optimum formulation [113-122]. Herein, we will not expand on the subject because there are many references, and the current state-of-theart can be found in an actualized review that has been published recently [123]. 
7. Food emulsions and foams [30,124,125], ice cream complex medium [24,126], and their stabilization with surfactants, polymers or particles have been used from antiquity [127-129].

8. Micelle filtration for chemicals recovery or water remediation, including toxic products like phenol removal [130].

9. Corrosion inhibition of metallic materials by surfactant adsorption on the surface and wettability change [131,132].

10. Surfactants used in other petroleum industry technologies such as drilling [133-136], acid stimulation and foam injection [137-139], and formation damage remediation [140-142]. This includes nanoemulsions formed with low energy emulsification [143,144].

11. Emulsion inversion techniques in industrial processes, in particular, to make very fine droplets for making highly stable emulsions [65,145].

12. Surfactants in heavy crude oil emulsified fluids for pipeline transportation or in asphaltic emulsions/dispersions of sand and gravel for road pavement [146-148].

\section{The Normalized Hydrophilic-Lipophilic Deviation (HLDN) as a semiquantitative tool to formu- late high-performance products}

We will start the scientific part of the subject with a brief introduction to better comprehend the increased research on the optimum formulation in SOW at the end of the 1970s. The political and economic troubles with crude oil production in the mid-1970s resulted in 10 times increase in its price over less than a decade. This was followed by a 3-4 year strong campaign of governmental R\&D financial backing, in particular in the US and European countries. It was felt that to improve the final oil recovery was essential, which was only at about $25 \%$ of the original oil with the water flooding the most advanced method at this time. This was a significant opportunity to develop investigations everywhere but forced both academic and industrial researchers to go to practical issues and publish their results. Winsor's R theory [102,149] on the occurrence of particular phase behavior in surfactant-oilwater (SOW) systems when the interfacial interaction of the adsorbed surfactant with oil and water phases were equal was rediscovered as it has been explained in details elsewhere $[2,62,136]$. The point was that the SOW formulation to attain a three-phase behavior in SOW systems corresponded to a (very low) minimum interfacial tension which was crucial for enhanced oil recovery (EOR) with surfactants [101].

The basic technique to find what was called the optimum formulation was to carry out a single variable scan to alter one of the interactions of the surfactant with the oil or water. These variables are the salinity of the aqueous phase, that when increased reduces the surfactant-water interaction, or an increase in the length of the surfactant tail, which increases the surfactant-oil interaction, and other variables like the hydrophilicity of the surfactant head group, the oil phase type, the temperature, etc. [78].

The first scan was carried out in the 1970s $[150,151]$ by changing the oil type in the n-alkane series in the so-called alkane carbon number (ACN) scan.
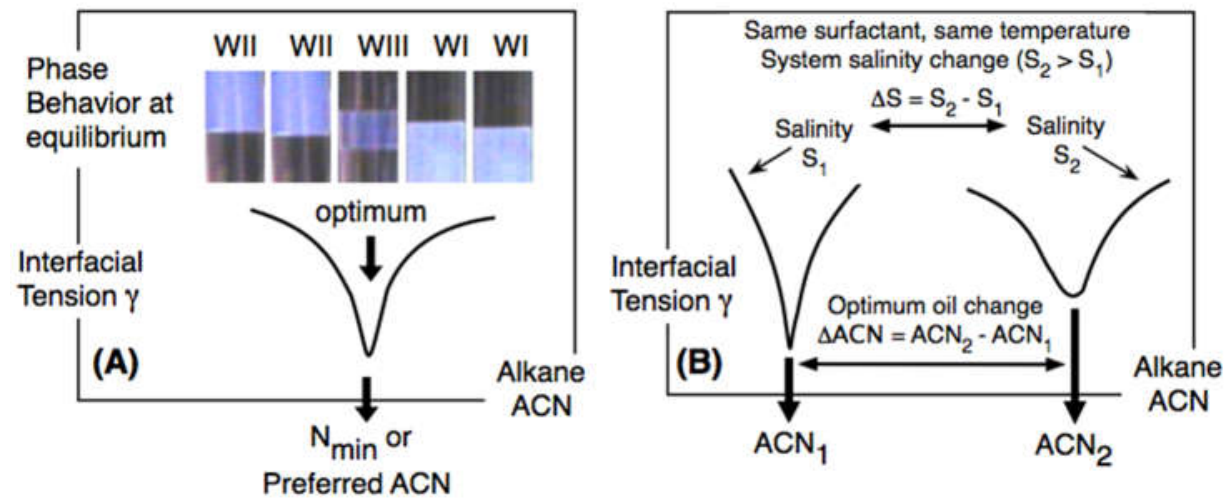

Figure 5. Oil-ACN scan for a typical surfactant-oil-water system. Left (A) plot: Phase behavior according to Winsor's types (WI, WII, WIII) and interfacial tension as a function of oil ACN. The bluish phase contains most of the surfactant with structured aggregates like swollen micelles. The variation of the interfacial tension has a minimum at $\mathrm{N}_{\min }$ or Preferred ACN. Right (B) Plot: Variations of the interfacial tension along the oil ACN scan for two systems with different salinities at all other variables (surfactant and cosurfactant, $\mathrm{T}$ and $\mathrm{P}$ ) constant. 
Figure 5 indicates the variation of the interfacial tension versus the oil's ACN for a given system. It is seen in left Figure 5(A) that at some ACN value (called first Nmin and then Preferred ACN in the 1970s), the interfacial tension passes through a deep minimum, typically $0.001 \mathrm{mN} / \mathrm{m}$ or less, which is well defined as far as the scanned variable is concerned as shown in the figure. The minimum tension occurs at the ACN formulation value corresponding to the center of the three-phase behavior zone. The surfactant has exactly the same interaction for the oil and water phases, which is called "optimum" because it is the best for EOR application. In the right Figure 5(B), the previous scan is repeated for two systems with different salinities, $S_{1}$ for the left plot and $S_{2}\left(>S_{1}\right)$ for the right one. The surfactant, eventual co-surfactant, temperature and pressure, and composition (surfactant concentration and WOR) are constant in both cases. Hence, Figure 5(B) indicates that when the salinity increases from $\mathrm{S}_{1}$ to $S_{2}$, then the optimum $A C N$ changes from $A_{C N}$ to $A C N_{2}$, i.e., there is some compensation between the salinity variation effect (the change of interaction of the surfactant with the water phase) and the $\mathrm{ACN}$ variation effect (i.e., the interaction of the surfactant with the oil phase).

Since both the $S$ and $A C N$ are numerical data, some quantitative equivalence can be written. The comprehensive studies of surfactant-oil-water systems, particularly at the University of Texas (USA) in the late 1970s, allowed to find the equation of the optimum formulation variation in the $\mathrm{S}-\mathrm{ACN}$ space $[103,104,152,153]$ as a fairly straight line which is essentially corresponding to the first power terms in a MacLaurin expansion as explained elsewhere [154]:
$\Delta \mathrm{LnS}=\mathrm{K}_{\mathrm{AI}} \triangle \mathrm{ACN}$
(1) for ionic surfactants
$\Delta \mathrm{S}=\mathrm{KAN} \Delta \mathrm{ACN}$
(2) for nonionic surfactants

where $\mathrm{S}$ is the salinity of the aqueous phase, for instance, in \%wt $\mathrm{NaCl}$, and $\mathrm{ACN}$ the number of carbon atoms in an $\mathrm{n}$-alkane oil phase. The $\mathrm{K}$ term value was found to considerably depend on the surfactant head group, e.g., 0.16 for alkyl benzene sulfonates, 0.10 for alkyl sulfates or carboxylates, 0.05 for some alkyl polypropoxy sulfate extended surfactants following equation (1), and 1.15 for alkyl ethoxylates following equation (2), as indicated elsewhere $[2,38,67,136]$. The $\Delta$ indicates the corresponding changes of the two variables to compensate each other and return to optimum formulation (B). It is important to note that salinity is expressed in a natural logarithm scale for ionic surfactant systems, anionic, cationic or amphoteric, and alkyl polypropoxy polyethoxy anionic extended species. The logarithm scale for salinity was used because it was found to fit better as a proportional change in equation (1). For nonionic surfactants that are much less sensitive to salinity, such salinity change effect is found to be smaller and rather proportional to the ACN variation, including close to zero salinity that can happen with nonionic surfactants.

Even if the $\Delta$ changes producing a straight line in experimental data may be relatively large, such variation can be mathematically indicated as a derivative function of the variables. i.e., as
$\mathrm{dLnS}=\mathrm{K}_{\mathrm{AI}} \mathrm{dACN}$
(3) for ionic surfactants
$\mathrm{dS}=\mathrm{KAN} \mathrm{dACN}$
(4) for nonionic surfactants

and equations (3-4) can be integrated as follows

$$
\begin{array}{ll}
\text { LnS }-K_{A I} A C N+C S T=0 & \text { (5) for ionic surfactants } \\
S-K_{A N} A C N+C S T=0 & \text { (6) for nonionic surfactants }
\end{array}
$$

The constant integration terms (CST) in equations (5-6) depend on the other variables that do not change in the double S-ACN scan, i.e., the surfactant and co-surfactant types and concentrations, the temperature, and the pressure. It was also found that there is an effect with the change in composition (surfactant concentration and water-to-oil ratio) when the surfactant and oil phase are not strictly pure. However, this is not to be discussed here to avoid unnecessary complications. Consequently, the CST term value depends on each system. It is generally determined by entering in equations (5-6) the experimental $\mathrm{S}$ and $\mathrm{ACN}$ values that produce a minimum tension or a three-phase behavior with the system.

Such a linear bi-dimensional variation of both oil ACN and water salinity $S$ was originally found to be valid over a relatively wide range (typically $\triangle \mathrm{ACN} \sim 8-10$ ) for both anionic and nonionic systems [103,104]. 
Figure 6 shows in more detail the occurring variations in a double scan method to experimentally determine the relative effects of two independent variable changes on attaining an optimum formulation.

The experiment starts at an optimum formulation point (1) where a three-phase (WIII) or minimum tension is attained. The first change (here $\Delta S$ or $\Delta \mathrm{LnS}$ ) results in a phase behavior system out-ofoptimum. In the present case, since the increase in salinity reduces the interaction of the surfactant with water, the phase behavior becomes WII with most of the surfactant in the oil phase at the intermediate point (i).

Then a second change is carried out on the other variable (here oil type) to produce a variation $(\triangle \mathrm{ACN})$ until the system returns to optimum at the new salinity value at point (2). Therefore, the increase in ACN tends to increase the oil-oil interaction (because it varies as the square of ACN) than the oil-surfactant interaction (which varies only as ACN). Thus, the global effect of an increased ACN is to decrease the overall surfactant interaction with the oil phase as discussed in details elsewhere $[78,155]$. In other words, as ACN increases, the oil becomes a worse solvent for the surfactant, and thus its interaction surfactant oil decreases.

This ACN increase is thus equivalent to producing a greater interaction of the surfactant with the water phase, i.e., it results in the opposite of the previous effect of increasing salinity.

Thus, this opposite variation of the two effects is evident with the different signs appearing in front of $\mathrm{S}$ and $\mathrm{ACN}$ terms in equations (5-6).

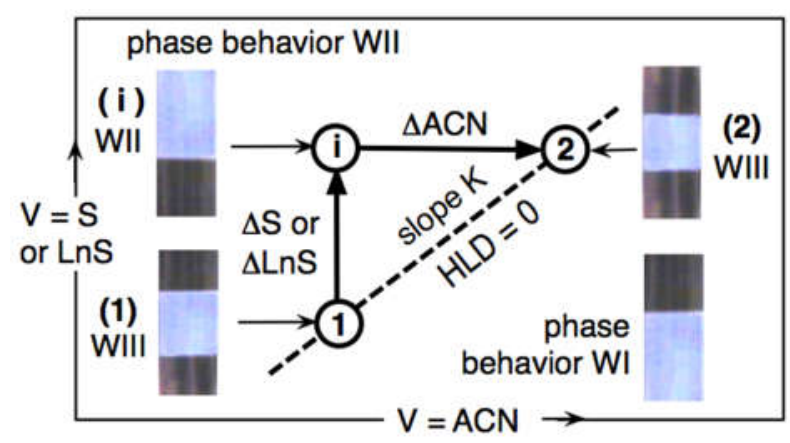

Figure 6. Double scan carried out with two variables (here $S$ and ACN). Starting from a system (1) at optimum and changing one variable ( $\Delta \mathrm{S}$ or $\Delta \mathrm{LnS}$ ) to go to an out-of-optimum intermediate system (i), and then carrying a second change, this time on the other variable $(\triangle \mathrm{ACN})$ up to a point (2) where the optimum behavior is found again.

Figure 6 indicates the occurrence of equations (1-2) for ionic and nonionic surfactants. It is worth noting here that in this double scan method, the numerical value for the relative effects of the changes in two formulation variables can be obtained, in this case, the water salinity and the oil ACN.

It is essential to underline that the equivalence of changes can also be written by dividing the equation by the ACN term coefficient $\mathrm{K}$, which results in new equations with a unit absolute value coefficient before the ACN term.

$$
\begin{array}{cc}
\text { KsI LnS }-\mathrm{ACN}+\mathrm{CST}=0 & \text { (7) for ionic surfactants } \\
\mathrm{KsN}_{\text {sN }}-\mathrm{ACN}+\mathrm{CST}=0 & \text { (8) for nonionic surfactants }
\end{array}
$$

It happens that this form of the equation is certainly better because it allows numerical comparisons with a variable $(\mathrm{ACN})$ scale, which has exactly the same meaning in all cases with no confusion. This avoids the misleading comparison of a change as $\Delta \mathrm{S}$ with a change as $\Delta \mathrm{LnS}$, or with a very different $\mathrm{K}$ coefficient because of different surfactant head groups. Another reason it has been proposed to add a unit coefficient in front of the ACN term in the equations is that it avoids different scales in surfactant or temperature effects in the CST term [156,157].

Equations (1-4) indicate that the optimum formulation takes place when there is an exact compensation of the hydrophilic and lipophilic effects at the interface. It means that the left part of the equation (7-8) is the summation of the interactions at their exact balance, with a hydrophilic contribution when the coefficient is negative and a lipophilic one when it is positive. In equations (7-8), the contributions 
are numerically expressed in the same units, i.e., one carbon atom in the n-alkane chain. These equations show only the lipophilic effect of increasing salinity and the hydrophilic effect of increasing $\mathrm{ACN}$. The remaining effects are hidden in the CST term, expressed in the same units, which gathers what does not vary in the used S-ACN double scan method.

Thus, the use of the abbreviation HLD for Hydrophilic-Lipophilic Deviation (or Difference) from zero has been proposed to express the exact equality of the interactions, including the summation of all effects in the left part of equations (7-8) [158]. This allows to improve the understanding of the effects of all variables. Subsequently, to avoid the problem of having different units for different surfactants as in equations (1-6), the HLD expression was divided by the ACN coefficient $\mathrm{K}$ to have the same (negative) unit coefficient in front of the ACN term in all equations $[2,62,67,136]$. The new name was the normalized HLD or HLDN.

$$
\begin{array}{ll}
\mathrm{HLDN}_{\mathrm{N}}=\mathrm{KSI}_{\mathrm{SI}} \mathrm{LnS}-\mathrm{ACN}+\mathrm{CST}=0 & \text { (9) for ionic surfactants } \\
\mathrm{HLDN}_{\mathrm{N}}=\mathrm{KSN}_{\mathrm{SN}} \mathrm{S}-\mathrm{ACN}+\mathrm{CST}=0 & \text { (10) for nonionic surfactants }
\end{array}
$$

In the $\mathrm{HLDN}_{\mathrm{N}}=0$ equation, the coefficients before $\mathrm{ACN}$ and CST are unity, with a negative sign for $\mathrm{ACN}$ and a positive salinity effect coefficient Ks. As before, this implies that the new CST term is a function of the remaining variables, i.e., the surfactant and co-surfactant types or effects and the temperature and pressure.

It is worth remarking that the Hydrophilic-Lipophilic Balance, so-called HLB value, introduced by Griffin a long time ago $[98,99]$ is essentially a parameter related to the surfactant effect. Thus, when HLB increases, for instance, when increasing the number of ethylene oxide groups EON of a nonionic surfactant, the surfactant becomes more hydrophilic, i.e., it will result in a negative participation in the CST term in equation (9-10).

For instance, this could result in a term $-\mathrm{K}_{\mathrm{H}} \mathrm{EON}$ in CST where the coefficient $\left(\mathrm{K}_{\mathrm{H}}=\partial \mathrm{ACN} / \partial \mathrm{EON}\right) \mathrm{de}-$ termined with an ACN-EON double scan is found to be about 6.7 for pure alcohol ethoxylates. The opposite effect in the CST term would occur when the surfactant alkyl tail (SAT), i.e., the number of carbon atoms in the tail, increases and results in a positive contribution in the CST term. It could be a term $+\mathrm{K}_{\mathrm{L}} \mathrm{SAT}$ where the coefficient $\left(\mathrm{K}_{\mathrm{L}}=\partial \mathrm{ACN} / \partial \mathrm{SAT}\right)$ determined with an ACN-SAT double scan is found to be generally 2.25 for n-alkyl tails.

Consequently, the effects of changes in the head and tail of an n-alkyl ethoxylate surfactant could be written as a contribution in the CST term in HLDN equation (6) as 2.25 SAT - 6.7 EON. This provides precise information that the addition of an ethylene oxide group in the head of a pure n-alkyl ethoxylate surfactant is perfectly compensated in the balance of interactions by the addition of three methylene groups in the tail (because 6.7/2.25=3)

Thus, the HLDN equation (10) for a system containing pure alcohol ethoxylates could be written with the additional effect of two more variables, i.e., EON and SAT as:

$$
\mathrm{HLDN}_{\mathrm{N}}=\mathrm{K}_{\mathrm{SN}} \mathrm{S}-\mathrm{ACN}+2.25 \mathrm{SAT}-6.7 \mathrm{EON}+\mathrm{CST}=0
$$

In equation (11), the CST term includes only the effect of remaining variables (e.g., the co-surfactant, the temperature, and the pressure) and the integration constant, which has to do with the references of all variables.

This method using two compensating effects produced by a bi-dimensional variation has been carried out in the past 40 years with all variables susceptible to alter the surfactant interactions with oil and water, i.e., salinity, $\mathrm{ACN}$, temperature, pressure, surfactant head, surfactant tail, surfactant intermediate for extended type, co-surfactant type and concentration, $\mathrm{pH}$, and probably others. The corresponding data schematically illustrated in Figure 7 can be found in old [103,104,159-169] and new articles [170-180], including a comprehensive review book [78] and recent general articles [2,136,157], which report the numerical value of the coefficients, i.e., the numerical value of the slope of the optimum line indicated in Figure 7 plots. 

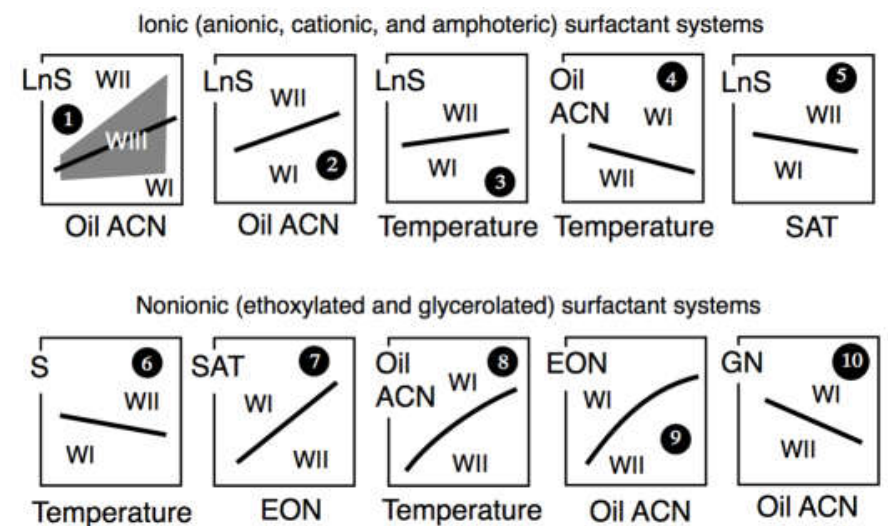

Figure 7. Schematic representation of the optimum formulation line in two variable spaces with the most practically used variables in a surfactant-oil-water system. GN indicates the number of glycerol groups in the corresponding kind of nonionic surfactant.

It is worth noting some particularities in these schematic plots. Figure 7, plot \#1 indicates in the LnSACN space the three-phase behavior zone in gray and the exact optimum formulation (i.e., the minimum interfacial tension) as the black line, which is in practice in the middle of the WIII zone. It is also seen in plot\#1 that the gray zone may be quite wide at high salinity and high ACN, in the ionic surfactant system. It is generally the same in all other plots, including the nonionic surfactant cases, particularly plots \#8-9, which are not strictly straight lines with commercial surfactants. It means that the accuracy of positioning the optimum line at the center of the WIII zone, and its linearity, is not the same in all cases. Although not precisely studied and published in detail, it has been known that sometimes the middle of the WIII zone along a (horizontal) ACN scan is not necessarily the middle of the WIII zone along a (vertical) S or LnS scan. This happens when the gray zone is not symmetrical compared with the optimum straight line.

The width of the gray zone in plot\#1 provides some extra information that could be interesting for some applications. As a systematic trend, it has been found that the wider the WIII zone, the lower the system's performance, as far as the minimum tension or the maximum solubilization at optimum is concerned [181,182].

When the optimum line indicated in Figure 7 plots is straight, it means that the linear relation appearing in equation $\mathrm{HLDN}_{\mathrm{N}}=0$ with any pairs of variables is pretty good over a range of $\triangle \mathrm{ACN} \sim 7-8$ or its equivalence in another variable scale. However, the linear range is not so wide when the line is shown twisted as in plots \# 8 \& 9 with nonionic surfactants. Figure 8 is a plot similar to the ones shown in Figure 7. However, it is exhibiting a deviation from linearity in the bi-dimensional EON-T studied range, where the EON indicated average value is attained by mixing two commercial surfactants of wide EON (Poisson) distributions each [183-186]. Acceptable linearity for such a case is only over an $\triangle \mathrm{EON}$ range of 0.5 units or a $\Delta \mathrm{T}$ range of $10^{\circ} \mathrm{C}$, which is equivalent to an $\triangle \mathrm{ACN} \sim 3-4$ units' range. This nonlinearity is believed to be due to the strong partitioning of the low ethoxylation oligomers into the oil phase, which results in a considerable difference between the average EON in the entire system and its value at the interface which could be 1-2 units higher.

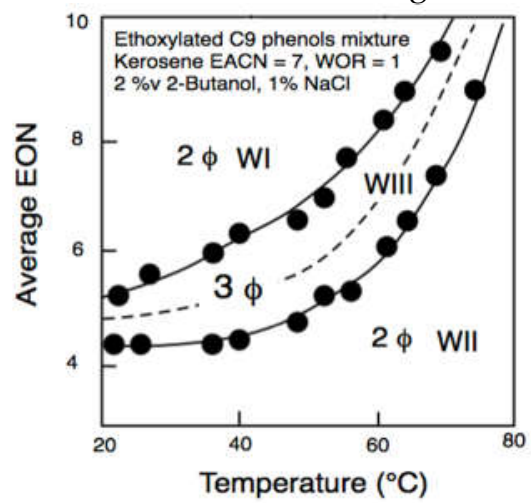

Figure 8. Three-phase zone and optimum formulation (dashed) line in a bi-dimensional space (EON-T), using a mixture of two commercial ethoxylated nonylphenols, both with a Poisson distribution [187]. 
Strict linearity over a wide range seems to be associated with the surfactant's purity, as discussed elsewhere [181,188-192].

It is worth remarking that when the optimum line slope is positive in a Figure $7 \mathrm{plot}$, it means that the two corresponding variables have a different sign in equation $H L D_{N}=0$. On the contrary, when the slope is negative, the two variables have the same effect on the interfacial interactions.

Comparing Figure 7 plots $\# 2$ and $\# 6$ or $\# 4$ and $\# 8$, it is evident that the temperature effect is opposite on systems containing ionic and nonionic surfactants. The temperature coefficient in the CST term will be negative for the first case and positive for the other, an interesting opposite effect that would permit to attain an insensitivity to temperature with a proper ionic/nonionic mixture of surfactants $[193,194]$.

In all surfactants, the increase in SAT, i.e., the surfactant alkyl tail length, tends to increase the HLDN, i.e., in practice, it tends to increase the surfactant lipophilicity and thus the CST term. In ethoxylated nonionic surfactants, the increase in the length of the head (EON number) tends to decrease the HLDN, i.e., in practice, it tends to increase the hydrophilicity of the surfactant and thus to reduce the CST term. Consequently, the SAT variable should appear in the CST term with a positive coefficient and the EON variable with a negative one as in equation (11).

The previously mentioned double scan method could be extended to a triple scan, involving not two but three changes. In such a case, the optimum line found in a double scan will become an optimum plane as reported in some publications $[2,163,195]$ but not used intensively because of more complex handling.

Expanding the HLDN expression (11) with the $S$ term coefficient and using the CST value from very accurate data [196], it was shown that for pure n-alkyl ethoxylate surfactant systems, the numerical HLDN equation was as follows $[2,136]$ :

$$
\mathrm{HLDN}_{\mathrm{N}}=0.87 \mathrm{~S}-\mathrm{ACN}+0.33 \mathrm{~T}+2.25 \mathrm{SAT}-6.67 \mathrm{EON}+13=0
$$

Here, the CST term in equation (10) is now separated into four terms, three with a coefficient obtained from a double scan technique. The temperature contribution $(+0.33 \mathrm{~T})$ indicates that for this kind of surfactant system, a temperature rise notably increases the HLDN, i.e., only an increase in $3{ }^{\circ} \mathrm{C}$ is required to compensate for the decrease in one unit of $\mathrm{ACN}$. In contrast, the temperature coefficient for an alkyl sulfate is -0.05 , and thus an opposite decrease in $20^{\circ} \mathrm{C}$ is needed to produce the same effect. However, let's remember that for commercial ethoxylate mixtures, the temperature coefficient is quite variable, passing from 0.25 at EON 5-6 and ambient temperature to 1.0 when both EON and T are high [136] e.g., $\mathrm{EON} \sim 10$ and $\mathrm{T}$ close to $100^{\circ} \mathrm{C}$.

It is worth noting that the last term in equation (12) (numerical value 13) is the value necessary to match the HLDN $=0$ equation in the experimental cases of the optimum formulation. It thus includes the effect of the non-appearing variables like pressure or co-surfactant contribution and the integration constant, which has to do with the references of all variables. This delicate problem of references has been recently discussed elsewhere $[2,136,197]$ to avoid confusion resulting from publications having used zero salinity, benzene (equivalent $\mathrm{ACN}=0$ ), $0^{\circ} \mathrm{C}$ (which is not the best $\mathrm{T}$ in a system containing water without salt) to have all the references disappear from the HLDN equation.

Because the most important variables in practice have been the water salinity, the oil ACN, the temperature, and the surfactant type, the most used HLD (as HLDN) equation was written as follows for ionic (13) and nonionic (14) systems as:

$$
\begin{aligned}
& H_{L D N}=K_{S I} L n S-E A C N-K_{T I} \mathrm{~T}+\mathrm{SCP}=0 \\
& H_{L D N}=K_{S N} S-E A C N+K_{T N} T+S C P=0
\end{aligned}
$$

The equivalent oil characteristic parameter $(\mathrm{EACN})$ is a number representing the effect of an oil phase, when the oil is not a n-alkane but is exactly producing the same effect as far as the optimum formulation is concerned. It was first introduced by mixing two n-alkanes [151], and afterward by comparing the results of a different scan (i.e., salinity or surfactant SAT or other) and identifying the correspondence [150], or even better, using the HLD or HLDN equation with the experimental values of all the other terms to produce an optimum $[78,180,192,198]$. It is thus calculated using one of the HLD equations and could thus result in slight differences depending on the accuracy of the used coefficients. It 
is worth noting that the EACN could now be empirically predicted by calculating the number of carbon atoms in the linear part of a hydrocarbon (EACN=26 for squalene that has 30 carbon atoms but only 26 in a straight chain) by reducing the value in the presence of double bonds (EACN=14 for squalene) and cycles, e.g., adding to the n-alkane part, only 2-3 for cyclohexane and 0 for a benzene ring. As far as polar oils are concerned, increased polarity diminishes EACN, i.e., often very much with ether and ester groups (EACN=2 for diisopropyl ether, 7 for ethyl oleate) or halogens substitutes ( 1 for chloro-octane). Recently, a physicochemical model was proposed to estimate EACN from the oil molecule structure [199].

Numerous studies from various laboratories in the past 40 years $[78,103,176,179,200,201]$ indicated that this linear relationship in equations (13-14) is essentially valid but with very different $\mathrm{K}_{\mathrm{A}}$ values in the original (1-2) equations. Other researchers adjusted their equations for an essentially constant value of $K_{A}$ for all surfactants, which is not true due to the large number of new surfactant molecules designed for different applications in recent years. [202,203].

In the early 1970s [106], the surfactant parameter was called Nmin because it corresponded to the minimum tension in an ACN scan. The term hydrocarbon "preference" was introduced at the same time [106,204]; thus, the PACN name (i.e., preferred ACN in an alkane carbon number scan) was used early. This happened especially with a more detailed definition as EPACNUS for "extrapolated PACN at unit salinity and no-alcohol" in the original publications of a multivariable correlation for the optimum formulation. It was also called $\sigma / \mathrm{K}_{\mathrm{A}}$ for ionic and $\beta / \mathrm{K}_{\mathrm{A}}$ for nonionics in the literature $[38,103,104]$, including a comprehensive recent review $[62,156]$. The $\mathrm{SCP}$ ref reference term was always taken as zero to avoid confusion. However, it could be an erroneous value when related to a surfactant characteristic curvature, so-called CC $[205,206]$ (which is the same as $\sigma$ or $\beta$, instead of their value divided by $K_{A}$, see $[2,103,104])$. On the other hand, CC has not really been demonstrated to be a curvature and is probably a misleading name for that. It depends on many aspects other than the surfactant type and thus is not a characteristic of it $[2,46,207]$.

The recently proposed SCP (also called SCPN) abbreviation is the normalized surfactant contribution term $[2,67]$, and is probably a piece of correct information to represent the surfactant contribution in the HLDN multivariable expression. However, the C does not mean "characteristic" because SCP includes the effects of missing variables and the integration constant in equations (13-14). Consequently, in equations (13-14), the term must be altered by a change in surfactant (and thus the $C$ means contribution) since the other terms do not deal with the surfactant.

The basic studies from Winsor dealt with a three-component system, particularly one surfactant. However, in practice, the used surfactants are mixtures, and even more, if there are two or more surfactants, the behavior could depend on two or more variables with the composition of the mixture. The question is thus to know whether a single variable could manage with a surfactant mixture effect or not. The answer is essentially positive if there is a way to find an equivalent surfactant parameter for the mixture. The same should happen for a mixture of electrolytes with an equivalent salinity and oil with its equivalent ACN. The problem is thus how to calculate the equivalent in a simple way, and the relevant solution is not necessarily simple, and it is not currently available in all cases.

The HLDN $=0$ equation is quite a progress over the original HLD expression because it makes it possible to numerically express the conditions for an optimum formulation in the same scale $(\triangle \mathrm{ACN}$ unit change) in all cases. In practice, the variation in a surfactant mixture appearing as a variation of the SCP term could be numerically compensated by the variation of any variable scan in equations (13-14). However, it is better to use ACN as the scanned variable because it has exactly the same meaning for all surfactants when $\mathrm{T}$ or $\mathrm{S}$ effect could be different in some cases, as for ionic-anionic mixtures.

Equations (13-14) at $\mathrm{S}$ and $\mathrm{T}$ constant become equation (15) when the mixture parameter $\mathrm{SCP}_{\operatorname{mix}}$ is measured by the optimum experimental value in an $\mathrm{ACN}$ scan, which will be called $\mathrm{ACN}$ mix. Of course, $\mathrm{ACN}$ could be replaced by (E)ACN if some range extension is required for the scan, although eventually with less accuracy.

$$
\mathrm{HLDNmix}_{\mathrm{N}}=\mathrm{SCP}_{\text {mix }}-\mathrm{ACN}_{\text {mix }}=0
$$

The mixing rule is thus checked through the following equations where $\mathrm{X}$ indicates the (molar, volume, or weight) fraction or proportion of one of the two surfactants in the mixture 


\section{$\mathrm{ACN}_{\text {mix }}=\sum \mathrm{X}_{\mathrm{i}} \mathrm{ACN}_{\mathrm{i}}$ or $\mathrm{SCP}_{\text {mix }}=\sum \mathrm{X}_{\mathrm{i}} \mathrm{SCP}_{\mathrm{i}}(16)$}

A long time ago, such experiments for a mixture of two very pure di-alkyl benzene sulfonates [208] confirmed equation (16) with an experimental scan carried out with pure n-alkanes, as seen in Figure 9. The mixture was carefully selected to be covering the maximum n-alkane range (from pentane to hexadecane), and it is clear that the optimum ACN increases linearly.

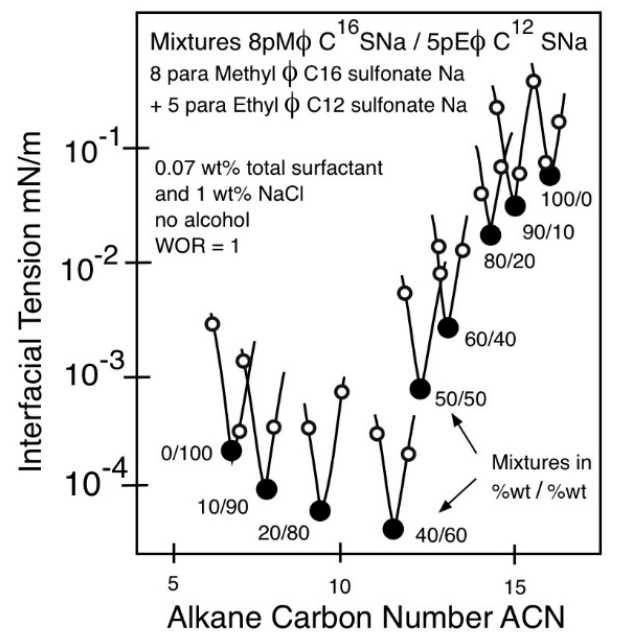

Figure 9. Interfacial tension variation in an oil ACN scan (from 6 to 17 at ambient temperature of $28^{\circ} \mathrm{C}$ ) for a mixture of two very pure di-alkyl benzene sulfonates with structures similar to what could be found in commercial products

However, using pure n-alkanes and very pure surfactants was not congruous with the technological relevance of enhanced oil recovery. Consequently, the experiments were carried out in the first years with the most likely candidates for EOR at this time, i.e., sulfonate surfactant mixtures with a tail like alkyl benzene/toluene/xylene, internal olefin or branched petroleum parts, and salinity scans.

In the very first significant report [195], mixtures of two surfactants (1 and 2) with the same $\mathrm{K}_{\mathrm{A}}$ value in the original HLD correlation showed a surprisingly accurate straight line variation

$$
\mathrm{LnS}_{\mathrm{mix}}=\mathrm{X}_{1} \mathrm{LnS}_{1}+\mathrm{X}_{2} \mathrm{LnS}_{2}=\mathrm{X}_{1}\left(\mathrm{LnS}_{1}-\mathrm{LnS}_{2}\right)+\mathrm{LnS}_{2}
$$

This relation, dividing by $\mathrm{K}_{\mathrm{A}}$ and replacing SCP by the surfactant parameter symbol " $\sigma$ " was exactly the same as equation (16).

This kind of straight line was found with many other cases of surfactant types, i.e., many other $\mathrm{K}_{\mathrm{A}}$ values in the original correlation, as well as many other scans (T, P, EON, SAT, co-surfactant type or concentrations) with essentially two conditions $[172,176,179]$. The first and most important condition was mixing two surfactants with no specific interactions between them, i.e., with a zero mixing energy term. When non-ideal mixtures are present, the Margules' equation has been used to compensate for the deviation, although this is often a rough approximation $[172,209]$ with a quite non-linear expression as a function of the composition of the binary mixture $X$ up to the third power. This has to be eliminated to keep the HLD expression as linear in X, as it is for all other formulation variables. This is discussed elsewhere [210]. To avoid the non-linearity difficulty, the second condition was using a scan variable with the same significance for the two surfactants. This is a problem with the salinity in ionic/nonionic mixtures, although using LnS as the salinity scale is not too bad for highly hydrophilic surfactants $(E O N>10)$ and if the salinity variation maximum range in one unit in LnS [104,211].

Equations (15-17) or equivalent ones with other scans thus allow making comparisons between the corresponding SCP values for various surfactants. It also makes it possible to estimate the mixture linearity range most of the time as equation (17) with LnS scans for ionic surfactants [195] and EON or T scan for nonionics $[104,212,213]$.

Therefore, it may be said that even with the currently recognized complexity, mixtures are used, and probably will be more used in the future, when an improved understanding of complex systems is at- 
tained. In any case, it should be stressed that recently the HLDNmix expression has been corroborated as more accurate than HLDmix in complex mixture systems [172], and thus should be the used one.

However, it cannot be forgotten that the mixture linearity could be completely erroneous if there is a partitioning of the different species, as in many commercial surfactants, particularly the ethoxylated nonionics that have an interfacial distribution very different from the one in the bulk of the system $[181,188,191]$.

Furthermore, if the mixture involves interacting surfactants, like anionic-cationic [214] or anionicnonionic [193,194,215], equations (15) do not work. Thus, a proper model has to be used, not necessarily the arbitrary selection of a Gex/RT relation proposed elsewhere some time ago [202]. A proper Margules' equation must be used with selected experimental data to calculate the two or more coefficients. Such mixing rule relation coefficients are extremely variable with small changes in the surfactants' nature [154], as seen in Figure 10. In this case, the optimum formulation is indicated as the salinity to reach the center of three-phase behavior. It is clear that if the nonionic surfactant is much more hydrophilic, i.e., has a much higher optimum salinity like when EON $>8$ in Figure 10, then the mixing rule is not far from linear. This is even better if the mixing rule is expressed in the ACN scale since it would be the same scale for the two surfactants, i.e., the left and right sides in Figure 10. However, it is not always possible to carry out a full range of such mixture through an ACN scan with different surfactant hydrophilicity, and it should be said that Figure 9 full matching of the alkane liquid range was exceptional.

On the contrary, when the nonionic surfactant has essentially the same hydrophilicity as the anionic one, i.e., the same optimum salinity in the scan as for the NP5.3EO case in Figure 10, the interaction is very large and the mixture extremely non-linear. This is probably because the ethoxylated nonionic head is short and dedicated to surrounding the anionic head, thus considerably altering its hydrophilicity.

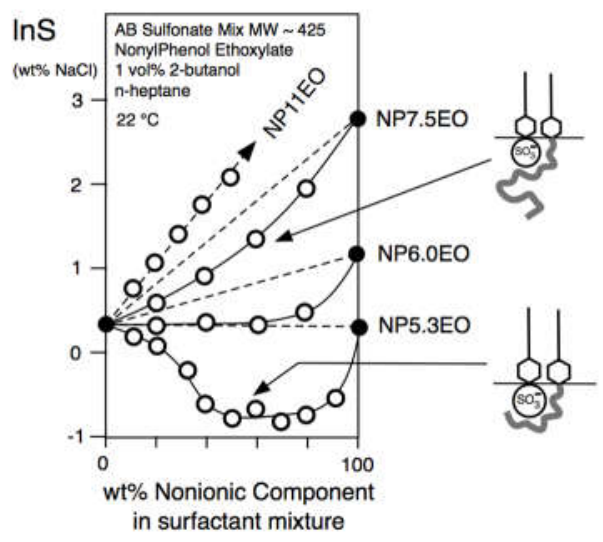

Figure 10. Optimum formulation for a salinity scan for anionic/nonionic surfactants mixtures. The indicated EON is the average value of a commercial nonionic with a Poisson distribution. The molecule arrangement schemes on the right of the figure indicate the interactions of the anionic and nonionic head groups [154].

Nevertheless, even if the interaction produces a decrease in hydrophilicity of the mixture, and thus some possible inconvenience, it also could present some advantages. One is a wide zone (from 40 to $80 \%$ of nonionic) where the optimum formulation of the mixture of anionic with the NP5.3EO nonionic is essentially constant, an interesting feature in practice. Second, it is worth noting that the same insensitivity with the mixture composition occurs with the NP6.0EO from 0 to $50 \%$ nonionic. In both cases, this insensitivity is due to the exact compensation of partitioning effects of anionic and nonionic species from bulk to interface and the interfacial interactions of what is adsorbed, which is extremely difficult to predict or even to guess.

It is also known that since the temperature has opposite effects on the hydrophilicity of ionic and nonionic surfactants, a proper mixture can produce an insensitivity to temperature [187,193], a situation that could be profitable for some applications.

A third complex and exceptional situation occurs when a commercial surfactant (mixture) concentration decreases in the system, its actual hydrophobicity (e.g., its SCP) of the interfacially adsorbed ionic surfactant mixture increases. In contrast, the opposite occurs for nonionic products. These systematic trends were discovered a long time ago $[104,216,217]$ with commercial surfactant at the generally used 
low concentration (about or less than 1-3 wt\%) and found to be absent with very pure species. This change in SCP with surfactant concentration is, of course, an inconvenience in many applications. That is the case when a surfactant is diluted as in washing-rising, or when a minimum interfacial tension is looked after in an oil reservoir, or minimum emulsion stability is required to clean a water pool. Fortunately, relevant use of this complication could be found in the applied literature. For instance, it was recently reported that the two opposite tendencies could be exactly canceled out by selecting a proper mixture in which a precise compensation is attained [218].

This was probably why anionic/nonionic mixtures of commercial surfactants have been empirically used in the past century for some applications, just by trial and error experience, without really knowing why they work in practice.

The previous section has just indicated the importance of the HLD numerical concept in the formulation because it provides some relevant synergy between the usual scientific rigor and the technological pertinence in applications.

This is going to be emphasized next in a section showing that the multivariable HLD simple expression is quite related to specific micro and macroemulsions properties and applications

\section{Why the HLD multivariable expression is important in many practical applications}

It has been found in the past 40 years that the value of any HLD expression is reasonably related to some properties for equilibrated and non-equilibrated systems.

In his four volumes Encyclopedia, Becher [219-221] reported a collection of articles dealing with some equilibrium and non-equilibrium properties of SOW system with Griffin's HLB. The studies using the HLD multivariable approach to estimate the formulation with a numerical value were more accurate corroborations of the many trends found since 1950. A crucial improvement in comparison with HLB, which was only taking into account the surfactant effect and was thus limited in accuracy.

The following synopsis about the correspondence between HLD and SOW systems properties could be found in more detail in several reviewing chapters published in the past 20 years by our group. There were mainly considering the phase behavior and micro-, macro-, and nanoemulsions properties from fundamental concepts to specific applied technologies $[6,46,65,66,90,147,154,222-226]$.

The general relations between the improved HLD approach and the properties of the SOW system at equilibrium or in a dynamic emulsified state are indicated in Figure 11 for common composition cases, i.e., a significant but small concentration of surfactant (e.g., from 0.5 to $3 \mathrm{wt} \%$ ) and a similar amount of oil and water (e.g., from 30 to $70 \%$ ).

Figure 11 abscissa corresponds to a formulation scan attained by changing one of the formulation variables at the bottom with an arrow indicating the direction of increase and corresponding to the change of sign of the HLD (or HLDN) according to equations (12-14).

Figure 11(a) corresponds to Winsor's phase behavior nomenclature and Figure 11(b) to the coincidence of the minimum tension with three-phase behavior, as seen in Figure 5. Figure 11(c) indicates the partitioning ratio $(\mathrm{P})$ of the surfactant between the phases, particularly between the two excess phase $(\mathrm{O}$ and $\mathrm{W})$ in the three-phase systems. As is visually evident in Figure 11 (a) the surfactant is mostly in the water if HLD $<0$, i.e., if $\mathrm{P}<<1$, or in the oil, if HLD $>0$, i.e., $\mathrm{P}>>1$. Both surfactant concentrations in the three-phase systems at HLD $=0$ are low in the excess phases, typically at or below the critical microemulsion concentration $\mathrm{c} \mu \mathrm{c}$. For pure anionic surfactants, the partitioning ratio $\mathrm{P}$ was found to be close to unity in the three-phase behavior system [152,164], as corroboration of equal chemical potentials since the very low concentrations in excess phases are close to the affinity as discussed elsewhere [158]. The same drastic change in partitioning applies to nonionic systems, but not necessarily with a unit ratio at optimum because of the high molecular solubility of ethoxylated surfactants in the oil phase [184,227-229], which is a complication not to be discussed here.

The following plots in Figure 11 indicate dynamic properties involving interfacial effects. Plot (d) shows a substantial variation of the electric conductivity of the emulsified system, just coinciding with the optimum formulation. Because the water is more conductive than the oil phase, and even more since it often contains some electrolyte, a high conductivity corresponds to an $\mathrm{O} / \mathrm{W}$ emulsion. At the same time, a low one indicates a W/O type. 


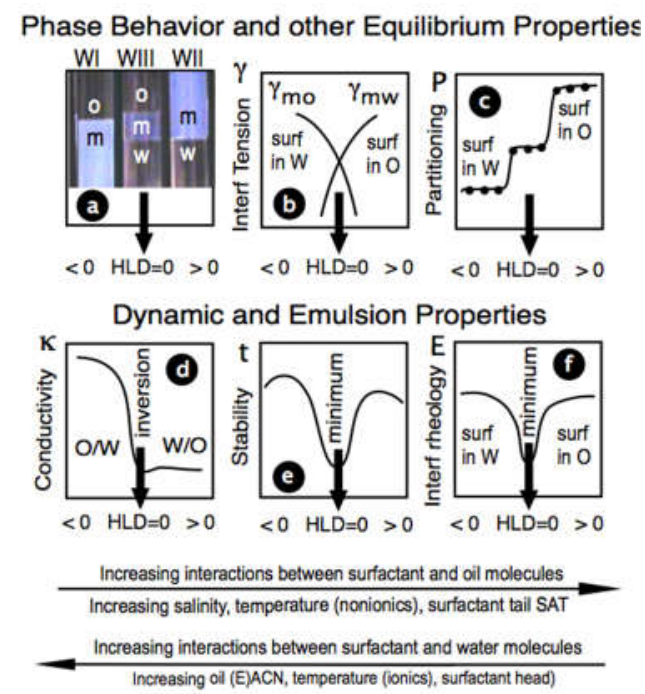

Figure 11. Synopsis of the generalized formulation variables' effect (that alter the HLD expression) on some properties of surfactant-oil-water systems at equilibrium and in an emulsified situation. The represented variations correspond to a system with a regular composition, i.e., a few wt \% of surfactant and similar amounts of oil and water $(0.3<$ WOR $<3)$.

The conductivity change corresponds to the emulsion inversion that was interesting in Bancroft's historical research on soaps more than 100 years ago. This emulsion inversion was related in the 1940s to a physicochemical situation by Griffin with the HLB parameter around 8-10, then by Davies with an HLB value around 7. Sometime later, it was called phase inversion temperature (PIT) by Shinoda, who systematically used temperature scans with ethoxylated nonionic surfactants $[217,230]$. Since it coincided with the three-phase behavior, it can be said that the PIT was the optimum formulation in a temperature scan. It was found that when the WOR was not far away from unity, the PIT was close to the so-called HLB-temperature (Тнгв) [212,231], which was the center of the three-phase zone and the point of minimum tension in such scan in most cases. However, it should be noted that the two criteria were not coinciding in systems containing more than $70-80 \%$ of water or oil phase $[65,232]$, as will be discussed next with the introduction of the effect of composition variables.

Figure 11 (e) indicates a very low emulsion stability zone at optimum formulation. Such event was more or less indicated before the EOR studies [217,233,234], but it was absolutely confirmed only when the optimum formulation was associated with the minimum tension. This extreme minimum stability at optimum formulation was extensively reported in the first years with different scans by many different groups [235-239] and was later repeatedly confirmed by everybody. It was also theoretically related to the interfacial rheology, i.e., to the elastic properties of the liquid film between approaching drops, and its influence on Gibbs-Marangoni effects [12,240-244].

The interdrop thin-film breaking, the crucial step in coalescence, was related to the so-called wedge theory model based on optimum formulation occurrence [245-248].

The introduction of a new interfacial rheometer based on an oscillating spinning drop a few years ago [249] has confirmed the systematic coincidence of an interfacial rheology minimum with minimum emulsion stability [250-252]. This behavior has been verified even with crude oil systems containing asphaltenes surfactant-like substances [119]. This is why the optimum formulation is the proper interfacial situation to break an emulsion as in crude oil dehydration or wastewater treatment, as discussed elsewhere in the past 30 years [113,114,116-118,253].

More information on the instability at optimum formulation is not included here because it has been recently reviewed elsewhere [254].

Let us now include the effects of the composition, i.e., the surfactant concentration Cs and the water/oil ratio WOR, which locate the situation in a Winsor ternary diagram.

The assembly of all formulation variables into a single expression is quite an advance since it leaves only three independent variables, i.e., the generalized formulation balance and two composition variables (Cs and WOR). Thus, the space to study the properties of SOW systems may be limited to three dimensions, which can be handled as shown in Figure 12 with a prism in which the effects of all for- 
mulation variables is represented by the change in HLD or in only one scanned variable, e.g., salinity, oil ACN or temperature, as it is often the case in practice.
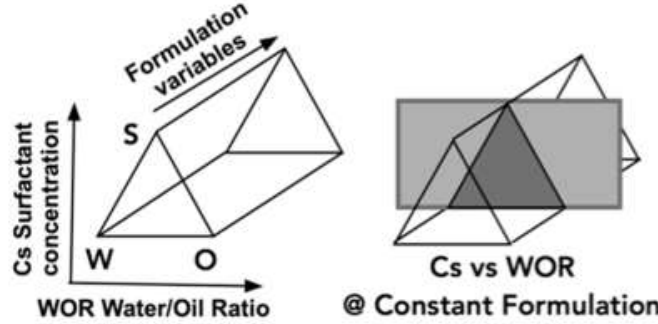

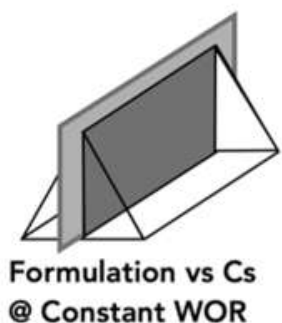

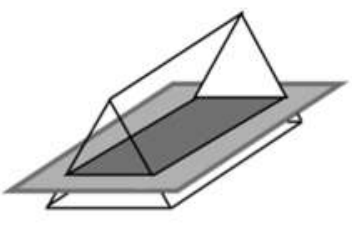

Formulation vs WOR

@ Constant Cs

Figure 12. The three-dimensional way to handle the description of a SOW system as a function of any formulation variable or its HLDN, as well as the surfactant concentration Cs and the water/oil ratio WOR [2].

Since the bi-dimensional space is easier to handle on a sheet of paper, it is better to use one of the three bidimensional cuts found in gray planes in Figure 12 graphs, i.e., (1) Cs vs. WOR at constant HLDN formulation, (2) HLDN vs. Cs at constant WOR=1 and (3) HLDN vs. WOR at constant surfactant concentration.

The constant formulation cut (Cs vs. WOR) generates the typical Winsor diagrams with the WI, WII, and WIII phase behavior zone in its center according to the HLDN formulation as discussed previously. However, since extensive studies of Winsor's diagrams could be found in the literature, in particular in some recent reviews $[2,62,136]$, such kind of cut, which is mainly related to the phase behavior, is not discussed here.

Figure 13 shows the next 2D cut at constant WOR, with formulation change, carried out through a salinity scan in the (A) plot and a temperature scan in (B) and (C) plots. The (A) case corresponds to any system with a very pure surfactant with optimum formulation at $H L D_{N}=0$ in abscissa a salinity at the center of the three-phase zone. This diagram is called a gamma diagram since it looks like the Greek letter $\gamma$. What is important to note is that in this case of a very pure surfactant, the optimum line at HLDN $=0$ is perfectly vertical from the $\mathrm{c} \mu \mathrm{c}$ to $\mathrm{Cs}^{*}$ in Figure 13 (A). The critical microemulsion concentration $\mathrm{c} \mu \mathrm{c}$, is the lowest concentration to obtain a three-phase behavior $[255,256]$. It is slightly higher than the critical micelle concentration $(\mathrm{cmc})$, i.e., quite low, usually less than $0.1 \mathrm{wt} \%$. The $\mathrm{Cs}^{*}$ optimum concentration corresponds to the highest part of the three-phase region, indicated as $(X)$ in Figure 13(A). This point is the highest in the three-phase zone WIII or the lowest in the single-phase zone referred to as Winsor IV phase behavior. It is in general at 20-30 wt\%, i.e., it is an extremely high value as far as cost issues are concerned. Consequently, it is not used in practice unless it is necessary to have a complete co-solubilization of oil and water in a single phase. Nevertheless, it is used in fundamental discussions because it is often recognized as the real optimum criterion concerning the phase behavior since the three-phase zone is reduced to a single point [180,192].

Figure 13(B) essentially indicates the same as Figure 13(A) but with a $90^{\circ}$ rotation, with the formulation scan as the ordinate axis. This time, the very pure surfactant is an ethoxylated nonionic, and the formulation scan is the temperature. As it is known from equations (12 and 14), an increase in temperature here will decrease the nonionic surfactant interaction with water, and thus an increase in HLDN, and a phase behavior change from WI to WII. In this kind of Figure 13(B), the aspect of the three-phase zone looks like a fish with the cuc point at its head and the $\mathrm{Cs}^{*}$ cross at its tail. The characteristic of the (B) plot is that the optimum line from $c \mu c$ to $\mathrm{Cs}^{*}$ points is perfectly horizontal, i.e., for this system containing a very pure surfactant, the optimum formulation (as the temperature for $\mathrm{HLDN}_{\mathrm{N}}=0$ in Figure 13(B) is constant. In other words, the optimum formulation (for attaining the minimum tension or as the center of the WIII zone, is the same at any concentration from $\mathrm{c} \mu \mathrm{c}$ to $\mathrm{Cs}^{*}$, for instance, at Cs1 or Cs2 intermediate cases in Figure 13 (B).

This has been reported for different surfactants in many academic studies from different groups, with a lot of theoretical aspects [196,257-259], but often showing complete unawareness of experimental results from industrial studies published before. This was probably because the available theoretical approach is not valid for real cases of SOW systems, as Rosen has pertinently mentioned in his book preface [77]. There are, however, some exceptions to this bias with review books written or edited by researchers having contacts with industry $[78,260,261]$. 
Nevertheless, the best would be to have theoretical scientists select their studies concerning real problems. However, the simplified theoretical aspects could be beneficial considering their validity, the approximate value of their significance, and a simple presentation to non-expert people. On the other hand, pedagogical publications help when they consider most aspects of formulation issues, fundamental and practical. For instance, a recent article on phase behavior in different cuts of the 3D prism exhibited in Figure 12 [229] also reports some curious anomalies with the ethoxylates surfactants like the possible very high $\mathrm{cmc}$ and $\mathrm{c} \mu \mathrm{c}$ concentrations.

Figure 13(C) is the same as Figure 13(B), though this time it is for a system containing a commercial ethoxylated nonionic or a mixture of two (or more) quite different pure ones which produce the same effect as shown a long time ago by Shinoda basic studies with temperature scans with ethoxylated nonionics $[262,263]$.
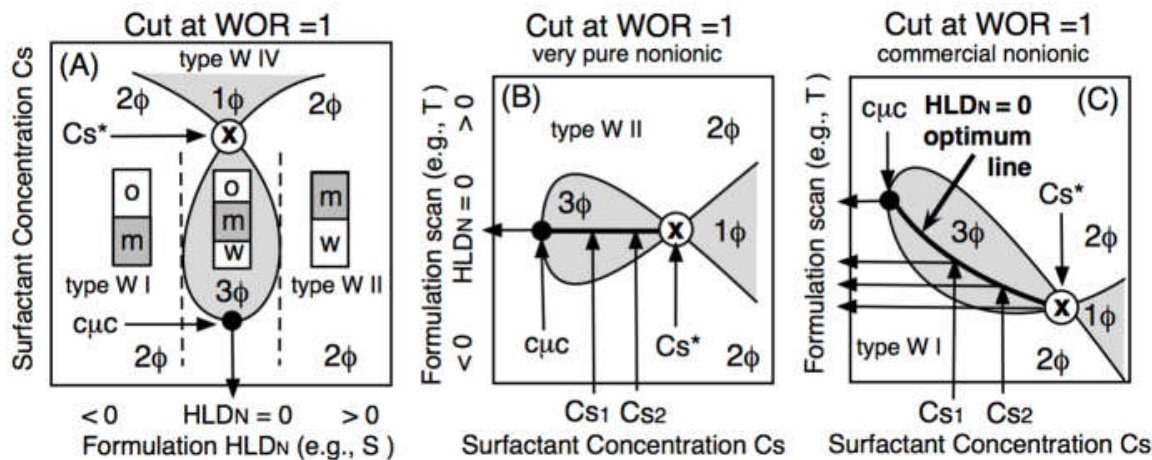

Figure 13. (A) Phase behavior in the formulation scan (as salinity variation) versus any surfactant concentration cut at constant WOR for a very pure ionic or nonionic surfactant. (B) Same kind of plot with the temperature as the formulation variable scan this time in the ordinate, for a very pure nonionic surfactant, (C) Same as (B) but with a commercial nonionic mixture of surfactants. The $\mathrm{HLDN}_{\mathrm{N}}=0$ in the middle and right plots corresponds to the three-phase behviour described at the Тньв by Kunieda and Shinoda $[231,263,264]$.

The obvious explanation of the fish inclination in Figure 13(C) is that the assumption (explicit in Winsor's model) that the surfactant adsorbed at the interface is the same as the one put in the system, is suitable with a single pure surfactant. However, it is not correct in the case of a mixture. The point is that with a mixture of two or more surfactants, many phenomena, as the partitioning of the different species of a mixture, are making such assumptions incorrect, and the optimum formulation in a scan will vary with the surfactant concentration and the water/oil ratio. This influence of composition was reported in the first studies with multivariable correlations for EOR [104,216], and was also mentioned with temperature scans and surfactant mixture scans in Shinoda's publications [262-264]. However, it is worth noting that this group from Japan has been mostly reporting such distorted optimum formulation lines due to a WOR effect in the constant Cs cut that will be discussed next, which is more linked to real systems.

As far as the relation between the HLDN expression value and the application is concerned, according to the title of this section, the first thing to say is that the very low (minimum) interfacial tension exactly attained at $\mathrm{HLDN}_{\mathrm{N}}=0$ is the best condition to displace the trapped petroleum, in the so-called enhanced recovery methods $[62,101,152,163]$. This has been studied for 40 years, thus somehow used, but not extensively, because of the difficulty to accurately control the formulation in the reservoir 2,000-3,000 meters below the surface, as will be discussed later.

Another important use of the numerical value of the formulation quantification is cleaning and detergency. An HLDN negative value in the range from -5 to -15 (close to zero but not necessarily at the optimum) is also essential to displace some greasy dirt from cloth, as well as to change the solid particle wettability around 0 to attain good detergency [79,265-270]. Although the detergency effectivity is related to the dirt's characteristic (like its exact EACN if it is an oil phase), and thus can change from place to place, this is a general tendency empirically used in the past 100 years.

The association of HLDN value with the emulsion type and properties is of great interest too. One of the most important ones has to do with emulsion type as indicated in Figure 11(d) and its stability, as seen in Figure 11(e) plot with minimum stability at optimum and two stability maxima on both sides. These properties were also found to depend on the composition, particularly the WOR, as in the constant Cs cut in Figure 12, which will be used next. 
Figure 14 indicates some interesting, complex combinations that could make things more complicated or, on the contrary, exceptionally interesting as far as the emulsion drop size is concerned. When the formulation approaches the optimum, it has been seen that both the tension and emulsion stability decrease, resulting in some opposite effects on the (average) drop size. A lower interfacial tension tends to decrease the size of the produced drops, while a lower stability tends to have them coalesce quickly and thus increase in size. However, the two effects are not necessarily changing the same way with the deviation from optimum, even if it is normalized with HLDN.

In general, the shallow stability zone takes place in a narrow range around $H_{L D N}=0$, typically \pm 5 $\mathrm{ACN}$ units. In contrast, the tension variation through a minimum takes place over a broader range, say $\pm 10 \mathrm{ACN}$ units or more. Consequently, far from optimum, the decreasing tension effect is essentially the only one to happen or at least the most significant. Thus, the drop size produced in a fixed stirring process tends to decrease as optimum is approached. On the other hand, very close to optimum, the extremely quick change in emulsion stability dominates, and the opposite occurs, i.e., the drop size produced after some stirring time tends to increase. Hence, it is not easy to measure a value of the drop size in this zone because of the rapid coalescence (often less than 1-2 minutes) taking place during the measurement process. In practice, a short non-variability of the drop size is required with a quick formulation change out of optimum (by fast temperature change or by diluting far away from WOR=1). For very small drop size, i.e., nanoemulsions, optical light scattering methods could provide instant measurement [229].

As seen in Figure 14, which is a schematic gathering of many experimental data from industry contracts, a significant drop size minimum happens on both sides of optimum formulation at a short distance from it $\left(\left|\mathrm{HLDN}_{\mathrm{N}}\right| \sim 5-10\right)$. The drop size value could be 10 or more times smaller than what is found at 20-30 or more units of HLDN on both sides of optimum where the emulsions are generally stable. Figure 14 indicates that the exact position and value of the minimum drop size changes with the applied energy (as the agitator rotational speed in rpm), being lower in drop size and further away from optimum and over a more comprehensive formulation range as stirring is increased. Other effects like the viscosities of the phases, mixing process, surfactant type and adsorption (and the interfacial tension minimum at optimum) have been found to influence the drop size and the minimum location, in particular, if a liquid crystal or other more or less solid aggregates could form at the interface.

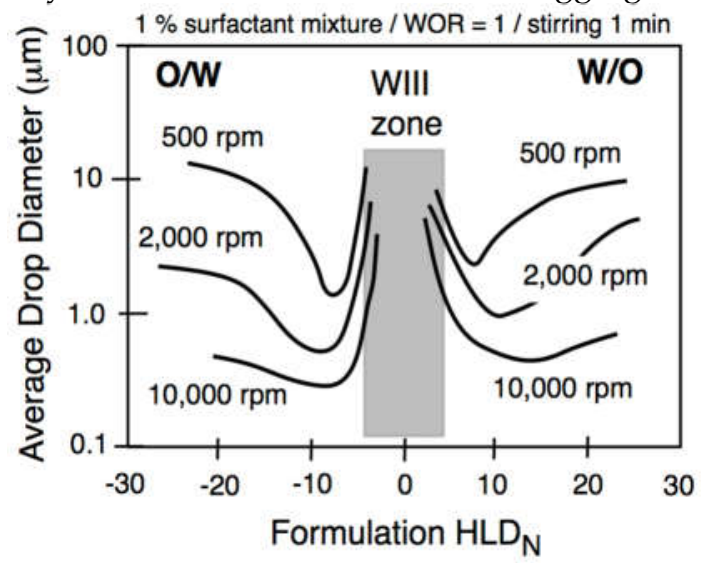

Figure 14. Emulsion drop size variation along a formulation scan at variable stirring energy indicted as revolution per minute rpm (unpublished data similar to reported trends [271].

The surfactant concentration Cs effect has been previously discussed, and can be relatively easily understood and predicted, since it is linked with surfactant molecules' interfacial adsorption and association. Consequently, the next part of this section is dedicated mainly to the effect of the WOR with the formulation in the Cs constant cut seen in Figure 12 right plot. This cut has been studied in great detail in Shinoda's group with an extremely significant effect of temperature in nonionic system formulation before a generalized HLD expression was proposed [272-275].

The different plots schematized in Figure 15 are for a system with an essentially pure surfactant whose emulsions have been produced from an equilibrated system. 
Plots (a-b) indicate the phase behavior according to Winsor's nomenclature. In plot (a), the surfactant concentration is high enough to be above the $c \mu c$, and below the $\mathrm{Cs}^{*}$, i.e., there is a WIII three-phase behavior at the optimum formulation in the center part. When there is a considerable amount of oil or water, i.e., on both WOR extremes, there is a single-phase, i.e., oil or water indicated as $1 \phi$, that corresponds to a swollen micelle situation. In the center of the plot, a variation of the formulation to produce a scan from negative to positive HLD, results in the typical phase behavior transition WI - WIII WII. At extreme values of WOR the transition is through a single phase at optimum. When the surfactant concentration increases, the three-phase behavior zone tends to be reduced at the center, and the lateral single-phase zone expands. When the surfactant concentration passes above $\mathrm{Cs}^{*}$, then the phase behavior at optimum is the W IV single microemulsion phase as indicated in plot (b) to happen at optimum over any WOR.

The main result shown in the following Figure 15 plots (c-f) is that the change in emulsion type from $\mathrm{O} / \mathrm{W}$ to $\mathrm{W} / \mathrm{O}$ or vice versa exactly corresponds to the optimum formulation where HLDN $=0$ in the center of the plots, i.e., from A+ to A- zones or vice versa. In other words, the phase inversion of the emulsion, e.g., the PIT in a temperature scan, is an almost horizontal straight line in the center range of the graph, typically from 30 to $70 \%$ of water or oil. Out of this range, i.e., when there is a large excess of one of the phases, as in the so-called $\mathrm{B}$ and $\mathrm{C}$ zones, the emulsion inversion line is essentially vertical, and the emulsion type depends on the WOR. Thus, the excess phase is the external phase, i.e., oil in the $\mathrm{B}$ zone and water in the $\mathrm{C}$ zone.
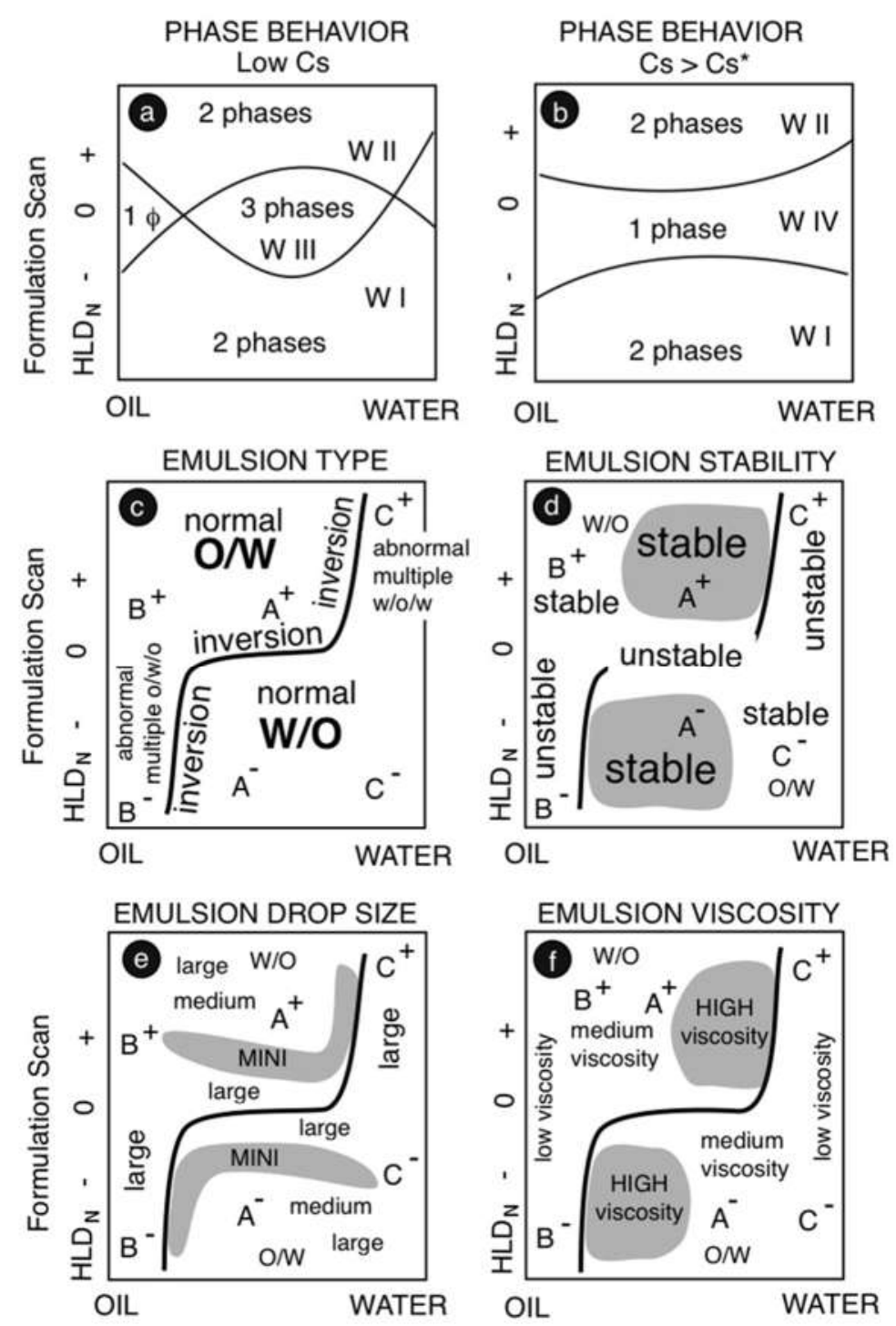

Figure 15. Phase behavior and Emulsion properties on the formulation-WOR space at constant surfactant concentration for a pure surfactant system 
This drastic change in the inversion line, from almost horizontal at the center to nearly vertical on the sides, is quite remarkable. It certainly indicates that there are different inversion mechanisms. Thus, the two kinds were called transitional, and catastrophic inversions in theoretical discussions presented 40 years ago [276-278].

The vertical line location, as far as the WOR value is concerned, depends on the emulsification process, particularly the apparatus and the phase viscosities, as well as the way of mixing the oil and water phases $[43,279]$.

However, it is quite vertical, only with a slight tendency to have narrower extreme B- and C+ zones as the formulation goes far away from optimum.

An additional complexity appears when the emulsification is not carried out from an equilibrated system and when either the formulation or the WOR is continuously changed, for instance, with a variation of the temperature or of the addition of oil or water to an emulsified system kept under stirring. On the other hand, the horizontal part, which is called the transitional inversion line (between A+ and A- zones), is essentially not affected, and it can be considered as general if the system is not too far from equilibrium [280,281].

On the contrary, the vertical line position, i.e., the so-called catastrophic inversion between A- and Bor A+ and $\mathrm{C}^{+}$, is systematically delayed in any direction. Thus, it exhibits hysteresis that becomes wider as the formulation goes away from optimum. This has been shown to be systematic, and it was found to agree with the catastrophic inversion model related to the so-called butterfly bifurcation [282]. This is quite complex from the mathematical point of view, and it is not to be discussed here. Nevertheless, it is mentioned because it is sometimes used in practice, and the reader must know that non-equilibrated systems can be tricky but useful in some cases.

In Figure 15(c), it is seen also that there are so-called normal and abnormal zones as far as the emulsion type is concerned. The normal ones follow the formulation and phase behavior, i.e., they are $\mathrm{O} / \mathrm{W}$ (respectively W/O) when the phase behavior is WI and HLD $<0$ (respectively WII and HLD $>0$ ). Figure 15(d) indicates that the normal zones correspond to stable emulsions, particularly in the gray area, far away enough from the instability zone close to the optimum formulation. The B- and C+ zones are quite unstable because the external phase in excess does not contain most of the surfactant as expected from Bancroft's rule. Actually, the W/O emulsion in the B zone is stable when HLD > 0 (in B+) and unstable when HLD < 0 (on B-). The opposite occurs in the $\mathrm{C}$ zone, producing stable $\mathrm{O} / \mathrm{W}$ emulsion only if HLD < 0 (in C-). Nevertheless, in some systems, the abnormal zones B- and C+ result in the formation of multiple emulsions, i.e. $\mathrm{O} / \mathrm{W} / \mathrm{O}$ in $\mathrm{B}-$ and $\mathrm{W} / \mathrm{O} / \mathrm{W}$ type in $\mathrm{B}+$, where the most external emulsion (big drops in external phase) is unstable, and the most internal one (small droplets inside big drops) is stable.

As seen in plots (e-f), the emulsions are more viscous when there are more drops, particularly small drops, as in the A+ and A- zone close to the vertical inversion line. In addition, the presence of microstructures or polymers in the external phase can quickly increase the viscosity if necessary for the application.

\section{Development of high-performance surfactant formulations in industrial production as well as in some everyday life examples}

In the following paragraphs, various examples where formulation and colloid and interface science can be applied are summarized in a practical and fundamental way. However, even if all the used phenomena are related to the same basic knowledge and know-how, it is seen that each case has its particularities. This is why the previously presented concepts on the HLD generalized formulation equation and its strong connection to the macro, mini, micro, and nanoemulsions properties were indispensable to be understood first.

\subsection{Surfactant formulation basics in Enhanced Oil Recovery}

The application of Enhanced Crude Oil Recovery is placed first in this list of examples because it was the one that in the mid-1970s motivated intensive studies on the behavior of surfactant-oil-water systems that resuscitated the early Winsor's work proposed 25 years before. Many reviews, probably 
more than 100, have been published in the past 40 years on this EOR application in different cases of petroleum reservoirs. Our purpose is not to add one more, but to give our opinion on what was important in the methods using the injection of surfactant. The first point to stress was the possibility of easily duplicating the final recovery for the typical water-flooding techniques at this time, e.g., from $25 \%$ to $50 \%$ of the original oil in place. Since such an increase in petroleum production represented a considerable amount of money, the available financing for research and development becomes much more than what had been and will be used for other applications of surfactants. Even if the possible scarcity of oil production in the future was not a critical reality as it was suggested then, a lot of research and development work was started in 1975. It was supported during 3-4 years by important financing from governments, particularly from the USA and other developed countries. The particular consequence of this kind of support was that an open divulgation of the results was required, contrary to the usual situation in the industry research dealing with business opportunities. This resulted in the publication of critical information even from industrial centers and a strong competition between many academic laboratories looking for financing.

Thus, it was also a rare situation in which a collaboration between university and industry could start with mutual interests, thus working with some synergy to increase both the knowledge and the knowhow. There is also no doubt that the results were useful for petroleum production and many other applications of surfactants, as can be seen in the considerable increase in publications exhibited in Figure 3 in the late 1970s.

\subsubsection{Capillary number criterion}

To understand in a simple way the principle on which EOR methods are based, let us remember that the capillary number, Nca, is a dimensionless number that relates the viscous drainage forces and the capillary forces.

$\mathrm{Nca}=\mathrm{v} \eta / \gamma$

where $\mathrm{v}$ is the fluid velocity, $\eta$ the viscosity, and $\gamma$ the water/oil interfacial tension. It is known that the recovery of crude oil in a porous medium is practically zero when the capillary number is less than 10${ }^{6}$ and almost $100 \%$ when the capillary number is greater than $10^{-3}[283,284]$.

Therefore, enhanced recovery methods aim to increase the capillary number by three to four orders of magnitude. As is logical, the most reasonable thing to do at the reservoir level is to reduce the interfacial tension since increasing the fluids' speed or the aqueous phase's viscosity to displace the crude oil has its physical limitations. Therefore, the most important aspects of the cEOR (chemical Enhanced Oil Recovery) in which the injection of surfactants is used to alter the capillary number will be only discussed here, and the chemical methods where the surfactant is combined with polymers or alkali are added to the system will not be discussed.

In the late 1970s, intensive studies using surfactants showed the possibility of attaining an ultralow interfacial tension between oil and water, with a typical value below $0.001 \mathrm{mN} / \mathrm{m}$, i.e., 100 times lower than the usual result reached with a detergent formula. Many studies on phase behavior and interfacial tension were carried out to find out the effect of the different variables involved in reducing the crude/water interfacial tension, and a numerical correlation was proposed. The HLD (hydrophilic- 
lipophilic deviation from optimum) equation became a generalized formulation tool increasingly used in applications out of the petroleum recovery, particularly for its relation with emulsion properties.

However, it is important to highlight that at the optimal formulation when HLDN =0, the minimum interfacial tension is obviously the important event to reduce the capillary forces. This is because the emulsions easily formed at low tension are very unstable [239, 251]. This is a crucial aspect because it avoids an increase in viscosity that would reduce the efficiency of the crude recovery process.

One of the most important challenges in using the optimal formulation is that it exists exactly at the condition HLD $=0$. This means that any change in any of the formulation variables leads to an increase of the interfacial tension, and thus a reduction of the crude recovery. This is probably why, half a century of research on formulations for SOW systems, an infinity of surfactant molecules have been developed and studied, many of them with applications in EOR.

On top of the optimum formulation issue, which is the warranty of minimum tension, there are two fundamental concepts related to the efficiency of a crude recovery process. They are the performance and the robustness.

\subsubsection{Performance of formulation in a SOW system}

The basic trends for improving formulation's performance, i.e., to attain a lower interfacial tension minimum, were proposed by Winsor's pioneering work and were corroborated during the basic EOR studies in the 1970s and early 1980s. Winsor postulated that the first condition to achieve maximum performance was to ensure equal interactions of the surfactant with oil (Aco) and water (Acw), such that $\mathrm{R}=\mathrm{Aco} / \mathrm{Acw}=1$ (see Figure 16 (a) in a formulation scan. As discussed previously, this is essentially the same as writing a zero HLD $=$ Aco-Acw $=0$. However, with the $R=1$ equivalent equation is easier to understand the performance concept. Winsor came up with a premise to improve performance at optimum by increasing the interactions in both sides, i.e., having at optimum $R=5 / 5$ instead of $R=2 / 2$, as indicated by the arrows in Figure 16 .
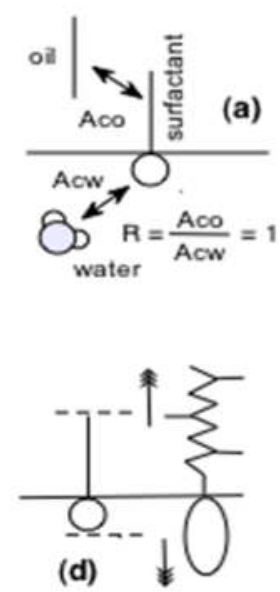
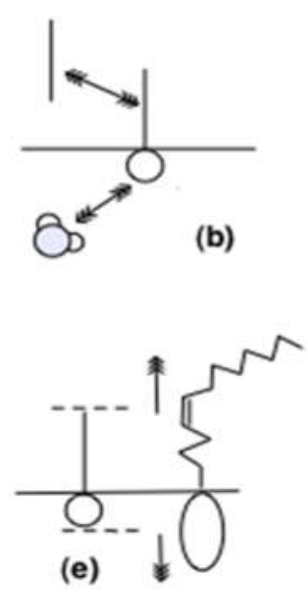
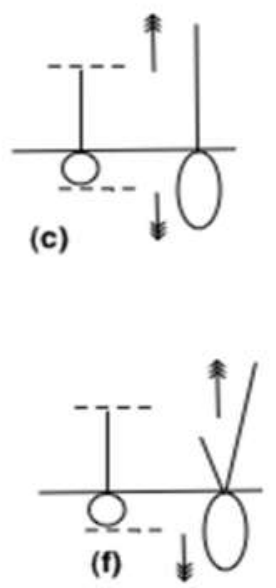

Figure 16. Different kinds of surfactant molecules tail at the interface. (a) Optimum formulation in a scan is attained when $\mathrm{R}=\mathrm{Aco} / \mathrm{Acw}=1$. Performance improvements at optimum formulation are attained with different. (b) Increasing the interactions on both sides by changing oil and water characteristics, e.g., lowering the water salinity and decreasing the oil ACN. (c) Increasing the interactions on both sides by changing surfactant characteristics, increasing the "size" or importance as far as interactions are concerned, of both head and tail groups. There 
are additional ways to increase the interaction of the surfactant tail with oil without producing surfactant precipitation: (d) branching; (e) bending with double bond; (f) having a double tail.

However, increasing both sides of the surfactant to improve the performance has a limit. Water solubility problems always limit a lipophilic tail increase, particularly with linear alkyl groups that cannot be longer than $\mathrm{C}_{16}-\mathrm{C}_{18}$. Nevertheless, the precipitation occurrence can be avoided or at least reduced in different ways. The simplest way is to introduce branching or twisting in the tail, either as side methyl groups resulting from the polymerization of propylene or butylene, by having double bonds, or by placing the head group in an internal position of a linear hydrocarbon chain, so that a double-tailed branch is formed as in internal olefin sulfonates (Figure $16 \mathrm{~d}, \mathrm{e}, \mathrm{f}$ ).

Other ways to increase performance and avoid fractioning problems [188,215,285], or species precipitation in high salinity reservoirs is by using surfactant mixtures [286], or by introducing hydrophilic and lipophilic linkers in the formulation [141]. However, intermolecular mixtures of surfactants and cosurfactants have fractionation problems [283, 284]. This is the main reason why new molecules called extended surfactants were designed to avoid these difficulties [157]. The first intramolecular surfactant mixtures used in EOR were designed to achieve an intermediate compromise between anionic species that precipitate at high salinity and polyethoxylated nonionics that become lipophilic at high temperatures [84, 107-108]. The principle of temperature insensitivity by mixing anionic and nonionic surfactants [59, 109] was applied to develop intramolecular species [54] termed extended surfactants. This molecules are longer than conventional surfactants, and have a better performance by increasing the reach of the molecule on both sides of the interface, but not with a long very hydrophobic part that could result in precipitation. These surfactants have a lipophilic spacer (polypropylene oxide chain - PPO-) between the conventional hydrophilic and lipophilic groups as seen in Figure 17 [168], eventually with about 1-3 ethylene oxide groups added to easily attach the ion head and facilitate packing as for the alkyl ether sulfates and more recently carboxylates.

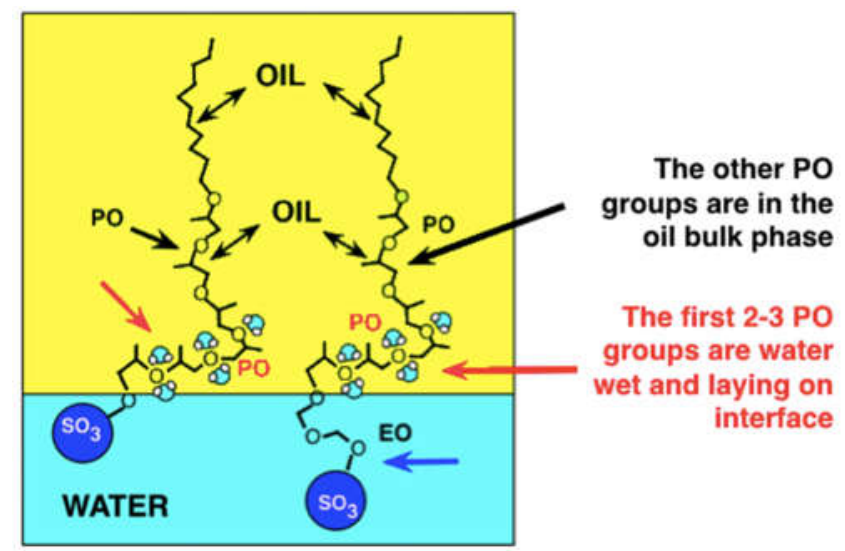

Figure 17. Typical extended surfactant molecules containing a polypropylene oxide (PO) intermediate (with a sulfate head on the left and an di-ethoxy-sulfate on the right.

The state of the art regarding trends with mixtures of surfactants and extended molecules, which have been proven to significantly improve the performance of a formulation, has been previously summarized [63], and corroborated from phase behavior studies, including interfacial tensions and oil recovery in laboratory tests [287]. 
The efficient formulations in EOR [285,288] are known by experience to be mixtures of surfactants with several characteristics previously mentioned as the keys to improve performance: long branched tail or double (twin) tail olefin or alkane sulfonates [289], extended surfactant with a polypropylene oxide spacer chain and a sulfate head, or typical anionics as alkyl aryl sulfonates [168,290,291], internal olefin sulfonates as mixtures including hydroxyalkene sulfonate species [292] with eventually a few ethylene oxide groups to improve salt tolerance $[293,294]$ and a definite ramification and branching to reduce or avoid the formation of gels, like in Guerbet alcohol double tail hydrophobes with EO \& PO intermediates [168],

Table 2 show the ingredients suggested to integrate high performance surfactant mixtures for producing a lower minimum tension, as well as higher maximum solubilization for other applications requiring a single-phase bicontinuous microemulsion.

Table 2. Principal surfactant species recommended as components of high performance mixtures for EOR $(\mathrm{R}=$ alkyl group, often branched or ramified)

\begin{tabular}{|c|c|}
\hline Type of surfactant & Molecular formula \\
\hline Alkyl benzene sulfonate $\mathrm{ABS}$ & $\mathrm{R}-\phi-\mathrm{SO}_{3}=$ \\
\hline Alpha olefin sulfonate AOS & $\mathrm{R}-\mathrm{CH}=\mathrm{CH}-\mathrm{CH}_{2}-\mathrm{SO}_{3}^{-}$ \\
\hline including hydroxy sulfonate & $\mathrm{R}-\mathrm{CH}(\mathrm{OH})-\mathrm{CH}-\mathrm{CH}_{2}-\mathrm{SO}_{3}^{-}$ \\
\hline Secondary alkane sulfonate SAS & $\mathrm{R}_{1}-\mathrm{CH}\left(\mathrm{SO}_{3}{ }^{-}\right) \mathrm{R}_{2}$ \\
\hline Internal olefin sulfonate IOS & $\mathrm{R}_{1}-\mathrm{CH}=\mathrm{CH}-\mathrm{CH}\left(\mathrm{SO}_{3}^{-}\right) \mathrm{R}_{2}$ \\
\hline including hydroxy sulfonate & $\mathrm{R}_{1}-\mathrm{CH}(\mathrm{OH})-\mathrm{CH}-\mathrm{CH}_{2}\left(\mathrm{SO}_{3}^{-}\right) \mathrm{R}_{2}$ \\
\hline Alcohol ethoxy sulfate AES & $\mathrm{R}-\mathrm{O}-\left[\mathrm{CH}_{2}-\mathrm{CH}_{2}-\mathrm{O}\right]_{\mathrm{n}}-\mathrm{SO}_{3}^{-}$ \\
\hline Alcohol ethoxy sulfonate AES & $\mathrm{R}_{1}-\mathrm{O}-\left[\mathrm{CH}_{2}-\mathrm{CH}_{2}-\mathrm{O}\right]_{n}-\mathrm{O}-\mathrm{CH}\left(\mathrm{R}_{2}\right) \mathrm{CH}_{2} \mathrm{SO}_{3}^{-}$ \\
\hline Alcohol ethoxy carboxylate AEC & $\mathrm{R}_{1}-\mathrm{O}-\left[\mathrm{CH}_{2}-\mathrm{CH}_{2}-\mathrm{O}\right]_{\mathrm{n}}-\mathrm{O}-\mathrm{CH}\left(\mathrm{R}_{2}\right) \mathrm{CH}_{2} \mathrm{COO}$ \\
\hline Extended alkyl-propoxy- & $\mathrm{R}-\mathrm{O}-\left[\mathrm{CH}\left(\mathrm{CH}_{3}\right)-\mathrm{CH}_{2}-\mathrm{O}\right]_{\mathrm{m}-\mathrm{SO}_{3}-}$ \\
\hline $\begin{array}{l}\text { sulfonate, sometimes including } \\
\text { a few ethoxy groups }\end{array}$ & $\mathrm{R}-\mathrm{O}-\left[\mathrm{CH}\left(\mathrm{CH}_{3}\right)-\mathrm{CH}_{2}-\mathrm{O}\right]_{\mathrm{m}}-\left[\mathrm{CH}_{2}-\mathrm{CH}_{2}-\mathrm{O}\right]_{\mathrm{n}} \mathrm{SO}_{3}^{-}$ \\
\hline $\begin{array}{l}\text { Extended carboxylates including } \\
\text { a few ethoxy groups }\end{array}$ & $\mathrm{R}-\mathrm{O}-\left[\mathrm{CH}\left(\mathrm{CH}_{3}\right)-\mathrm{CH}_{2}-\mathrm{O}\right]_{\mathrm{m}-}\left[\mathrm{CH}_{2}-\mathrm{CH}_{2}-\mathrm{O}\right]_{n} \mathrm{COO}^{-}$ \\
\hline
\end{tabular}

These proposed surfactant mixtures also contain, in general, co-surfactants, particularly branched ones like sec-butanol, isobutanol, or ter-pentanol, which do not significantly alter the HLD. These cosurfactants have been known since 1975 to produce disorder, avoid the formation of viscous gels or precipitates with anionic surfactants, and speed up equilibration. However, most of the time, they also decrease the performance by reducing the surfactant interfacial density [295].

Nevertheless, co-surfactants are also known to have some favorable effects, such as improving longtail surfactant solubility and reducing their adsorption [296].

\subsubsection{Robustness of an optimum formulation}

Optimum formulation robustness [297] is defined as the width of the area that presents a three-phase behavior around the optimal formulation, whatever the variable studied, salinity, temperature, etc. Since an ultra-low interfacial tension must be maintained during the formulation injection process, robustness is an important property of the injected fluid. However, even with formulations containing a single surfactant, there is the risk of chromatographic separation of amphiphiles, because a technical 
grade surfactant is composed not of a pure molecule, but rather a mixture of isomers and reaction byproducts.

Therefore, important strategies have been suggested to optimize the formulation with surfactants, ranging from using the salinity gradient [298], or the retrograde transition $[297,299,300]$ to increase formulation robustness against unavoidable changes such as surfactant concentration (due to active material loss because of adsorption on the rock), fractionation at the water/oil interface, changes in the WOR relationship [218,301], including temperature changes in different areas of the reservoir. It has been proven that formulation robustness is achieved through the best choice of mixtures from 2 and up to 3 types of surfactants, which produce insensivity to dilution, temperature and salinity [287,297].

The fact that there are many candidate surfactants in a SOW system with possible interactions, such as association, segregation and selective partitioning between phases and adsorption at the interface, coupled with the nature of oil and brine and their often complex composition, could be critical and could lead to considerable changes in the SCP, EACN and S description parameters on the interface.

Consequently, it can be said that the HLDN $=0$ published correlation with 4-5 global variables is not enough and should be completed with some information on 3-4 more variables at least, in particular on the surfactants and co-surfactants mixing rules as well as similar problems with oils and electrolytes. In this type of system with many variables, the Surfactant Contribution Parameter (SCP) is an important tool, together with all the information obtained in the last 50 years of studies, but most of the complex cases have not been published, and intensive empirical work has to be done for specific reservoir cases.

\subsection{Development of a detergent formula for washing machines}

We will examine in this section a classic formulation case, the development of a highperformance detergent product for machine washing clothes. It is a product with particular properties depending on the requirements or water characteristics of a country or city, or the conditions of use, such as temperature and electrolyte content of water. Such a product has been developed in several companies and, therefore, the product is not new, but usually, each case presents different results.

In the case of a detergent, there are requirements of various types in terms of products (surfactants, polymers, oxidants, $\mathrm{pH}$ agents, enzymes), and for different cleaning effects (roll off of the dirt, change of wettability, solubilization of water-insoluble material, saponification of grease) $[1,79]$.

Several mechanisms are into play during detergency. The two most important are the takeoff of dirty solid and dirty liquid, whose adhesion has a different nature, according to Figure 18. For dirty solids, the adsorption of the surfactant in the particles favors their separation. On the other hand, for dirty liquids, it is the variation of interfacial tension that produces a change in the wettability of the substrate and has a favorable effect reducing the adhesion of the dirt and preventing its redeposition. In all cases, mechanical agitation is decisive [1,39].

Nevertheless, this type of mechanism is different from enhanced oil recovery [287,297], or water in crude oil emulsion breaking $[114,116,119]$, where an $\mathrm{HLDN}_{\mathrm{N}}=0$ for minimum interfacial tension should be attained [62]. The detergency mechanism involves a change of wettability and solubilization in micelles in a WI microemulsion, not in a microemulsions middle phase, as depicted in Figure 18. This is mainly because the minimum surfactant or active component concentration should be used, which means a very diluted aqueous system at a WI situation [39,71].

Depending on the particular cases as to the nature of the dirt, temperature, electrolytes, mechanical agitation, one mechanism will be used more than another. In addition, other aspects must be taken into account, as redeposition of the dirt already detached from the substrate, or the formation of inconvenient foam by gas incorporation during agitation. 


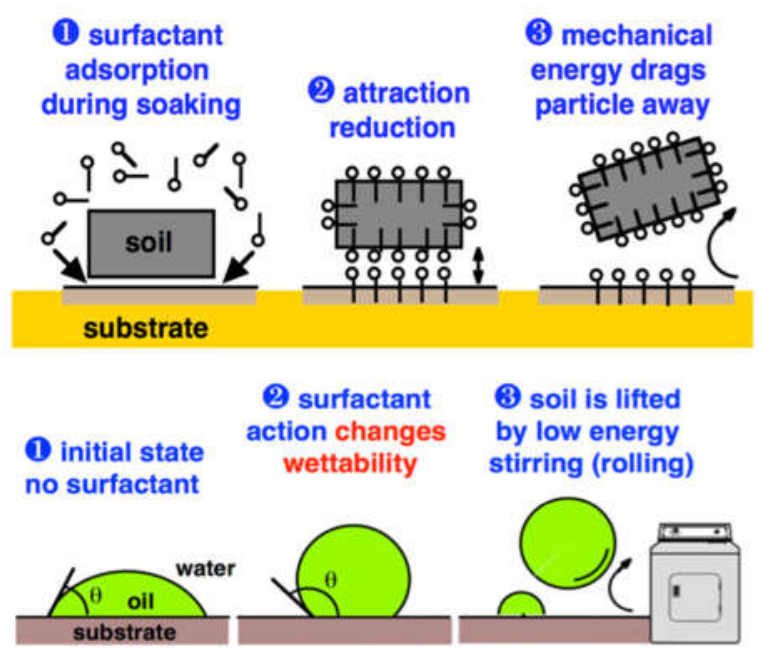

Figure 18. Mechanisms of takeoff of dirt of a solid substrate. a) dirty solid on a solid. b) dirty liquid on a solid

After several tests with different ingredients and a process study by washing, changing the soaking time, stirring, rinsing, etc., a formulation like the one shown in Table 3 is usually found. This is a typical example of a cold or warm washing machine with hard water and a large quantity of protein dirt.

Table 3. Typical formulation example for a powder detergent.

\begin{tabular}{llr}
\hline Component & Function & $\%$ \\
\hline Sodium dodecyl benzene sulfonate & ABS surfactant & 15 \\
Tridecanol + 8EO & Nonionic surfactant $\left(\mathrm{Ca}^{++}\right.$resist. $)$ & 5 \\
Oleic soap & Antifoamer & 3 \\
Hidrofobic silica & Antifoamer & 0,5 \\
Sodium tripolyphosphate & Builder-sequestering $\left(\mathrm{Ca}^{++}\right)$agent & 50 \\
Silicate (alkaline) & Builder & 15 \\
Sodium sulfate + water & Cohesion charge & 7 \\
Carboximethylcellulose & Antiredeposition agent & Variable \\
Protease, Lipase, Cellulase, Amylase & Enzymes & Variable \\
Perborate & Whitening agent & Variable \\
EDTA & Perborate activator & Variable \\
Fluorescence agents & Brightness & Variable \\
Parfum & Sensory & Variable \\
\hline
\end{tabular}

The formulation in Table 3 contains many ingredients with hundreds of possible cases of exchanging components for others and changing the quantities. Note that this type of formula is practically classic; hence to make innovation in a product, it is necessary to introduce new properties that improve the efficiency of the detergent in its use. For example, the surface of washed clothes can be conditioned to get less dirt in use and/or easier to wash the next time,

The effects are sometimes astonishingly innovative and have extraordinary properties as, for example, when Sasol, BASF, and Evonik presented new products, including new biobased surfactants [302-304]. This type of presentation as a sensational novelty is not new. However, it can sometimes have remarkable progress, such as introducing synthetic surfactants in 1930-1940 to replace soaps [72].

\subsubsection{Use of extended surfactants as detergency agents}

Extended surfactants are not the most suitable detergents due to biodegradability issues of the polypropylene/polyethylene oxide chain [305], in contrast with other applications such as EOR and 
crude oil dewatering, where the discharge isn't to water bodies. Nevertheless, since 2006 several studies have shown the performant properties of extended surfactants to clean dirty soils and surfaces. Studies in 2006 on detergency indicated that extended surfactants could solubilize hexadecane oil with efficiency on cotton fibers higher than $90 \%$, using A/12/12/2/S [306] and A/12-13/8/0/S at 0.2\% at optimum formulation, with $12 \% \mathrm{NaCl}(\mathrm{IFT}=0.011 \mathrm{mN} / \mathrm{m})$ [307]. This very high salinity in formulations [307] is a non-desirable situation for washing machines; hence studies continued with other extended molecule structures and other oils. In 2009 Do et al. [308] found a 90\% detergency efficiency for canola oil using $\mathrm{A} / 10 / 18 / 2 / \mathrm{S}$ at $5 \% \mathrm{NaCl}$ with an optimum of $0.008 \mathrm{mN} / \mathrm{m}$ at $25^{\circ} \mathrm{C}$. Although salinity reduction was found, $5 \% \mathrm{NaCl}$ is still far from a desirable cleaning formulation. Later, similar results were found $[309,310]$ with A/14-15/8/0/S and A/12-13/4/0/S surfactants, although still at a high 4-5\% $\mathrm{NaCl}$ content and Canola Oil at $25-40^{\circ} \mathrm{C}$. Phaodee et al. [270] worked with solid non-particulate soils (solidified coconut oil) at $10^{\circ} \mathrm{C}$ with only $45 \%$ removal at high salinity $(8 \% \mathrm{NaCl})$. Then, a year later, detergency higher than $90 \%$ removal was found at these cold temperatures using an octanol cosurfactant at $90 \mathrm{mmol}$, which probably acted as lipophilic linker, with an IFT of $0.03 \mathrm{mN} / \mathrm{m}$ [91,269]. Although some advances have been reached regarding detergency studies, the main feature extended surfactants present is having a linker-like intramolecular structure for the use at high salinities (with no precipitation) to solubilize polar oils. Also, another rather important feature is having a high SAT without surfactant precipitation (or liquid crystal formation), which lowers the optimum salinity where a WIII system occurs. In this last outlined research [91], a high detergency performance was seen at the WI condition, at $\operatorname{HLDN}_{\mathrm{N}}=0$, or even at negatives $\mathrm{HLDN}_{\mathrm{N}}$, which gives some robustness for lower salinity $(2 \% \mathrm{NaCl})$.

Table 4. Detergency studies using extended surfactants. Surfactant concentration, type of oil removed, temperature, interfacial tension at optimum, and detergency $\%$ are presented

\begin{tabular}{llllllll}
\hline $\begin{array}{l}\text { Extended } \\
\text { surfactant }\end{array}$ & $\begin{array}{l}\text { Surfactant } \\
\text { conc. }(\mathbf{\%})\end{array}$ & Oil & $\begin{array}{l}\mathbf{N a C l} \\
\mathbf{( \% )}\end{array}$ & $\mathbf{T}\left({ }^{\circ} \mathbf{C}\right)$ & $\begin{array}{l}\text { IFT } \\
(\mathbf{m N} / \mathbf{m})\end{array}$ & $\begin{array}{l}\text { Detergency } \\
(\%)\end{array}$ & Reference \\
\hline H/12/12/2/S & NR & Hexadecane & NR & NR & NR & 98 & {$[306]$} \\
A/12-13/8/0/S & 0.2 & Hexadecane & 12 & 30 & 0.011 & 93 & {$[307]$} \\
A/10/18/2/S & 0.25 & Canola oil & 5 & 25 & 0.008 & 93 & {$[308]$} \\
A/14-15/8/0/S & 0.06 & Canola oil & 4 & 25 & 0.08 & 93 & {$[309]$} \\
A/12-13/4/0/S & 0.1 & Palmitate & 5 & 40 & 0.02 & 78 & {$[310]$} \\
A/14-15/8/0/S & 0.1 & Palm oil & 8 & 10 & 0.08 & 45 & {$[270]$} \\
A/10/4/0/S & $0.1+\mathrm{C} 8 \mathrm{OH}$ & Canola oil & 2 & 10 & 0.08 & 98 & {$[269]$} \\
$\mathrm{A} / 14-15 / 8 / 0 / \mathrm{S}$ & $0.1+\mathrm{C} 8 \mathrm{OH}$ & Canola oil & 2 & 25 & 0.04 & 92 & {$[91]$} \\
\hline
\end{tabular}

*Nomenclature: A: Alfoterra, H: Huntsman. For example, H/12/12/2/S stands for Huntsman/C12/PO12/EO2/SO4.

\subsection{Development of a nanoemulsion formulation for intravenous administration (parenteral emulsion)}

Nanoemulsions for intravenous administration, also called submicronized emulsions or parenteral emulsions, have been used for decades to administer essential calorie lipids and drugs to patients who can't be fed by the gastrointestinal route [311-315]. This type of emulsions has been obtained traditionally by very high shear processing, including energy-intensive homogenizers and microfluidizers. Therefore having high $\mathrm{CO}_{2}$ equivalent emissions [316-320].

Since the early 2000s, low energy methods to attain nanoemulsions have been developed $[143,144,321]$ and used in practice for different applications [42,322,323]. Nanoemulsions have been defined as dispersed systems of two immiscible liquid phases. The dispersed phase presents droplet 
sizes smaller than $500 \mathrm{~nm}$ and can be as low as a few nanometers [44,319,324-327]. The know-how advanced throughout more than 10 years of research in the field has allowed attaining nanoemulsions of polar oils, e.g., paraffin oil and triglyceride oils from different sources (soya, corn, canola, almond) [328-333]. The process is mature and the physicochemical phenomena to obtain a fine particle emulsion with low energy of mixing has been explained [144,326,334,335].

Additionally, this type of emulsification permits obtaining functionalized systems by encapsulating substances with a specific property, e.g., antioxidant, anesthetic, analgesic, solar filter, etc., when formulation principles are applied properly [315,317,334,336,337].

Triglycerides with unsaturated fatty acid chains are difficult to emulsify due to their polar character and the generation of steric hindrance within the chains, which produces a bulky configuration [338]. Therefore, the emulsification procedure and the surfactant selection are crucial $[315,330,333]$. The surfactants used as emulsifiers in parenteral emulsions must be biocompatible and preferably transformed by the body, as in the case of soya and egg yolk lecithin [124,313,339-342]. The latter is mainly formed by phospholipids, behaving as amphoteric surfactants. Such is the case of 1,2 diacyl phosphocholine, better known as phosphatidylcholine [343,344]. Other food-grade surfactants have been used as non-ethoxylated and ethoxylated sorbitan esters, respectively [333,345], but with some limits for intravenous administration in high quantities [346,347].

Other types of triglycerides with smaller fatty acid chain sizes have also been used, including medium-chain triglycerides (MCT), which are common in many formulations nowadays. This functionalization allows more bioavailability of the triglycerides and easier emulsification due to the shorter chain, although at a higher cost [343,348-350].

The preferred low-energy emulsification method to attain nanoemulsions intended for parenteral application is the phase transition emulsification, also known as emulsion inversion composition method, or spontaneous emulsification [144,145,315,319,335,351-353], which is different from crossing the HLD $=0$ zone. It produces an emulsion with a low polydispersity droplet size distribution to ensure that all the droplet diameters are below the size of a vein capillary $(5 \mu \mathrm{m})$. The first step to formulate a parenteral emulsion is the selection of the oil (usually soya oil) and the content of the oil (internal phase), which usually is $20 \%$. Then adjusting the aqueous phase to an isotonic condition is performed using glycerol (generally $2.5 \%$ ) [311,313,315,333].

The surfactant choice is crucial for the phase transition method, i.e., this is mainly a physicochemical method based on the formation of a lamellar liquid crystal phase when the aqueous phase is added slowly to an oil and surfactant mixture $[2,36,143,144,323,326,331,354]$. This surfactant mixture is usually at an HLDN $<0$ but not too negative to allow the formation of an $\mathrm{O} / \mathrm{W}$ emulsion at equilibrium and also the intermediate liquid crystal phase [332,335,352]. It has been discussed that this L $\alpha \mathrm{LC}$ phase surrounds the droplet rendering its high stability and nanometric droplet size [143$145,315,335,355,356]$. Soya lecithin has a negative $S C P_{N}$, whose structure provides hydrophilicity, and it has been shown that the phase transition method works acceptably well for this mixture of several phosphatidylcholines [315].

The liquid crystalline phase formation in SOW systems using sorbitan surfactants, e.g., Tween 80 $(\mathrm{HLB}=15)$ and Span $20(\mathrm{HLB}=8.6)$ to attain a mixture at HLB near 12, i.e., hydrophilic [331,333]. This allows to form a high stability $\mathrm{O} / \mathrm{W}$ emulsion in the gray zone A- in Figure 15 (d), which has been argued, is stabilized by a liquid crystal layer that surrounds the droplet. This type of emulsification depends mainly on two factors. First, the attainment of a formulation situation at HLD $<0$ but not too far from $\mathrm{HLD}=0$, allows the formation of a hydrophilic surfactant in oil microemulsion (red point) that becomes a curvature zero lamellar liquid as soon as some water is added, as seen in Figure 19. The second is that when more water is added, the system composition moves along the arrow in the $\mathrm{W}$ corner direction. The LC swells into layers, breaking under low shear to form very small elongated aggregates that become nanodroplets [143,315,352,357]. Another interesting feature is that when the nonionic surfactant solution is diluted, i.e., when its concentration decreases along the arrow displacement, the interfacially adsorbed ethoxylated mixture becomes more hydrophilic (Figure 19). This means that the system HLDN tends to decrease, its representative point going to the center of the A zone in Figure 15(d), where stability is higher.

Homogenization continues to be the preferred industrial method in the formulation of parenteral emulsions, attaining droplet sizes lower than $0.2 \mu \mathrm{m}[318,320,325,358,359]$, nevertheless, with a high 
energy cost. This will allow low-energy emulsification methods, with better mixing technologies for viscous fluids, to be used in different areas of research, mainly pharmaceutics and cosmetics.

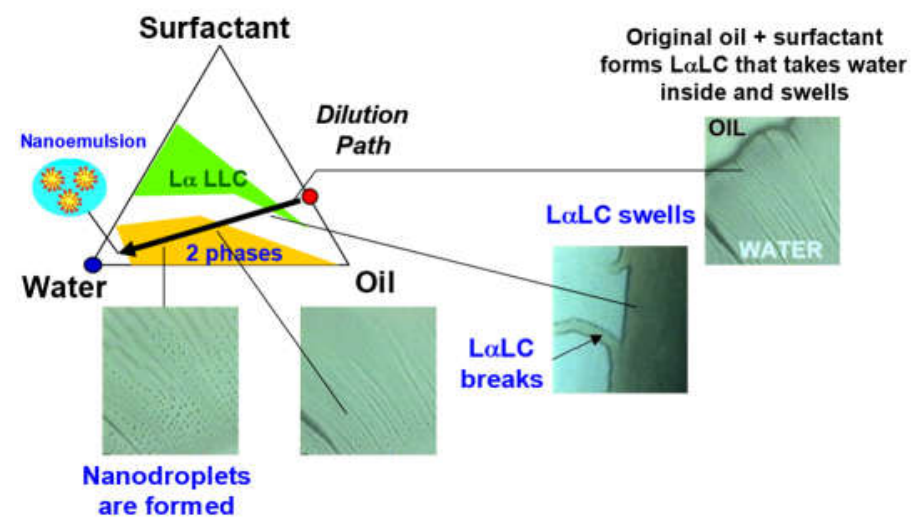

Figure 19. Spontaneous emulsification method is shown in a schematic surfactant-oil-water ternary diagram. The red dot on the surfactant-oil axis is the starting composition. The arrow shows the path followed during aqueous phase addition and the structures formed during this displacement.

\subsection{Formulation of a functionalized nanoemulsion for the administration of a pharmaceutical or cosmetic active substance}

Formulators can also use the low energy emulsification method [143,144] to attain O/W nanoemulsions for administering a pharmaceutical or cosmetic substances $[325,336]$. This functionalized nanoemulsion must be formulated with biocompatible substances that allow not only an efficient administration (humectability, adequate film formation, no irritation [360-362]), but also the diffusion and adsorption of the active substance in the target layer of the skin [363-365]. Assays on surrogate membranes that simulate the skin transdermal passage are of utmost importance in this regard. Different surrogate membranes have been engineered to attain similar diffusion coefficients to those of a wide variety of substances throughout the skin [364,366,367]. One of them, Strat-M synthetic membranes, as depicted schematically in Figure 20. This type of assay is performed as a membrane passage experiment with a Franz diffusion cell method [368,369]. Fick's laws of diffusion describe the transdermal permeation $[366,367,370]$ by relating flow and apparent permeability.

Performant passage of the pharmaceutical or cosmetic active principle through the synthetic membrane has been proven to indicate a similar behavior on the skin. Therefore, the study of the transdermal passage of an active substance in a functionalized nanoemulsion can be performed in a reproducible and repeatable manner. Recently, this approach was used to formulate and deploy a promising Leishmaniasis treatment with a nanoemulsion-based cream, tailored to be applied on the skin [371].

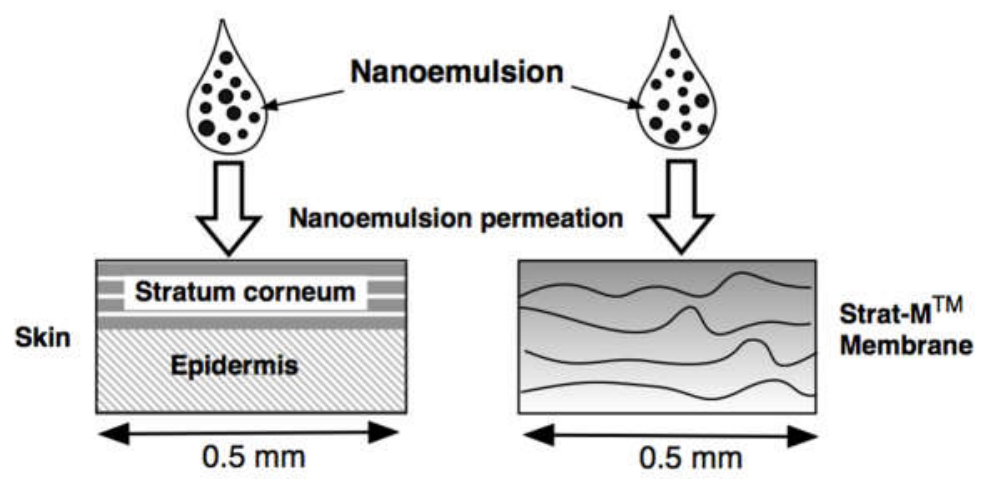

Figure 20. Schematical representation of the transdermal delivery through human skin and Strat-MTM membrane [364,368,370].

After a high stability nanoemulsion and adequate transdermal passage have been attained, the formulation's final steps are performed. This comprises adding the components for achieving a product with sensory properties that will provide consumer acceptance, including [372,373]: 
1. Viscosifier: a skin-compatible polymer like Carbopol in an adequate concentration can be used. Attaining good rheological properties will generate spreading over the skin and a concomitant adequate film formation. Good administration at high shear requires a shear-thinning behavior (for example, a Carreau type flow curve would be preferable). Feeling to the touch is attained by having a viscoelastic but a relatively not so high elastic (or normal stress) component, avoiding a "sticky" feeling to the touch $[58,362]$.

2. Fragrance: usually small organic molecules that gives a specific sense. Those could be inside the droplets (if they are oil soluble) or in the aqueous phase. Usually, encapsulating the essence in the droplets will provide a more lasting effect due to a controlled release. The high volatility of such small substances in an aqueous phase can make their evaporation fast [374,375].

3. Color: The color of a nanoemulsion is most of the time bluish white with good consumer acceptance. If that is not the case, some biocompatible color-giving substances can be added [376].

Sensory studies are done preferably at the end of the formulation stage before in vivo trials. A detailed feasibility study, including consumer perception, is performed after in vivo trials are finished.

After all the previous steps are attained, the system, the fluid emulsion, cream, or gel (according to its final presentation) will have properties intrinsically related to its microstructure. A schematic representation of a nanoemulsion with a polymer as a rheology modifier for application as a cream is presented in Figure 21 [362].

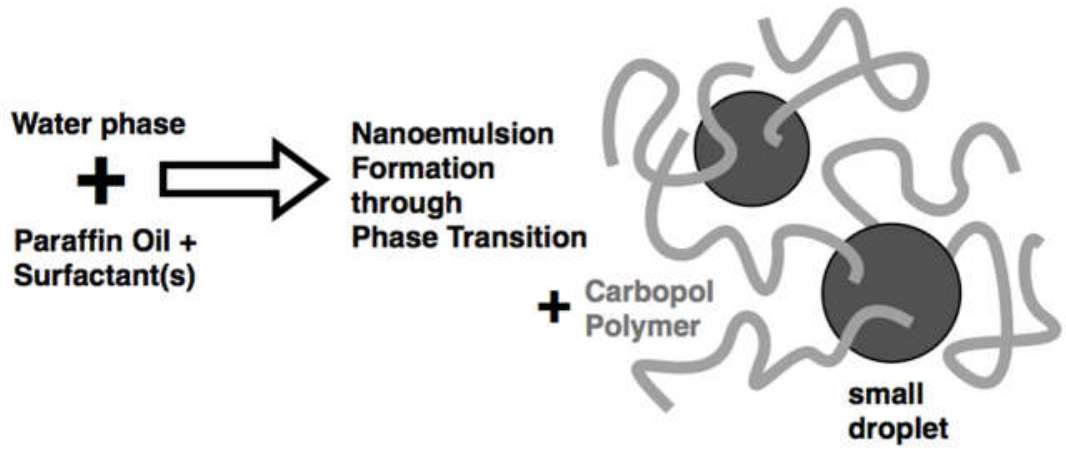

Figure 21. Scheme of the proposed microstructure and mechanism of stabilization of the cream [371]

These previous steps (i.e., formulation and in vitro trials) would indicate a well-formulated product ready for in vivo trials [361,377]. These trials could include application in animal skin (e.g., rabbits) or human skin. Multiple factors are analyzed in this step, maintaining the skin integrality (no rash or irritation) and studying the effects and effectiveness of the active principle on the subjects, which are related to health and pharmaceutical sciences. This type of study was performed in a recent report where a cutaneous Leishmaniasis treatment has been implemented in patients with efficacy and good results [371]. This is an example of synergy when University and the pharmaceutical industry collaborate to formulate a product in an expedited manner. In this case, a non-profit project is helping thousands of inhabitants in tropical countries that don't have the economic resources to receive treatment without painful and costly cutaneous parenteral injections [378,379], [225].

\subsection{Development of a microemulsion formula for wood preservation}

The success of wood protection depends on the species it comes from, its impregnability, the quality of the preservative formulation and the treatment method. Therefore, it is necessary to establish a wettability map of the wood to be treated [380].

The heterogeneous characteristics of wood surfaces and the diversity of fibers, internal spaces, and capillarity of this matrix are crucial to understand and characterize the interface created between the solid (wood surface) and the liquid of the preservative formulation. Selecting one formulation requires studying the effect of penetration and interaction of the different media selected with the various substances that naturally occur and exist within the selected woods. The retention and absorption process of preservative substances will depend on several factors, including the wood type and species, the types of degrading agents to which the wood will be exposed (biological risks), environment 
conditions (dry or wet), end-use, volume to be protected, absorption capacity and the amount of product applied that is inserted in the matrix within the wood [381,382].

A strategy to achieve a more homogeneous distribution of a wood preservative involves the formulation of emulsions or microemulsions that fulfill two main functions: the first being the distribution of the preservative's active component and the second to ensure the complete penetration of the preservative throughout the wood, without the leaching of the product outside.

The use of products based on heavy metals salts or petroleum derivatives (creosotes), both very toxic and potentially carcinogenic, must be avoided in the formulation of new preservatives. Several active ingredients of organometallic compounds of zinc and copper have been developed in our laboratory that can be readily dissolved in vegetable oil. Mixtures of these zinc and copper-based surfactants and their respective single phase (as seen in Figure 22) microemulsions attained at HLDN $=0$ have been proven to have high protection activity in different wood substrates, hardwoods and softwoods. In addition, the organometallic compounds of zinc and copper have low water solubility. Thus, when dissolved in vegetable oil and using a microemulsion as a vehicle, the copper and zinc salts can penetrate more easily into the wood when diluted in an aqueous phase.

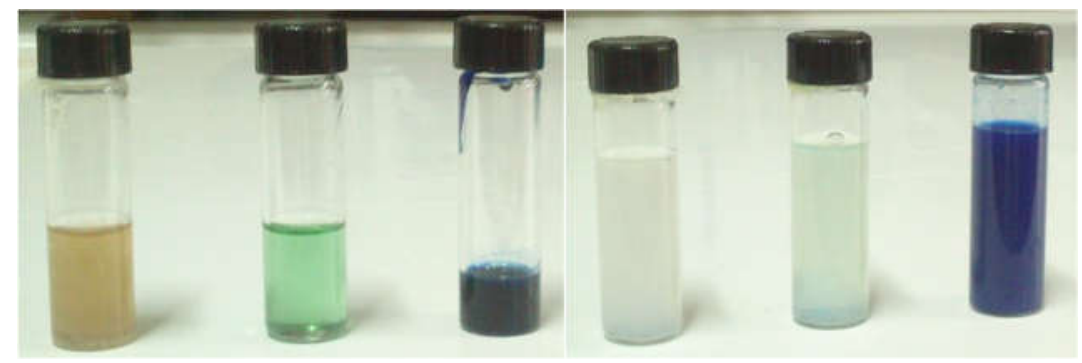

Figure 22. Left. Liquid crystals of organometallic zinc, copper and copper chloroacetate, respectively; Right. Microemulsions of organometallic zinc, copper and copper chloroacetate [383].

\subsection{Emulsion development for the lubrication and cooling of metal lamination machines}

Lamination is used in steels, aluminum, copper, magnesium, lead, tin, zinc, and their alloys manufacturing processes. Almost all metals used in industry have undergone lamination at some stage of their formation. The development of an aluminium lamination product has been developed in our Laboratory by using aluminum plates of $5 \times 1 \mathrm{~m}$ in an industrial partner plant. The plates are subjected to pressure between two rollers of a 1,000 atm to attain an aluminum plaque of less than $1 \mathrm{~cm}$ thickness (Figure 23). The plates require several passes between the rollers, until they reach the desired foil thickness.

This process requires lubricating the plate where there is some slipping and removing the heat generated by friction losses and metal heating. In addition, lamination should be done homogeneously to avoid irregularities in the sheet (thickness).

The laminating emulsion containing $5 \%$ oil and $95 \%$ water is formulated with a nonionic surfactant that allows a phase transition from an $\mathrm{O} / \mathrm{W}(\mathrm{HLDN}<0$ at relatively low temperature in the red point) to a $\mathrm{W} / \mathrm{O}$ emulsion $\left(\mathrm{HLDN}_{\mathrm{N}}>0\right)$ at a higher final temperature. The changes in the process follow the arrow in Figure 23, which indicates the double change, i.e., an extreme reduction of the water content produced by water evaporation and the change in HLD sign from negative to positive due to the temperature increase effect on a nonionic surfactant system.

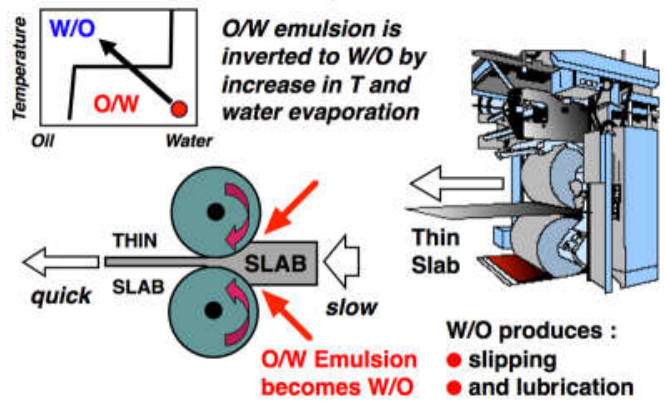

Figure 23. Schematic of $\mathrm{O} / \mathrm{W}$ emulsion formulation and application for high-performance lamination 


\subsection{Treating petroleum field outputs: breaking of W/O emulsions in dehydration processes and of $\mathrm{O} / \mathrm{W}$ low internal phase emulsion in production water}

In the current oil production technology, and after the first months from starting with a new reservoir, a mixture of oil and water is produced. Soon it often contains a high percentage of water as in the usual waterflood methods, as a loose O/W emulsion. Since the speed of displacement in the reservoir pores is quite low, e.g., $1 \mathrm{ft} /$ day, the stirring of the two-phase flow is very low. Thus, the interfacial tension is high so that the usually produced dispersion of oil in water separates in a quick creaming of the oil and a large part of the water phase separates at the well output in the so-called "free water knock out" shown in Figure 24 left. This separation can be enhanced by other physical processes like artificial gravity (hydro cyclone centrifugation) and/or filtration on some membranes with appropriate wettability. As far as the produced oil is concerned, it is usually a W/O emulsion stabilized by the asphaltenes and other slightly polar molecules present in the crude oil, resulting in a positive HLD value. Solid particles, often of precipitated asphaltenes resulting from the physicochemical changes in temperature and pressure during the production, are also present after some time from one to several days.

The water drops in the $\mathrm{W} / \mathrm{O}$ emulsion are generally small (in the $\mu \mathrm{m}$ range) and are critical for the quality of the oil, because of the increase of the liquid to be transported and because they have to be removed quickly in the so-called dehydration processes, which is carried out in equipment schematically shown in Figure 24 right. The most important item in this scheme is introducing the proper demulsifier product as soon as possible, eventually downhole in some cases. The demulsifier formulation, i.e., the product to attain an optimum formulation to considerably reduce the W/O emulsion stability, i.e., 10,000 times or more, has been discussed in several hundred papers over the past 40 years. It is not treated here because an extensive review on the chemical demulsifying has been just published [254], showing how much progress has been made in the past decades applying the HLD concept. The review also reports that there are still difficulties because of the complexity of crudes oils and the lack of numerical evaluation of the asphaltenes as lipophilic surfactants. The W/O emulsion breaking also includes physical effects like increasing temperature to reduce the oil external phase viscosity, often increases the density difference in the phases, and helps to desorb asphaltenes. It also increases the drop collision frequency, the Stokes's law sedimentation factor, and tends to dissolve paraffin crystals and asphaltenes clusters and aggregates. Another physical effect that has been used for a long time, and is currently used in the separation equipment is the electrocoalescence applying a direct or alternate electrical field, as well as magnetic fields, as recently proposed [384,385].

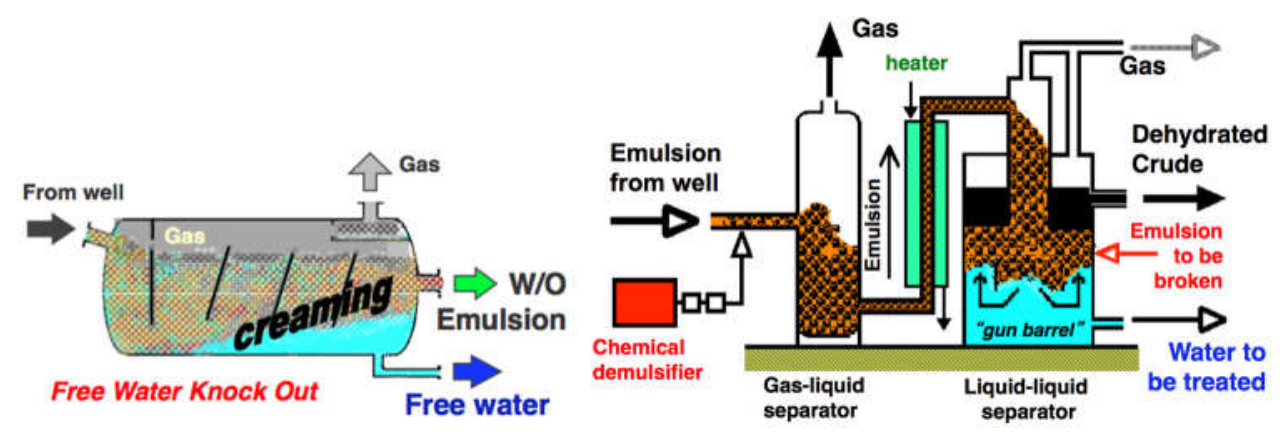

Figure 24. Separation of oil and water phase at the petroleum well

During the oil production process, large volumes of water associated with crude oil are generated and called "production waters." They correspond to the FWKO (Free Water Knockout) and separated water shown in Figure 24 equipment. After being separated from the crude oil in settling tanks or API (American Petroleum Institute) separators, among other processes, these waters often contain less than $5000 \mathrm{ppm}$ of crude oil with droplet sizes close to one micron, in addition to suspended and dissolved solids. These tiny drops of crude oil make the water quite cloudy. Its treatment with flocculating agents is difficult, since it is unlikely that there will be interactions between the drops to promote their coalescence, because of their scarcity and low settling velocity. Waters with the same characteristics, such as effluents from oil refineries, can also be found with the same problems [386]. 
Different types of treatment for these effluents are designed through an environmental management plan. There are physical and chemical methods to separate the crude, which bring the produced water to specifications, either for its disposal into the environment (rivers, lakes, and seas) or for reinjection in wells. The gravitational, coalescence, flotation, and filtration methods are used at the physical level. At a chemical level, in the treatment of the produced water, flocculating additives, biocides, scale inhibitors, among others, are used to achieve its adequate disposal [387-389].

Water, in some cases, may have alternative uses, but these are severely limited due to its quality. Once treated, these waters can be injected into abandoned oil wells through Water Injection Plants (Figure 25) or injected into wells intentionally to maintain pressure in the reservoir or as a secondary recovery method when injected with polymers.

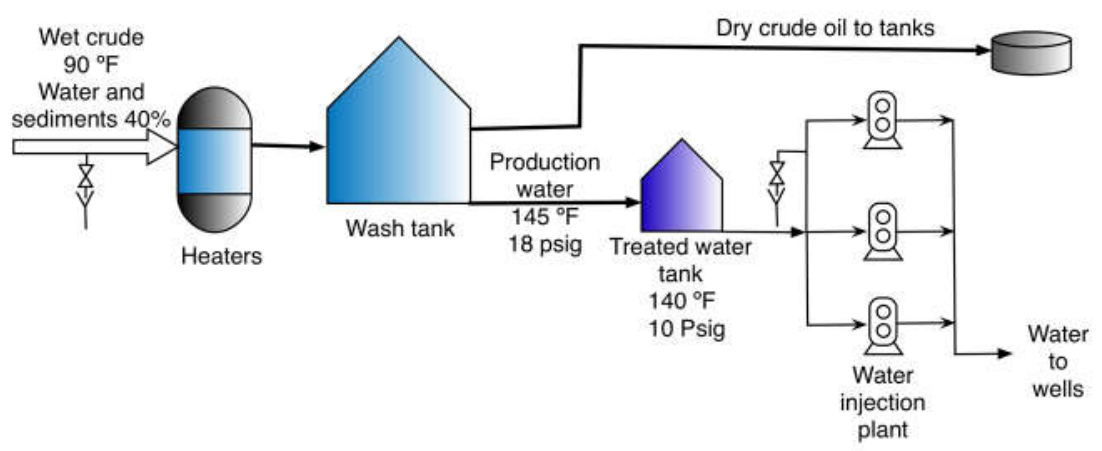

Figure 25. Separation scheme of production water and Water Injection Plant

The characterization of effluents is necessary to study and design production water treatments. Among the most critical parameters to be determined are oil content (oil), solids content, sizes, and densities of oil particles and solids. These characterizations are carried out through different standards, such as ASTM-D-7678 [390] and Standard Methods for the Examination of Water \& Wastewater (2560 - 2000) [391].

The dispersed oil droplet's diameter in O/W emulsions ranges from $0.5 \mu \mathrm{m}$ to $200 \mu \mathrm{m}$ (Figure 26) and represents a key factor in water treatment selection. In these processes, Stokes' law governs the relationship between the diameter of the oil drop and its sedimentation rate, having a great effect on the efficiency of the separation equipment used for its removal. According to Stokes ' law, the larger the droplet size, the higher their separation efficiency, which is crucial for the removed water to comply with standards and regulations. Consequently, the smallest droplets around $1 \mu \mathrm{m}$ are the most critical problem.

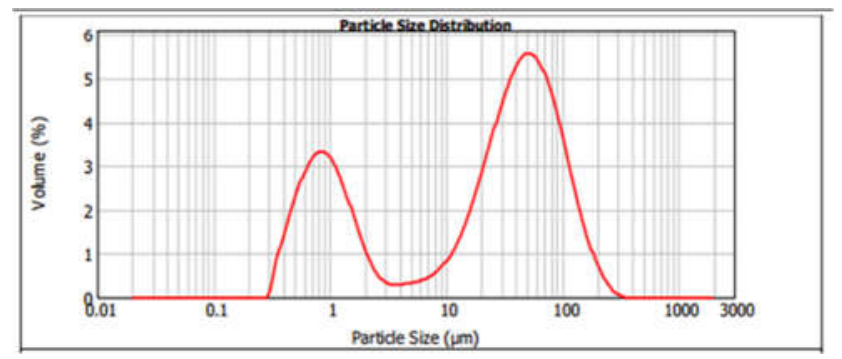

Figure 26. Crude oil droplets size distribution in water. Heavy crude oil from the Orinoco Belt (Venezuela). Measuring equipment: Malvern Mastersizer. Model 2000. 
Generally, the separation equipment manufacturers do not recommend chemical demulsifier formulations to treat these $\mathrm{O} / \mathrm{W}$ emulsions at $\mathrm{HLD}=0$, so service companies perform fancy applications. Many of these formulations are designed and adjusted by trial and error.

Duan et al. [392] developed a block polymer that helps flocculate oil droplets in water for these systems. The EACN of the crude oil, the salinity of the production water must be determined, leaving the temperature and the characteristics of the surfactant as adjustment variables. Moreover, some recent practical equipment designs [393] use the HLD model as a tool to study O/W emulsions and develop formulations that allow oil separation for different oil concentrations. The knowledge and application of the HLD method and the use of the formulation composition diagram (Figure 15) allow predicting the phase behavior and stability of the surfactant-water-oil systems and design formulations for oil containing effluents treatment. In this sense, as in crude oil dewatering and desalting processes in the refineries where the oil amount is, in general, more than $60-70 \%$, the HLDN is a more complete tool to design emulsion breaking formulations. HLDN accounts for the different $\mathrm{K}_{\mathrm{A}}$ coefficients in the original HLD equation of the natural surfactants and demulsifiers in a normalized way. When the previous treatments have involved an $\mathrm{O} / \mathrm{W}$ formulation (in particular because of an excess of demulsifier used in the petroleum production) the formulation change is performed in this case from $\mathrm{HLD}_{\mathrm{N}}<0$ to $\mathrm{HLDN}_{\mathrm{N}}=0$, by adding a somewhat lipophilic surfactant with an $\mathrm{SCP}_{\mathrm{N}}>0$, generally block copolymers, i.e. very big surfactant-like molecules that play complex synergies, and allows to flocculate small oil droplets and to concentrate them and favor their separation.

\subsection{Explosive products made with an unusual W/O emulsion}

The highly concentrated emulsions (HEC) correspond to the case in which the internal phase droplets exceed $70 \%$ of the total volume, with a maximum close packing of uniform spheres at $74 \%$. However, even if a higher content of spheres could be attained when there is a size distribution, above $75 \%$ of internal phase volume, there are strong interactions of neighboring drops and thus an often considerable deformation of them. This results in a mechanical interference with a free movement and a significantly high viscosity with a non-newtonian behavior, often called gel-emulsion [394].

In such cases, thin external phase lamellae between the droplets and the emulsion stabilization require a very effective surfactant at the interface to avoid film breaking. HEC has various applications, particularly in foods, cosmetics and medical products [395], but one of the most interesting and surprising cases is their use as creamy explosives.

The first explosive stronger than black powder was nitroglycerin introduced in 1850, later replaced by less dangerous nitrotoluene, or even more complex and stable mixtures like dynamite proposed by the famous Alfred Nobel. The ammonium nitrate $\left(\mathrm{NH}_{4} \mathrm{NO}_{3}\right)$, available as fertilizer more than 100 years ago, was also found to be eventually an explosive, but nitroglycerin dominated the civil market until 1950. Then, the commercial explosives mostly used in surface or underground mining as well as quarrying, tunneling, or construction in the past 70 years, have been the mixture of ammonium nitrate (AN) often as small pellets and hydrocarbon fuel oil (FO), so-called ANFO [396].

The AN was selected in the explosive business because of its contents of oxygen in a solid substance, and its strong reaction with hydrocarbons that results in gas molecules at high pressure, that produces a shock wave velocity of detonation (VOD) of 2,000-3,000 m/s, i.e., much higher than the sound velocity $(300 \mathrm{~m} / \mathrm{s})$ 
$3 \mathrm{NH}_{4} \mathrm{NO}_{3}+-\mathrm{CH}_{2-}=>\mathrm{N}_{2}+\mathrm{CO}_{2}+7 \mathrm{H}_{2} \mathrm{O}+82 \mathrm{Kcal} / \mathrm{mol}$ or $3900 \mathrm{~kJ} / \mathrm{kg}$

It was shown that at the stoichiometric balance of $94.5 \mathrm{wt} \% \mathrm{AN}$ and $5.5 \mathrm{wt} \%$ diesel $\mathrm{FO}$, the gases mentioned above are the only ones when detonation conditions are optimal. However, the blast results in small amounts of toxic gases like carbon monoxide and various nitrogen oxides in practice. It was shown that in real cases, a small lack of hydrocarbon notably reduces the produced energy, much more than a small excess of it. Consequently, the amount of hydrocarbon is taken as slightly higher than ideal, i.e., of about 6-7\%. Other studies indicated that a small amount of gas in the mixture, e.g., with extra porous AN prills, hollow microballoons or gasing agents (e.g., sodium nitrite, urea or hydrazine hydrate), results in long term stability and higher VOD [396].

Moisture in AN particles has to be very low $(<0.2 \%)$ because it alters the VOD; thus, the mixture of AN prills and diesel oil should stay dry and not be used in a watery borehole. Some plastic coverage of the hole wall or water-proof coating of the prills with a resistant barrier made with guar gum or other polymers was not found to be satisfactory.

This is why the formation of a $\mathrm{W} / \mathrm{O}$ emulsion with a very small amount of external oil phase has become the right solution in the late 1960s, after more than a decade of confidential studies, because AN/FO emulsion is not diluted when contacted with water [100].

Emulsions with aqueous jelly-like AN small drops, say from 1 to $10 \mu \mathrm{m}$ size in general with a wide distribution to reduce the emulsion viscosity [397,398] produce an intimate contact, and thus a good performance in the explosion. The water phase pseudo-liquid state is kept by creating AN crystallization resistance, which should remain liquid down to freezing temperature, when the fudge point to make the AN solution is about $70^{\circ} \mathrm{C}$. Thorough research has been dedicated to preventing crystal growth and its propagation through the emulsion, with many improvements found with anionics mixture containing lauryl sulfate or phosphate, phenyl or naphthyl sulfonate [396].

The oil phase of the W/O emulsion isn't necessarily a very pure product. In practice, some partially refined products like \#2 diesel oil with a high boiling point but a low viscosity is appropriate. In addition, using light crude oil with asphaltenes in a small quantity might help in retarding the water drop coalescence, which has been reported to be advantageous in some cases [396].

This kind of W/O emulsions should be stabilized by lipophilic surfactants, usually with a 4-5 value in the HLB scale proposed by Griffin, who worked in Atlas Powder ten years before the same company started to patent the explosive emulsion formulations. This seems to be a strange coincidence, even if Griffin's official goal when he proposed the HLB scale was to produce stable O/W emulsions for other purposes.

The proposed lipophilic surfactants to stabilize the ANFO W/O emulsions are not so evident because one of the important roles is to avoid the nucleation of the nitrate salts, to keep the molten state of the water phase. The fact that the salinity in the supersaturated water phase is extremely high (sometimes with calcium ions) allows selecting surfactants that generate $\mathrm{O} / \mathrm{W}$ emulsions at low salinity like alkyl carboxylates or sulfates. Thus, passing to an inverse emulsion W/O at high salinity according to the HLD equation discussed previously because of the strong effect of the LnS term to change the HLD sign.

However, such short and n-alkyl tail surfactant candidates were not very good at strongly stabilizing the $\mathrm{W} / \mathrm{O}$ emulsion because of the thin film produced. 
Consequently, the most proposed surfactant in the first patents in the 1960-1970s were sorbitan esters with one, two or three stearic or oleic chains, i.e., the typical so-called Span products. More recently, derivatives of the polyisobutenyl succinic anhydride (PIBSA) have been preferred by companies formulating the emulsion explosives, with a polyisobutylene part having a MW of about 1,000 Da, i.e., about 80 carbon atoms [399]. The PIBSA is producing surfactant derivatives by reacting with ethylenediamine, diethylene tetramine, mono/di-ethanolamines, urea, methyl urea, biuret or triuret, aminourea, polysuccinimide, alkyl or aryl compounds with nitrile, keto, halogen, nitro, and other structures, some of them shown in Figure 27.

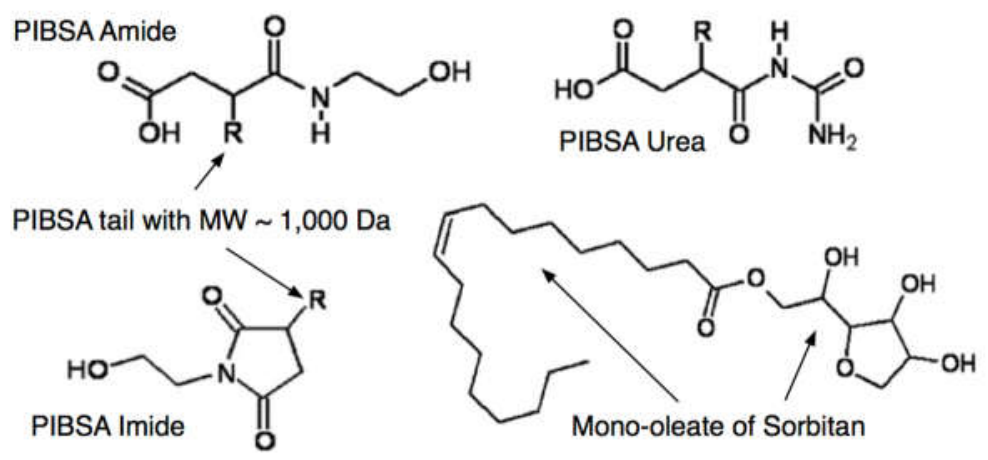

Figure 27. Typical surfactant derivatives used in explosive emulsions, in particular the polyisobutylene succinic anhydride (PIBSA) derivatives in which $\mathrm{R}$ contains about 20 PIB units.

It was suggested that the stabilization of such emulsion requires several demands on the emulsifier effects: (1) the surfactant has to reduce the interfacial tension to stabilize the new surface quickly. (2) the second reality is the production of a bilayer in the thin films between the packed droplets with non-spherical shape. (3) the slower coalescence and (4) the reduction of crystallization of ammonium nitrate. (5) the explosion capacity.

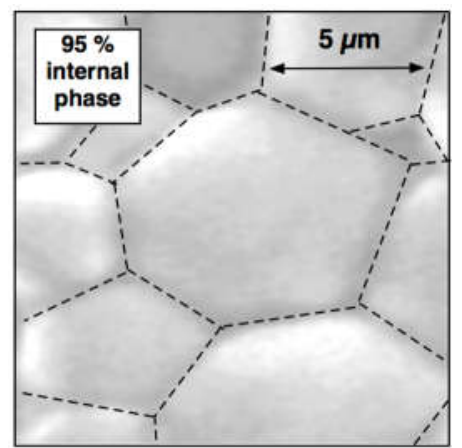

Figure 28. Typical aspect of compacted drops in a high internal phase W/O emulsion with a dispersed distribution.

The liquid droplets have a wide distribution of size to reduce the viscosity, often a binary mixture [400], but because of the very high content, the drops in a gel emulsion have a polygonal shape, as seen in Figure 28. It is worth remembering that the drop phase consists of a supercooled aqueous solution of $80-85 \mathrm{wt} \%$ or more ammonium nitrate, which is in the state of hydrous melt where ions can move about easily, as discussed in the literature despite the viscoelasticity [401]. Rheology of HEC emulsions is, of course, complex [400,402-404], but it is possible to have it pumped 
in a stable flow [405]. As far as the fabrication of the HEC emulsion is concerned, there are many methods, mostly copied from the food products. They essentially consist of step by step adding an aqueous gel phase into a stirred oil phase, not with a very strong energy that could invert the emulsion. In

practice, the initial temperature is above the melting point of the $\mathrm{AN}\left(70^{\circ} \mathrm{C}\right)$, and then it is cooled down using a second mixing process with a slow motion and very high shear apparatus. No citation is proposed here to avoid unfairness because of an extreme variety linked with specific equipment and emulsifier products which is easily found in the technical literature.

\section{Conclusions and Perspectives}

The formulation of multiphase systems progressed extensively in the 20th century. The study of theoretical and practical aspects of surfactant-oil-water systems allowed the significant development of know-how and the formulation of thousands of products in cosmetic, food, pharmaceutics, petroleum, pulp and paper, environmental remediation industries.

At the beginning of the development of surfactant science, there were practical (Bancroft, Griffin) and fundamental (Winsor, Beerbower) contributions, even though they were from different industries, e.g., soaps, cosmetics, explosives, or researchers in universities. In the 1960s, contributions and advances on solubilization parameters were attained, in this case, related to polymer solubilization for paints. Nevertheless, Hansen proposal of three components (HSP), and eventually Hildebrand \& Scott, who introduced the solubilization parameter concept, helped understand soft matter behavior better. These pioneers gave way to the 1960-1970s studies by Shinoda's group in Japan and Wade and Schechter's group in the University of Texas. The background and advances in surfactant science and mainly Winsor's studies were of utmost importance to develop the multivariable equation (known today as HLD) that can account for the interactions of simple surfactant systems with oil and water.

There is no doubt that HLB was a sometimes arbitrary number. Nevertheless, it was an excellent abbreviation and a clear name, although not based on a balance of interactions, because Griffin was looking for a stable $\mathrm{O} / \mathrm{W}$ emulsion, that is, $\mathrm{HLB}=15-20$. Incidentally, Griffin wanted a stable $\mathrm{O} / \mathrm{W}$ emulsion, but his company Atlas Powder, which had gotten into explosive emulsions, wanted stable $\mathrm{W} / \mathrm{O}$ emulsions with $90 \%$ water phase (actually from a medium nitrate gel, which is to say, liquidsolid oxygen).

Despite the conceptual advances of Winsor and Beerbower and the development of the hydrophilic-lipophilic deviation equation in its normalized form (HLDN), there are still advances to make, including resolving a confusion of the surfactant parameter with a "characteristic curvature" of the surfactant [67]. Also, using the HLD-NAC equation with different units (mixing anionic and cationic, or nonionic HLD equations) leads to significant deviations when complex systems are formulated, as was experimentally shown recently [172]. Basically, the HLD correlation is a sum of effects equal to zero at the so-called optimum formulation, that is, an exact balance between the phases. Therefore, until those aspects related to confusion on the application of the equation in complex systems are resolved, using advanced computing and artificial intelligence to aid in solving faster this type of formulation problem will not be possible, until the use of the HLD equation with unifying criteria (for example using the HLDN normalized equation).

Nowadays, with new environmental regulations (e.g., dioxane limits) and sustainability challenges, advances in surfactant formulation science are of utmost importance, including the broad use of biomass-derived surfactants and biosurfactants $[111,406]$. However, this type of systems are generally surfactant mixtures and will generate complexity in formulations, requiring going back to the Winsor fundamentals to look for computational application of HLDN-like multivariable equations with simple equivalents of the natural substances.

Author Contributions: Conceptualization, J.L.S; writing-original draft preparation, J.L.S.; writing-review and editing, J.L.S., R.M., J.B., A.F.; All authors have read and agreed to the published version of the manuscript.

Funding: This research received no external funding.

Data Availability Statement: Not applicable. 
Acknowledgments: We acknowledge the contributions of all the Professors, Students, Researchers, and support staff that have worked in FIRP Laboratory throughout its 45 years since it was founded. We also recognize the collaboration of university laboratories and companies that have contributed to the formation of our Ph.D. students and with research projects worldwide.

Conflicts of Interest: The authors declare no conflict of interest.

\section{References}

1. Aubry, J.-M.; Schorsch, G. Formulation - Présentation générale, Techniques de l'Ingénieur, J2110, 1999 Available online: https://www.techniques-ingenieur.fr/base-documentaire/procedes-chimie-bio-agro-th2/principes-de-formulation42489210/formulation-j2110/.

2. Salager, J.-L.; Antón, R.E.; Bullón, J.; Forgiarini, A.; Marquez, R. How to Use the Normalized Hydrophilic-Lipophilic Deviation (HLDN) Concept for the Formulation of Equilibrated and Emulsified Surfactant-Oil-Water Systems for Cosmetics and Pharmaceutical Products. Cosmetics 2020, 7, 57, doi:10.3390/cosmetics7030057.

3. Hargreaves, T. Chemical Formulation: An Overview of Surfactant Based Chemical Preparations Used in Everyday Life.; The Royal Society of Chemistry: Cambridge, UK, 2003; ISBN 9788578110796.

4. Salager, J.-L. Quantifying the concept of physico-chemical formulation in surfactant-oil-water systems - state of the art. In Trends in Colloid and Interface Science X; Springer, 1996; pp. 137-142.

5. Rataj, V. Formulation des microémulsions: Propriétés et exemples d'application. Actual. Chim. 2016, 31-33.

6. Salager, J.-L.; Antón, R.E.; Forgiarini, A.; Márquez, L. Formulation of Microemulsions. In Microemulsions; Wiley Online Books; 2009; pp. 84-121 ISBN 9781444305524.

7. Haas, S.; Hässlin, H.W.; Schlatter, C. Influence of polymeric surfactants on pesticidal suspension concentrates: dispersing ability, milling efficiency and stabilization power. Colloids Surfaces A Physicochem. Eng. Asp. 2001, 183-185, 785-793, doi:10.1016/S0927-7757(01)00505-2.

8. Poucher, W.A. Poucher's Perfumes, Cosmetics and Soaps - Volume 1; 9th editio.; Springer: New Delhi, India, 1991; ISBN 0751404799 .

9. Borchers, G. Design and manufacturing of solid detergent products. J. Surfactants Deterg. 2005, 8, 123-128, doi:10.1007/s11743-005-339-1.

10. Donaldson, E.C.; Alam, W. Wettability; Gulf Publishing Company: Houston, Texas, 2008; ISBN 1933762292.

11. Christian, S.D.; Scamehorn, J.F. Solubilization in Surfactant Aggregates; Christian, S.D., Scamehorn, J.F., Eds.; CRC Press: Boca Raton, USA, 2019;

12. Langevin, D. Emulsions, Microemulsions and Foams; Springer: Gewerbestr, Switzerland, 2020; ISBN 978-3-030-55681-5.

13. Israelachvili, J.N.; Mitchell, D.J.; Ninham, B.W. The science and applications of emulsions - an overview. J. Chem. Soc. Faraday Trans. 2 Mol. Chem. Phys. 1994, 91, 1-8, doi:10.1016/0927-7757(94)02743-9.

14. Prausnitz, J.M.; Lichtenthaler, R.N.; De Azevedo, E.G. Molecular thermodynamics of fluid-phase equilibria; 3rd Editio.; Pearson Education: New Jersey, USA, 1999; ISBN 0132440504.

15. Showell, M. Handbook of Detergents, Part D: Formulation; Showell, M., Ed.; CRC Press: Boca Raton, USA, 2005;

16. Ho, L.; Tai, T. Formulating Detergents and Personal Care Products A Guide to Product Development; AOCS Press: Urbana, Illinois, 2000; ISBN 1893997103.

17. Jeirani, Z.; Mohamed Jan, B.; Si Ali, B.; Noor, I.M.; See, C.H.; Saphanuchart, W. Formulation and phase behavior study of a nonionic triglyceride microemulsion to increase hydrocarbon production. Ind. Crops Prod. 2013, 43, 15-24, doi:10.1016/j.indcrop.2012.07.004.

18. Bera, A.; Mandal, A. Microemulsions: a novel approach to enhanced oil recovery: a review. J. Pet. Explor. Prod. Technol. 2015, 5, 255-268, doi:10.1007/s13202-014-0139-5.

19. Ogunberu, A.L.; Ayub, M. The role of wettability in petroleum recovery. Pet. Sci. Technol. 2005, 23, 169-188, 
doi:10.1081/LFT-200028145.

20. Tadros, T. Colloids in Paints; WILEY-VCH Verlag GmbH \& Co. KGaA: Weinheim, Germany, 2010; Vol. 6; ISBN 9783527314669.

21. Tadros, T. Encyclopedia of Colloid and Interface Science; Springer-Verlag Berlin Heidelberg: Berlin, Germany, 2013; ISBN 9783642206658.

22. Birdi, K.S. Handbook of Surface and Colloid Chemistry; Birdi, K.S., Ed.; 4th editio.; CRC Press: Boca Raton, 2015; ISBN 0471490830 .

23. Tadros, T.F. Emulsion Science and Technology: A General Introduction; Tadros, T., Ed.; WILEY-VCH Verlag GmbH \& Co. KGaA: Berlin, Germany, 2009; ISBN 9783527325252.

24. Clarke, C. The Science of Ice Cream; Royal Society of Chemistry: Cambridge, UK, 2003;

25. Doroszkowski, A. The physical chemistry of dispersion. Paint Surf. Coatings 1999, 198-242, doi:10.1533/9781855737006.198.

26. Sun, S.F. Physical Chemistry of Macromolecules: Basic Principles and Issues - 2nd Ed; 2nd ed.; John Wiley \& Sons, Inc: Hoboken, New Jersey, US., 2004; ISBN 9786468600.

27. Hildebrand, J.H. Emulsion type. J. Phys. Chem. 1941, 45, 1303, doi:10.1021/j150413a016.

28. Schwartz, J.B. Optimization techniques in product formulation. J. Soc. Cosmet. Chem 1981, 32, $287-301$.

29. Olejnik, O.; Firestone, B.A. Scale-up of dermatological dosage forms: A case for multivariate optimization and product homogeneity. Dermatological Transdermal Formul. 2002, 499-510, doi:10.1201/9780824743239-12.

30. McClements, D.J.; Rao, J. Food-Grade nanoemulsions: Formulation, fabrication, properties, performance, Biological fate, and Potential Toxicity. Crit. Rev. Food Sci. Nutr. 2011, 51, 285-330, doi:10.1080/10408398.2011.559558.

31. Rondón-Gonzaléz, M.; Sadtler, V.; Choplin, L.; Salager, J.-L.J.L. Emulsion catastrophic inversion from abnormal to normal morphology. 5. Effect of the water-to-oil ratio and surfactant concentration on the inversion produced by continuous stirring. Ind. Eng. Chem. Res. 2006, 45, 3074-3080, doi:10.1021/ie060036l.

32. Rondón-González, M.; Madariaga, L.F.; Sadtler, V.; Choplin, L.; Márquez, L.; Salager, J.-L. Emulsion catastrophic inversion from abnormal to normal morphology. 6. Effect of the phase viscosity on the inversion produced by continuous stirring. Ind. Eng. Chem. Res. 2007, 46, 3595-3601, doi:10.1021/ie070145f.

33. Binks, B.P.; Lumsdon, S.O. Catastrophic Phase Inversion of Water-in-Oil Emulsions Stabilized by Hydrophobic Silica. Langmuir 2000, 16, 2539, doi:10.1021/la991081j.

34. Tyrode, E.; Mira, I.; Zambrano, N.; Márquez, L.; Rondón-Gonzalez, M.; Salager, J.L.J.-L.; Rondón-González, M.; Salager, J.L.J.-L. Emulsion Catastrophic Inversion from Abnormal to Normal Morphology. 3. Conditions for Triggering the Dynamic Inversion and Application to Industrial Processes. Ind. Eng. Chem. Res. 2003, 42, 4311-4318, doi:10.1021/ie0300629.

35. Gorevski, N.; Miller, R.; Ferri, J.K. Non-equilibrium exchange kinetics in sequential non-ionic surfactant adsorption: Theory and experiment. Colloids Surfaces A Physicochem. Eng. Asp. 2008, 323, 12-18, doi:10.1016/j.colsurfa.2007.12.032.

36. Solans, C.; Morales, D.; Homs, M. Spontaneous emulsification. Curr. Opin. Colloid Interface Sci. 2016, 22, 88-93, doi:10.1016/j.cocis.2016.03.002.

37. Márquez, R.; Tolosa, L.; Gómez, R.; Izaguirre, C.; Rennola, L.; Bullón, J.; Sandia, B. Reproducción de un ambiente de innovación en el salón de clase. Una estrategia para promover la creatividad en la educación en Ingeniería Química. Educ. Quim. 2016, 27, 249-256, doi:10.1016/j.eq.2016.07.001.

38. Salager, J.-L.; Antón, R.E.; Anderez, J.M.; Aubry, J.-M. Formulation des micro-émulsions par la méthode HLD, Techniques de l'Ingénieur, J2157, 2001 Available online: https://www.techniques-ingenieur.fr/basedocumentaire/procedes-chimie-bio-agro-th2/principes-de-formulation-42489210/formulation-des-microemulsions-parla-methode-du-hld-j2157/. 
39. Smulders, E.; von Rybinski, W.; Sung, E.; Rähse, W.; Steber, J.; Wiebel, F.; Nordskog, A. Laundry Detergents. In Ullmann's Encyclopedia of Industrial Chemistry; WILEY-VCH Verlag GmbH \& Co. KGaA: Hoboken, New Jersey, US., 2007 ISBN 3527305203.

40. Caenn, R.; Chillingar, G. V. Drilling fluids: State of the art. J. Pet. Sci. Eng. 1996, 14, 221-230, doi:10.1016/09204105(95)00051-8.

41. Grenoble, Z.; Trabelsi, S. Mechanisms, performance optimization and new developments in demulsification processes for oil and gas applications. Adv. Colloid Interface Sci. 2018, 260, 32-45, doi:10.1016/j.cis.2018.08.003.

42. Roger, K. Nanoemulsification in the vicinity of phase inversion: Disruption of bicontinuous structures in oil/surfactant/water systems. Curr. Opin. Colloid Interface Sci. 2016, 25, 120-128, doi:10.1016/j.cocis.2016.09.015.

43. Salager, J.-L.; Márquez, L.; Peña, A.A.; Rondón, M.; Silva, F.; Tyrode, E. Current phenomenological know-how and modeling of emulsion inversion. Ind. Eng. Chem. Res. 2000, 39, 2665-2676, doi:10.1021/ie990778x.

44. Fryd, M.M.; Mason, T.G. Advanced nanoemulsions. Annu. Rev. Phys. Chem. 2012, 63, 493-518, doi:10.1146/annurevphyschem-032210-103436.

45. Figueiredo Neto, A.M.; Salinas, S.R.A. The Physics of Lyotropic Liquid Crystals: Phase Transitions and Structural Properties. Phys. Lyotropic Liq. Cryst. Phase Transitions Struct. Prop. 2010, 9780198525, 1-320, doi:10.1093/acprof:oso/9780198525509.001.0001.

46. Salager, J.; Forgiarini, A.M.; Bullon, J. Progress in Over a Century of Designing Emulsion Properties: Emerging Phenomenological Guidelines from Generalized Formulation and Prospects to Transmute the Knowledge into KnowHow. In Surfactant Science and Technology: Retrospects and Prospects; Romsted, L.S., Ed.; CRC Press, Taylor \& Francis, 2014; pp. 455-483.

47. Hansen, C.M. The Three-Dimensional Solubility Parameter - Key to Paint Component Affinities. J. Paint Technol. 1967, 39, 104-117.

48. Hansen, C.M. The universality of the solubility parameter. Ind. Eng. Chem. Prod. Res. Dev. 1969, 8, 2-11, doi:10.1021/i360029a002.

49. Binks, B..; Lumsdon, S.. Pickering Emulsions Stabilized by Monodisperse Latex. Langmuir 2001, 4540-4547, doi:10.1021/la0103822.

50. Binks, B.P.; Clint, J.H. Solid wettability from surface energy components: Relevance to pickering emulsions. Langmuir 2002, 18, 1270-1273, doi:10.1021/la011420k.

51. Arditty, S.; Schmitt, V.; Giermanska-Kahn, J.; Leal-Calderon, F. Materials based on solid-stabilized emulsions. J. Colloid Interface Sci. 2004, 275, 659-664, doi:10.1016/j.jcis.2004.03.001.

52. Dickinson, E. Food emulsions and foams: Stabilization by particles. Curr. Opin. Colloid Interface Sci. 2010, 15, 40-49, doi:10.1016/j.cocis.2009.11.001.

53. Menner, A.; Verdejo, R.; Shaffer, M.; Bismarck, A. Particle-stabilized surfactant-free medium internal phase emulsions as templates for porous nanocomposite materials: Poly-pickering-foams. Langmuir 2007, 23, 2398-2403, doi:10.1021/la062712u.

54. Miller, R.; Fainerman, V.B.; Kovalchuk, V.I.; Grigoriev, D.O.; Leser, M.E.; Michel, M. Composite interfacial layers containing micro-size and nano-size particles. Adv. Colloid Interface Sci. 2006, 128-130, 17-26, doi:10.1016/j.cis.2006.11.004.

55. Goddard, E.D. Polymer/surfactant interaction-Its relevance to detergent systems. J. Am. Oil Chem. Soc. 1994, 71, 1-16, doi:10.1007/BF02541467.

56. Pal, R. Rheology of simple and multiple emulsions. Curr. Opin. Colloid Interface Sci. 2011, 16, 41-60, doi:10.1016/j.cocis.2010.10.001.

57. Langevin, D. Rheology of adsorbed surfactant monolayers at fluid surfaces. Annu. Rev. Fluid Mech. 2014, 46, 47-65, 
doi:10.1146/annurev-fluid-010313-141403.

58. Gallegos, C.; Franco, J.M. Rheology of food, cosmetics and pharmaceuticals. Curr. Opin. Colloid Interface Sci. 1999, 4, 288-293, doi:10.1016/S1359-0294(99)00003-5.

59. Wilde, P.; Mackie, A.; Husband, F.; Gunning, P.; Morris, V. Proteins and emulsifiers at liquid interfaces. Adv. Colloid Interface Sci. 2004, 108-109, 63-71, doi:10.1016/j.cis.2003.10.011.

60. Berni, M.G.; Lawrence, C.J.; Machin, D. A review of the rheology of the lamellar phase in surfactant systems. Adv. Colloid Interface Sci. 2002, 98, 217-243, doi:10.1016/S0001-8686(01)00094-X.

61. Gaudin, T.; Lu, H.; Fayet, G.; Berthauld-Drelich, A.; Rotureau, P.; Pourceau, G.; Wadouachi, A.; Van Hecke, E.; Nesterenko, A.; Pezron, I. Impact of the chemical structure on amphiphilic properties of sugar-based surfactants: A literature overview. Adv. Colloid Interface Sci. 2019, 270, 87-100, doi:10.1016/j.cis.2019.06.003.

62. Salager, J.-L.; Forgiarini, A.M.; Bullón, J. How to attain ultralow interfacial tension and three-phase behavior with surfactant formulation for enhanced oil recovery: A review. Part 1. Optimum formulation for simple surfactant-oilwater ternary systems. J. Surfactants Deterg. 2013, 16, 449-472, doi:10.1007/s11743-013-1470-4.

63. Salager, J.-L.; Forgiarini, A.; Marquez, R. Extended Surfactants Including an Alkoxylated Central Part Intermediate Producing a Gradual Polarity Transition-A Review of the Properties Used in Applications Such as Enhanced Oil Recovery and Polar Oil Solubilization in Microemulsions. J. Surfactants Deterg. 2019, 22, 935-972, doi:10.1002/jsde.12331.

64. Brouillet, F.; Bullón, J.; Cárdenas, A.; Sánchez, J.; Marti-Mestres, G.; Briceño, M.I. Modification of the droplet size and distribution of parenteral emulsions by tangential microfiltration. J. Memb. Sci. 2003, 221, 199-206, doi:10.1016/S03767388(03)00262-X.

65. Salager, J.-L. Emulsion Phase Inversion Phenomena. In Emulsions and Emulsion Stability; Sjoblom, J., Ed.; CRC Publishing, 2006; p. 185.

66. Salager, J.-L.; Nielloud, F.; Marti-Mestres, G. Pharmaceutical Emulsions and Suspensions : Emulsion properties and related know-how to attain them. 2000, 20000573.

67. Salager, J.-L. A normalized Hydrophilic-Lipophilic Deviation expression HLDN is necessary to avoid confusions close to the optimum formulation of Surfactant-Oil-Water systems. J. Surfactants Deterg. 2021, 24, 731-748, doi:10.1002/jsde.12518.

68. Levey, M. Chemistry and chemical technology in ancient Mesopotamia; Elsevier: Amsterdam, Netherlands, 1959;

69. Ruckenstein, E. Microemulsions, macroemulsions, and the Bancroft rule. Langmuir 1996, 12, 6351, doi:10.1021/la960849m.

70. Bancroft, W.D. The Theory of Emulsification, V. J. Phys. Chem. 1913, 17, 501-519, doi:10.1021/j150141a002.

71. Scheibel, J.J. The evolution of anionic surfactant technology to meet the requirements of the laundry detergent industry. J. Surfactants Deterg. 2004, 7, 319-328, doi:10.1007/s11743-004-0317-7.

72. Miller, M.M. Soap and other Detergents; Minnesota, US, 1950;

73. Ekwall, P.; Mandell, L.; Fontell, K. Some observations on binary and ternary aerosol OT systems. J. Colloid Interface Sci. 1970, 33, 215-235, doi:10.1016/0021-9797(70)90024-X.

74. Boyd, J.; Sherman, P. Two-dimensional rheological studies on surfactant films at interfaces. J. Colloid Interface Sci. 1970, 34, 76-80, doi:10.1016/0021-9797(70)90260-2.

75. Halliday, H.L. Surfactants: past, present and future. J. Perinatol. 2008, 28, S47-S56, doi:10.1038/jp.2008.50.

76. Rosen, M.J.; Kunjappu, J.T.; Seymour, K.G. Surfactants and Interfacial Phenomena; John Wiley \& Sons: New York, USA, 2012; Vol. 62; ISBN 9780470541944.

77. Rosen, M.J.; Dahanayake, M. Industrial Utilization of Surfactants: Principles and Practice; AOCS Press: Urbana, Illinois, 2000; ISBN 1893997111.

78. Bourrel, M.; Schechter, R.S. Microemulsions and Related Systems; 1st ed.; Marcel Dekker, Inc: New York and Basel, 1988; 


\section{ISBN 978082477951.}

79. Broze, G. Handbook of detergents. Part A: properties; Broze, G., Ed.; CRC Press: Boca Raton, USA, 1999;

80. Cutler, W.G.; Kissa, E. Detergency: Theory and Technology; Cutler, W.G., Ed.; 1st ed.; CRC Press: New York, 1987;

81. Friberg, S.E. Organized Solutions. Surfactant Science Series; CRC Press: Cleveland, Ohio, 1992; Vol. 44; ISBN 9780824786984 .

82. Holmberg, K. Novel Surfactants: Preparation Applications And Biodegradability; Holmberg, K., Ed.; 2nd ed.; CRC Press, Taylor \& Francis: Cleveland, Ohio, 2003; ISBN 0824756215.

83. Miller, C.A.; Neogi, P. Interfacial Phenomena: Equilibrium and Dynamic Effects; Miller, C.A., Neogi, P., Eds.; 2nd ed.; CRC Press DOI: Boca Raton, 2007;

84. Mittal, K.L. Microemulsions in Foods: Challenges and Applications. In Adsorption and Aggregation of Surfactants in Solution; Gaonkar, A.G., Bagwe, R.P., Eds.; CRC Press: Cleveland, Ohio, 2002; pp. 407-430.

85. Myers, D. Surfactant science and technology; Wiley-VCH Verlag GmbH \& Co. KGaA: Hoboken, New Jersey, US., 2006; ISBN 9780471680246.

86. Sjoblom, J. Emulsions and Emulsion Stability; Sjoblom, J., Ed.; 1st ed.; CRC Press: Boca Raton, USA, USA, 2005;

87. Zana, R. Polymer/Surfactant Systems. In Structure-Performance Relationships in Surfactants; Esumi, K., Ueno, M., Eds.; CRC Press: Cleveland, Ohio, 2003; p. 16.

88

https://app.dimensions.ai/discover/publication?search_mode=content\&search_text=surfactant

formulation\&search_type=kws\&search_field=text_search (accessed on Nov 15, 2021).

89. Scopus "Formulation" + "Surfactant" Available online: https://www.scopus.com/results/results.uri?sid=c3cea6344053ae03df2007ba8be13abc\&src=s\&sot=b\&sdt=b\&origin=sear chb (accessed on Nov 15, 2021).

90. Salager, J.-L.; Anton, R.E. Ionic Microemulsions. Handb. Microemulsion Sci. Technol. 2020, 247-280, doi:10.1201/9780203752739-8.

91. Phaodee, P.; Sabatini, D.A. Effect of Surfactant Systems, Alcohol Types, and Salinity on Cold-Water Detergency of Triacylglycerol Semisolid Soil. Part II. J. Surfactants Deterg. 2020, 23, 423-432, doi:10.1002/jsde.12374.

92. Tanthakit, P.; Chavadej, S.; Scamehorn, J.F.; Sabatini, D.A.; Tongcumpou, C. Microemulsion formation and detergency with oily soil: IV. Effect of rinse cycle design. J. Surfactants Deterg. 2008, 11, 117-128, doi:10.1007/s11743-008-1062-x.

93. Flick, E.W. Cosmetic and toiletry formulations, Vol. 8; Noyes Publications: New Jersey, USA, 2007; ISBN 0815514549.

94. Prieto-Blanco, M.C.; Fernández-Amado, M.; López-Mahía, P.; Muniategui-Lorenzo, S.; Prada-Rodríguez, D. Surfactants in Cosmetics: Regulatory Aspects and Analytical Methods. In Analysis of Cosmetic Products; Salvador, A., A. Chisvert, Eds.; Elsevier: Amsterdam, Netherlands, 2018; pp. 249-287 ISBN 9780824798055.

95. Flick, E.W. Cosmetic and Toiletry Formulations; 2nd. Ed.; Noyes Publications: New Jersey, USA, 1992; Vol. 2; ISBN 9780815513827.

96. Soontravanich, S.; Walsh, S.; Scamehorn, J.F.; Harwell, J.H.; Sabatini, D.A. Interaction between an anionic and an amphoteric surfactant. Part II: Precipitation. J. Surfactants Deterg. 2009, 12, 145-154, doi:10.1007/s11743-009-1106-x.

97. Phaodee, P.; Sabatini, D.A. Anionic and Cationic Surfactant Synergism: Minimizing Precipitation, Microemulsion Formation, and Enhanced Solubilization and Surface Modification. J. Surfactants Deterg. 2021, 24, 551-562, doi:10.1002/jsde.12512.

98. Griffin, W. Classification of surface-active agents by" HLB". J. Soc. Cosmet. Chem. 1949, 1, 311-326.

99. Griffin, W. Calculation of HLB Values of Non-ionic Surfactants. J. Soc. Cosmet. Chem. 1954, 5, 249.

100. Bampfield, H.; Cooper, J. Emulsion Explosives. In Encyclopedia of emulsion technology vol. 3 Basic theory, measuremens, applications; Becher, P., Ed.; Marcel Dekker: New York, 1988; pp. 282-304. 
101. Shah, D.O.; Schechter, R.S. Improved oil recovery by surfactant and polymer flooding; Elsevier: Amsterdam, Netherlands, 1977; ISBN 978-0-12-641750-0.

102. Winsor, P. Hydrotropy, solubilisation and related emulsification processes. Trans. Faraday Soc. 1948, 44, 376-398, doi:10.1039/TF9484400376.

103. Salager, J.-L.; Morgan, J.C.; Schechter, R.S.; Wade, W.H.; Vasquez, E. Optimum formulation of surfactant/water/oil systems for minimum interfacial tension or phase behavior. Soc. Pet. Eng. J. 1979, 19, 107-115, doi:10.2118/7054-PA.

104. Bourrel, M.; Salager, J.L.; Schechter, R.S.; Wade, W.H. A correlation for phase behavior of nonionic surfactants. J. Colloid Interface Sci. 1980, 75, 451-461, doi:10.1016/0021-9797(80)90470-1.

105. Puerto, M.C.; Gale, W.W. Estimation of Optimal Salinity and Solubilisation Parameters for Alkyl Orthoxylene Sulfonate Mixtures. Soc. Pet. Eng. J. 1977, 17, 193, doi:10.2118/5814-PA.

106. Doe, P.; El-Emary, M.; Wade, W.H.; Schechter, R.S. Surfactants for producing low interfacial tensions I: Linear alkyl benzene sulfonates. J. Am. oil Chem. Soc. 1977, 54, 570-577, doi:10.1007/BF03027638.

107. Cayias, J.L.; Schechter, R.S.; Wade, W.H. Measurement of Low Interfacial Tension Via the Spinning Drop Technique. ACS Symp. Ser. 1975, 234-247, doi:10.1021/bk-1975-0008.ch017.

108. Vera, R.E.; Salazar-Rodríguez, F.; Marquez, R.; Forgiarini, A.M. How the Influence of Different Salts on Interfacial Properties of Surfactant-Oil-Water Systems at Optimum Formulation Matches the Hofmeister Series Ranking. J. Surfactants Deterg. 2020, 23, 603-615, doi:10.1002/jsde.12406.

109. Somasundaran, P.; Cleverdon, J. A study of polymer/surfactant interaction at the mineral/solution interface. Colloids and Surfaces 1985, 13, 73-85, doi:https://doi.org/10.1016/0166-6622(85)80007-X.

110. Somasundaran, P.; Huang, L. Adsorption/aggregation of surfactants and their mixtures at solid-liquid interfaces. Adv. Colloid Interface Sci. 2000, 88, 179-208, doi:10.1016/S0001-8686(00)00044-0.

111. Hayes, D. Biobased Surfactants: Overview and Industrial State-of- the-Art. In Biobased surfactants and detergents; Hayes, D., Kitamoto, D., Solaiman, D., Ashby, R., Eds.; AOCS Publishing: Urbana, Illinois, 2009; pp. 3-25 ISBN 978-1-893997$67-7$.

112. Kramek-Romanowska, K.; Odziomek, M.; Sosnowski, T.R. Dynamic tensiometry studies on interactions of novel therapeutic inhalable powders with model pulmonary surfactant at the air-water interface. Colloids Surfaces $A$ Physicochem. Eng. Asp. 2015, 480, 149-158, doi:10.1016/j.colsurfa.2015.02.017.

113. Rondón, M.; Pereira, J.C.; Bouriat, P.; Graciaa, A.; Lachaise, J.; Salager, J.-L. Breaking of water-in-crude-oil emulsions. 2. Influence of asphaltene concentration and diluent nature on demulsifier action. Energy \& Fuels 2008, 22, 702-707, doi:10.1021/ef7003877.

114. Rondón, M.; Bouriat, P.; Lachaise, J.; Salager, J.L. Breaking of water-in-crude oil emulsions. 1. Physicochemical phenomenology of demulsifier action. Energy $\mathcal{E}$ Fuels 2006, 20, 1600-1604, doi:10.1021/ef060017o.

115. Pereira, J.C.; Delgado-Linares, J.; Scorzza, C.; Rondón, M.; Rodríguez, S.; Salager, J.-L. Breaking of Water-in-Crude Oil Emulsions. 4. Estimation of the Demulsifier Surfactant Performance To Destabilize the Asphaltenes Effect. Energy E Fuels 2011, 25, 1045, doi:10.1021/ef100979y.

116. Delgado-Linares, J.G.; Pereira, J.C.; Rondón, M.; Bullón, J.; Salager, J.L. Breaking of Water-in-Crude Oil Emulsions. 6. Estimating the Demulsifier Performance at Optimum Formulation from Both the Required Dose and the Attained Instability. Energy \& Fuels 2016, 30, 5483-5491, doi:10.1021/acs.energyfuels.6b00666.

117. Delgado-Linares, J.G.; Alvarado, J.G.; Véjar, F.; Bullón, J.; Forgiarini, A.M.; Salager, J.L. Breaking of Water-in-Crude Oil Emulsions. 7. Demulsifier Performance at Optimum Formulation for Various Extended Surfactant Structures. Energy $\mathcal{E}$ Fuels 2016, 30, 7065-7071, doi:10.1021/acs.energyfuels.6b01286.

118. Alvarado, J.G.; Delgado-Linares, J.G.; Forgiarini, A.M.; Salager, J.-L. Breaking of Water-in-Crude Oil Emulsions. 8. Demulsifier Performance at Optimum Formulation Is Significantly Improved by a Small Aromatic Content of the Oil. 
Energy E Fuels 2019, 33, 1928-1936, doi:10.1021/acs.energyfuels.8b03994.

119. Marquez, R.; Forgiarini, A.; Langevin, D.; Salager, J.-L. Breaking of Water-In-Crude Oil Emulsions. Part 9. New Interfacial Rheology Characteristics Measured Using a Spinning Drop Rheometer at Optimum Formulation. Energy $\mathcal{E}$ Fuels 2019, 33, 8151-8164, doi:10.1021/acs.energyfuels.9b01476.

120. Raya, S.A.; Mohd Saaid, I.; Abbas Ahmed, A.; Abubakar Umar, A. A critical review of development and demulsification mechanisms of crude oil emulsion in the petroleum industry. J. Pet. Explor. Prod. Technol. 2020, 10, 1711-1728, doi:10.1007/s13202-020-00830-7.

121. Sjöblom, J.; Aske, N.; Auflem, I.H.; Brandal, Ø.; Havre, T.E.; Sæther, Ø.; Westvik, A.; Johnsen, E.E.; Kallevik, H. Our current understanding of water-in-crude oil emulsions. Recent characterization techniques and high pressure performance. Adv. Colloid Interface Sci. 2003, 100-102, 399-473, doi:10.1016/S0001-8686(02)00066-0.

122. Marquez, R.; Bullon, J.; Forgiarini, A.; Salager, J.-L. The Oscillatory Spinning Drop Technique. An Innovative Method to Measure Dilational Interfacial Rheological Properties of Brine-Crude Oil Systems in the Presence of Asphaltenes. Colloids and Interfaces 2021, 5, doi:10.3390/colloids5030042.

123. Salager, J.-L.; Marquez, R.; Delgado-Linares, J.G.; Rondon, M.; Forgiarini, A. Fundamental Basis for Action of a Chemical Demulsifier Revisited after 30 Years: HLDN as the Primary Criterion for Water-in-Crude Oil Emulsion Breaking. Energy E Fuels 2022, 36, 711-730, doi:10.1021/acs.energyfuels.1c03349.

124. Chung, C.; Sher, A.; Rousset, P.; Decker, E.A.; McClements, D.J. Formulation of food emulsions using natural emulsifiers: Utilization of quillaja saponin and soy lecithin to fabricate liquid coffee whiteners. J. Food Eng. 2017, 209, 111, doi:10.1016/j.jfoodeng.2017.04.011.

125. Lv, S.; Zhou, H.; Bai, L.; Rojas, O.J.; McClements, D.J. Development of food-grade Pickering emulsions stabilized by a mixture of cellulose nanofibrils and nanochitin. Food Hydrocoll. 2021, 113, 106451, doi:10.1016/j.foodhyd.2020.106451.

126. Chávez-Montes, B.E.; Choplin, L.; Schaer, E. Rheological characterization of wet food foams. J. Texture Stud. 2007, 38, 236-252, doi:10.1111/j.1745-4603.2007.00096.x.

127. Paunov, V.N.; Cayre, O.J.; Noble, P.F.; Stoyanov, S.D.; Velikov, K.P.; Golding, M. Emulsions stabilised by food colloid particles: Role of particle adsorption and wettability at the liquid interface. J. Colloid Interface Sci. 2007, 312, 381-389, doi:10.1016/j.jcis.2007.03.031.

128. Hunter, T.N.; Pugh, R.J.; Franks, G. V.; Jameson, G.J. The role of particles in stabilising foams and emulsions. Adv. Colloid Interface Sci. 2008, 137, 57-81, doi:10.1016/j.cis.2007.07.007.

129. Qingrong, H.; Peter, G.; Michael, Q. Micro/Nanoencapsulation of Active Food Ingredients; American Chemical Society: Washington, USA, 2009; Vol. 1007; ISBN 0841269645.

130. Cardenas, A.; Fillous, L.; Rouviere, J.; Salager, J. An experimental method to estimate the mass transfer through the interfacial region of liquid membrane systems. Ciencia 2001, 9, 70-76.

131. Zhang, R.; Somasundaran, P. Advances in adsorption of surfactants and their mixtures at solid/solution interfaces. Adv. Colloid Interface Sci. 2006, 123-126, 213-229, doi:10.1016/j.cis.2006.07.004.

132. Kiran, S.K.; Nace, V.M.; Silvestri, M.A.; Monk, K.A.; Moloney, J.; Schmidt, L.; Acosta, E.J. The HLD study of surfactant partitioning for oilfield corrosion inhibitors. J. Surfactants Deterg. 2014, 17, 1193-1201, doi:10.1007/s11743-014-1631-0.

133. Salager, J.L.; Forgiarini, A.M.; Antón, R.E.; Quintero, L. Available know-how in transforming an emulsified drilling fluid to be removed from an unwanted location into a low-viscosity single-phase system. Energy E Fuels 2012, 26, 4078-4085, doi:10.1021/ef300260v.

134. Skalli, L.; Buckley, J.S.; Zhang, Y.; Morrow, N.R. Surface and core wetting effects of surfactants in oil-based drilling fluids. J. Pet. Sci. Eng. 2006, 52, 253-260, doi:10.1016/j.petrol.2006.03.012.

135. Quintero, L. An overview of surfactant applications in drilling fluids for the petroleum industry. J. Dispers. Sci. Technol. 2002, 23, 393-404, doi:10.1081/DIS-120003327. 
136. Forgiarini, A.; Marquez, R.; Salager, J.-L. Formulation improvements in the applications of surfactant-oil-water systems using the HLDN approach with extended surfactant structure. Molecules 2021, 26, 3771, doi:10.3390/molecules26123771.

137. Nasr-Ei-Din, H.A.; Al-Zahrani, A.; Still, J.; Lesko, T.; Kelkar, S. Laboratory evaluation of an innovative system for fracture stimulation of high-temperature carbonate reservoirs. Proc. - SPE Int. Symp. Oilf. Chem. 2007, 238-249, doi:10.2523/106054-ms.

138. Mamun, C.K.; Rong, J.G.; Kam, S.I.; Liljestrand, H.M.; Rossen, W.R. Extending Foam Technology from Improved Oil Recovery to Environmental Remediation. Proc. - SPE Annu. Tech. Conf. Exhib. 2002, 1953-1965, doi:10.2523/77557-ms.

139. Kam, S.I.; Frenier, W.W.; Davies, S.N.; Rossen, W.R. Experimental study of high-temperature foam for acid diversion. J. Pet. Sci. Eng. 2007, 58, 138-160, doi:10.1016/j.petrol.2006.12.005.

140. Quintero, L.; Pietrangeli, G.; Hughes, B.; Salager, J.L.; Forgiarini, A. Optimization of microemulsion formulations with linker molecules. SPE - Eur. Form. Damage Conf. Proceedings, EFDC 2013, 2, 1275-1287, doi:10.2118/165207-ms.

141. Brege, J.; El Sherbeny, W.; Quintero, L.; Jones, T. Using microemulsion technology to remove oil-based mud in wellbore displacement and remediation applications. Soc. Pet. Eng. - North Africa Tech. Conf. Exhib. 2012, NATC 2012 Manag. Hydrocarb. Resour. a Chang. Environ. 2012, 1, 323-330, doi:10.2118/150237-ms.

142. Christian, C.F.; Quintero, L.; Clark, D.E.; Jones, T.A. Production enhancement of cased-hole wells using mesophase fluids. Soc. Pet. Eng. - SPE Saudi Arab. Sect. Tech. Symp. 2009 2009, doi:10.2118/126062-ms.

143. Forgiarini, A.; Esquena, J.; González, C.; Solans, C. Formation of Nano-emulsions by Low-Energy Emulsification Methods at Constant Temperature. Langmuir 2001, 17, 2076-2083, doi:10.1021/la001362n.

144. Forgiarini, A.; Esquena, J.; González, C.; Solans, C. Formation and stability of nano-emulsions in mixed nonionic surfactant systems. Prog. Colloid Polym. Sci. 2001, 118, 184-189, doi:10.1007/3-540-45725-9_42.

145. Salager, J.-L.; Forgiarini, A.; Márquez, L.; Peña, A.; Pizzino, A.; Rodriguez, M.P.; Rondón-González, M. Using Emulsion Inversion in Industrial Processes. Adv. Colloid Interface Sci. 2004, 108-109, 259, doi:10.1016/j.cis.2003.10.008.

146. Briceno, M.I.; Chirinos, M.L.; Layrisse, I.; Martinez, G.; Nunez, G.; Padron, A.; Quintero, L.; Rivas, H. Emulsion technology for the production and handling of extraheavy crude oils and bitumens. Rev. Tec. INTEVEP 1990, 10, 5-14.

147. Briceno, M.I.; Salager, J.-L.; Luis Bracho, C. Heavy Hydrocarbon Emulsions Making Use of the State of the Art in Formulation Engineering. In Encyclopedic Handbook of Emulsion Technology; Sjoblom, J., Ed.; Marcel Dekker Inc: New York, 2001; pp. 455-495.

148. Brûlé, B.; Ramond, G.; Such, C. Relationships Among Composition, Structure, and Properties of Road Asphalts. In Asphaltenes and Asphalts, 1; Yen, T.F., Chilingarian, G., Eds.; Elsevier: Amsterdam, Netherlands, 1994; pp. 427-449 ISBN 0376-7361.

149. Winsor, P. Solvent properties of amphiphilic compounds; Butterworths Scientific Publications: London, UK, 1954;

150. Cayias, J.L.; Schechter, R.S.; Wade, W.H. Modeling crude oils for low interfacial tension. Soc. Pet. Eng. J. 1976, 16, 351357, doi:doi.org/10.2118/5813-PA.

151. Cash, R.; Cayias, J.L.; Fournier, G.; McAllister, D.; Shares, T.; Schechter, R.S.; Wade, W.H. The Application Of Low Interfacial Tension Scaling Rules to Binary Hydrocarbon Mixtures. J. Colloid Interface Sci. 1977, 59, 39-44, doi:10.1016/0021-9797(77)90336-8.

152. Salager, J.-L. Physico-chemical properties of surfactant-water-oil mixtures: phase behavior, micro-emulsion formation and interfacial tension, University of Texas at Austin, Ph.D. Dissertation, 1977.

153. Antón, R.E.; Garcés, N.; Yajure, A. A correlation for three-phase behavior of cationic surfactant-oil-water systems. J. Dispers. Sci. Technol. 1997, 18, 539-555, doi:10.1080/01932699708943755.

154. Salager, J.-L.; Forgiarini, A.M.; Bullón, J.; Marquez, R.; Alvarado, J.G. A Review on the Surfactant Characteristic Parameter used in Enhanced Oil Recovery, Crude Oil Dehydration and Other Formulation Applications Available 
online: https://es.firp-ula.org/wp-content/uploads/2020/05/E719B.pdf (accessed on Nov 10, 2021).

155. Bourrel, M.; Verzaro, F.; Chambu, C. Effect of Oil Type on Solubilization by Amphiphiles. SPE Reserv. Eng. 1987, 2, 4153, doi:10.2118/12674-PA.

156. Salager, J.-L.; Forgiarini, A.; Márquez, L.; Manchego, L.; Bullón, J.; Marquez, L.; Manchego, L.; Bullon, J. How to Attain an Ultralow Interfacial Tension and a Three-Phase Behavior with a Surfactant Formulation for Enhanced Oil Recovery: A Review. Part 2. Performance Improvement Trends from Winsor's Premise to Currently Proposed Inter- and IntraMolecular Mixtu. J. Surfactants Deterg. 2013, 16, 631-663, doi:10.1007/s11743-013-1485-x.

157. Salager, J.L.J.-L.J.L. A Normalized Hydrophilic-Lipophilic Deviation Expression HLDN Is Necessary to Avoid Confusion Close to the Optimum Formulation of Surfactant-Oil-Water Systems. J. Surfactants Deterg. 2021, 24, 731-748, doi:https://doi.org/10.1002/jsde.12518.

158. Salager, J.-L.; Marquez, N.; Graciaa, A.; Lachaise, J. Partitioning of ethoxylated octylphenol surfactants in microemulsion-oil-water systems: Influence of temperature and relation between partitioning coefficient and physicochemical formulation. Langmuir 2000, 16, 5534-5539, doi:10.1021/la9905517.

159. Miñana-Perez, M.; Graciaa, A.; Lachaise, J.; Salager, J.-L. Solubilization of polar oils with extended surfactants. Colloids Surfaces A Physicochem. Eng. Asp. 1995, 100, 217-224, doi:10.1016/0927-7757(95)03186-H.

160. Pérez, M.M.; Salager, J.-L.; Graciaa, A.; Lachaise, J. Solubilization of polar oils in microemulsion systems. Trends Colloid Interface Sci. IX 1995, 177-179, doi:10.1007/bfb0115232.

161. Milter, J.; Austad, T. Chemical flooding of oil reservoirs. 7. Oil expulsion by spontaneous imbibition of brine with and without surfactant in mixed-wet, low permeability chalk material. Colloids Surfaces A Physicochem. Eng. Asp. 1996, 117, 109-115, doi:10.1016/0927-7757(96)03693-X.

162. Wade, W.; Morgan, J.C.; Jacobson, J.K.; Schechter, R.S. Low interfacial tensions involving mixtures of surfactants. Soc. Pet. Eng. J. 1977, 17, 122-128, doi:10.2118/6002-PA.

163. Bourrel, M.; Lipow, A.M.; Wade, W.H.; Schechter, R.S.; Salager, J.-L. Properties Of Amphiphile/Oil/Water Systems At An Optimum Formulation For Phase Behavior. In Proceedings of the 53rd Annual Fall Technical Conference SPE AIME October 1-3; Society of Petroleum Engineers: Houston, 1978.

164. Wade, W.; Vasquez, E.; Salager, J.-L.; El-Emary, M.; Koukounis, C.; Schechter, R.S.; Mittal, K.L. Solution chemistry of surfactants. In; Mittal, K.L., Ed.; Plenum Press: New York, 1979; Vol. 2, p. 801.

165. Bourrel, M.; Koukounis, C.H.; Schechter, R.; Wade, W. Phase and Interfacial Tension Behavior of Nonionic Surfactants. J. Dispers. Sci. Technol. 1980, 1, 13-35, doi:10.1080/01932698008962159.

166. Puerto, M.C.; Reed, R.L. A three-parameter representation of surfactant/oil/brine interaction. Soc. Pet. Eng. J. 1983, 23, 669-682, doi:10.2118/10678-PA.

167. Austad, T.; Hodne, H.; Staurland, G. Effects of pressure, temperature and salinity on the multiphase behavior of the surfactant/methane and n-decane/NaCl brine system. Surfactants Macromol. Self-Assembly Interfaces Bulk 2008, 310, 296310, doi:10.1007/bfb0118272.

168. Aoudia, M.; Wade, W.H.; Weerasooriya, V.; Aoudia, M.; Wade, W.H.; Weerasooriya, V. Optimum microemulsions formulated with propoxylated Guerbet alcohol and propoxylated tridecyl alcohol sodium sulfates. J. Dispers. Sci. Technol. 1995, 16, 115-135, doi:10.1080/01932699508943664.

169. Pope, G.A.; Wade, W.H. Lessons from Enhanced Oil Recovery Research for Surfactant-Enhanced Aquifer Remediation. 1995, 160, 142-160, doi:10.1021/bk-1995-0594.ch011.

170. Nardello, V.; Chailloux, N.; Poprawski, J.; Salager, J.L.; Aubry, J.M. HLD concept as a tool for the characterization of cosmetic hydrocarbon oils. Polym. Int. 2003, 52, 602-609, doi:10.1002/pi.1012.

171. Chailloux, N.; Nardello, V.; Salager, J.-L.; Aubry, J. Propriétés amphiphiles des tensioactifs de la famille du monolaurate de polyglycérol et application à la préparation de microémulsions à base d'esters gras. Oléagineux, Corps 
Gras Lipides 2003, 386, 382-386.

172. Kittithammavong, V.; Charoensaeng, A.; Khaodhiar, S. A Normalized HLD (HLDN) Tool for Optimal SaltConcentration Prediction of Microemulsions. Appl. Sci. 2021, 11, doi:10.3390/app11199151.

173. Witthayapanyanon, A.; Harwell, J.H.; Sabatini, D.A. Hydrophilic-lipophilic deviation (HLD) method for characterizing conventional and extended surfactants. J. Colloid Interface Sci. 2008, 325, 259-266, doi:10.1016/j.jcis.2008.05.061.

174. Phan, T.T.; Witthayapanyanon, A.; Harwell, J.H.; Sabatini, D.A. Microemulsion-based vegetable oil detergency using an extended surfactant. J. Surfactants Deterg. 2010, 13, 313-319, doi:10.1007/s11743-010-1184-9.

175. Solairaj, S.; Britton, C.; Lu, J.; Kim, D.H.; Weerasooriya, U.; Pope, G.A. New correlation to predict the optimum surfactant structure for EOR. SPE - DOE Improv. Oil Recover. Symp. Proc. 2012, 2, 1390-1399, doi:10.2118/154262-MS.

176. Hammond, C.E.; Acosta, E.J. On the characteristic curvature of alkyl-polypropylene oxide sulfate extended surfactants. J. Surfactants Deterg. 2012, 15, 157-165, doi:10.1007/s11743-011-1303-2.

177. Ghosh, S.; Johns, R.T. Dimensionless Equation of State to Predict Microemulsion Phase Behavior. Langmuir 2016, 32, 8969-8979, doi:10.1021/acs.langmuir.6b02666.

178. Khorsandi, S.; Qiao, C.; Johns, R.T.; Torrealba, V.A. Simulation of surfactant-polymer floods with a novel microemulsion equation of state. SPE - DOE Improv. Oil Recover. Symp. Proc. 2016, 2016-Janua, doi:10.2118/179566-ms.

179. Nguyen, T.T.; Morgan, C.; Poindexter, L.; Fernandez, J. Application of the Hydrophilic-Lipophilic Deviation Concept to Surfactant Characterization and Surfactant Selection for Enhanced Oil Recovery. J. Surfactants Deterg. 2019, 22, 983999, doi:https://doi.org/10.1002/jsde.12305.

180. Aubry, J.M.; Ontiveros, J.F.; Salager, J.-L.; Nardello-Rataj, V. Use of the normalized hydrophilic-lipophilic-deviation $(\mathrm{HLDN})$ equation for determining the equivalent alkane carbon number (EACN) of oils and the preferred alkane carbon number (PACN) of nonionic surfactants by the fish-tail method (FTM). Adv. Colloid Interface Sci. 2020, 276, 102099, doi:10.1016/j.cis.2019.102099.

181. Graciaa, A.; Lachaise, J.; Sayous, J.G.; Grenier, P.; Yiv, S.; Schechter, R.S.; Wade, W.H. The partitioning of Complex Surfactant Mixtures between Oil/Water/Microemulsion phases at high Surfactant Concentrations. J. Colloid Interface Sci. 1983, 93, 474-486, doi:10.1016/0021-9797(83)90431-9.

182. Barakat, Y.; Fortney, L.N.; Schechter, R.S.; Wade, W.H.; Yiv, S.H.; Graciaa, A. Criteria for structuring surfactants to maximize solubilization of oil and water: II. Alkyl benzene sodium sulfonates. J. Colloid Interface Sci. 1983, 92, 561-574, doi:10.1016/0021-9797(83)90177-7.

183. Márquez, N.; Bravo, B.; Chávez, G.; Ysambertt, F.; Salager, J.L. Analysis of polyethoxylated surfactants in microemulsion-oil-water systems: Part II. Anal. Chim. Acta 2002, 452, 129-141, doi:10.1016/S0003-2670(01)01439-8.

184. Márquez, N.; Bravo, B.; Ysambertt, F.; Chávez, G.; Subero, N.; Salager, J.L. Analysis of polyethoxylated surfactants in microemulsion-oil-water systems: III. Fractionation and partitioning of polyethoxylated alcohol surfactants. Anal. Chim. Acta 2003, 477, 293-303, doi:10.1016/S0003-2670(02)01407-1.

185. Márquez, N.; Anton, R.E.; Graciaa, A.; Lachaise, J.; Salager, J.-L. Partitioning of ethoxylated alkylphenol surfactants in microemulsion- oil-water systems. Part II: Influence of hydrophobe branching. Colloids Surfaces A Physicochem. Eng. Asp. 1998, 131, 45-49, doi:10.1016/S0927-7757(96)03944-1.

186. Acosta, E.; Natali, S. Effect of surfactant concentration on the hydrophobicity of polydisperse alkyl ethoxylates. $J$. Surfactants Deterg. 2021, doi:10.1002/jsde.12548.

187. Antón, R.E. Contribution à l'étude du comportement de phase des systèmes mélanges de surfactifs-eau-huile, Universidad de Los Andes, Venezuela, 1992.

188. Graciaa, A.; Lachaise, J.; Bourrel, M.; Osborne-Lee, I.; Schechter, R.S.; Wade, W.H. Partitioning of nonionic and anionic surfactant mixtures between oil/microemulsion/water phases. Soc. Pet. Eng. AIME, SPE 1984, 2, 305-314.

189. Graciaa, A.; Lachaise, J.; Cucuphat, C.; Bourrel, M.; Salager, J.L. Interfacial Segregation of an Ethyl Oleate/Hexadecane 
Oil Mixture in Microemulsion Systems. Langmuir 1993, 9, 1473-1478, doi:10.1021/la00030a008.

190. Graciaa, A.; Lachaise, J.; Morel, G.; Salager, L.; Bourre, M. Optimal phase behavior of water oil blend/surfactant systems. Prog. Colloid Polym. Sci. 1993, 93, 257-260, doi:10.1007/bfb0118539.

191. Graciaa, A.; Andérez, J.; Bracho, C.; Lachaise, J.; Salager, J.-L.; Tolosa, L.; Ysambertt, F. The selective partitioning of the oligomers of polyethoxylated surfactant mixtures between interface and oil and water bulk phases. Adv. Colloid Interface Sci. 2006, 123, 63-73, doi:10.1016/j.cis.2006.05.015.

192. Queste, S.; Salager, J.L.; Strey, R.; Aubry, J.M. The EACN scale for oil classification revisited thanks to fish diagrams. J. Colloid Interface Sci. 2007, 312, 98-107, doi:10.1016/j.jcis.2006.07.004.

193. Antón, R.E.; Graciaa, A.; Lachaise, J.; Salager, J.L. Surfactant-Oil-Water Systems Near the Affinity Inversion, Part VIII : Optimum Formulation and Phase Behavior of Mixed Anionic-Nonionic Systems Versus Temperature. J. Dispers. Sci. Technol. 1992, 13, 565-579, doi:10.1080/01932699208943334.

194. Antón, R.E.; Rivas, H.; Salager, J.-L. Surfactant-oil-water systems near the affinity inversion. Part X: Emulsions made with anionic-nonionic surfactant mixtures. J. Dispers. Sci. Technol. 1996, 17, 553-566, doi:10.1080/01932699608943524.

195. Salager, J.L.; Bourrel, M.; Schechter, R.S.; Wade, W.H. Mixing Rules for Optimum Phase-Behavior Formulations of Surfactant/Oil/Water Systems. Soc. Pet. Eng. AIME J. 1979, 19, 271-278, doi:10.2118/7584-pa.

196. Sottmann, T.; Strey, R. Ultralow interfacial tensions in water-n-alkane-surfactant systems. J. Chem. Phys. 1997, 106, 8606-8615, doi:10.1063/1.473916.

197. Salager, J.-L.; Marquez, R. How to Avoid the Current Confusion in Using the SOW Generalized Formulation Expression HLD $=0$ for Optimum Formulation. In Proceedings of the 2021 AOCS Annual Meeting \& Expo; AOCS: Urbana, Illinois, 2021.

198. Bouton, F.; Durand, M.; Nardello-Rataj, V.; Serry, M.; Aubry, J.M. Classification of terpene oils using the fish diagrams and the Equivalent Alkane Carbon (EACN) scale. Colloids Surfaces A Physicochem. Eng. Asp. 2009, 338, 142-147, doi:10.1016/j.colsurfa.2008.05.027.

199. Bouton, F.; Durand, M.; Nardello-Rataj, V.; Borosy, A.P.; Quellet, C.; Aubry, J.M. A QSPR model for the prediction of the "fish-tail" temperature of CiE4/water/polar hydrocarbon oil systems. Langmuir 2010, 26, 7962-7970, doi:10.1021/la904836m.

200. Schowanek, D.; Borsboom-Patel, T.; Bouvy, A.; Colling, J.; de Ferrer, J.A.; Eggers, D.; Groenke, K.; Gruenenwald, T.; Martinsson, J.; Mckeown, P.; et al. New and updated life cycle inventories for surfactants used in European detergents: summary of the ERASM surfactant life cycle and ecofootprinting project. Int. J. Life Cycle Assess. 2018, 23, 867-886, doi:10.1007/s11367-017-1384-x.

201. Velásquez, J.; Scorzza, C.; Vejar, F.; Forgiarini, A.M.; Antón, R.E.; Salager, J.L. Effect of temperature and other variables on the optimum formulation of anionic extended surfactant-alkane-brine systems. J. Surfactants Deterg. 2010, 13, 69-73, doi:10.1007/s11743-009-1142-6.

202. Acosta, E.J.; Bhakta, A.S. The HLD-NAC model for mixtures of ionic and nonionic surfactants. J. Surfactants Deterg. 2009, 12, 7-19, doi:10.1007/s11743-008-1092-4.

203. Acosta, E.J.; Kiran, S.K.; Hammond, C.E. The HLD-NAC model for extended surfactant microemulsions. J. Surfactants Deterg. 2012, 15, 495-504, doi:10.1007/s11743-012-1343-2.

204. Doe, P.H.; El-Emary, M.; Wade, W.H.; Schechter, R.S. Surfactants for producing low interfacial tensions: III. Di and tri n-alkylbenzenesulfonates. J. Am. Oil Chem. Soc. 1978, 55, 513-520, doi:10.1007/BF02668496.

205. Acosta, E. The HLD-NAC equation of state for microemulsions formulated with nonionic alcohol ethoxylate and alkylphenol ethoxylate surfactants. Colloids Surfaces A Physicochem. Eng. Asp. 2008, 320, 193-204, doi:10.1016/j.colsurfa.2008.01.049.

206. Acosta, E.; Yuan, J.S.; Bhakta, A.S. The characteristic curvature of ionic surfactants. J. Surfactants Deterg. 2008, 11, 145, 
doi:10.1007/s11743-008-1065-7.

207. Abbott, S. Surfactant science: principles and practice Available online: https://www.stevenabbott.co.uk/practicalsurfactants/the-book.php (accessed on Nov 10, 2021).

208. Doe, P.H.; El-Emary, M.; Wade, W.H.; Schechter, R.S. Surfactants for producing low interfacial tensions: II. Linear alkylbenzenesulfonates with additional alkyl substituents. J. Am. oil Chem. Soc. 1978, 55, 505-512, doi:10.1007/BF02668495.

209. Kittithammavong, V.; Charoensaeng, A.; Khaodhiar, S. Effect of Ethylene Oxide Group in the Anionic-Nonionic Mixed Surfactant System on Microemulsion Phase Behavior. J. Surfactants Deterg. 2020, doi:10.1002/jsde.12475.

210. Salager, J.-L.; Marquez, R.; Ontiveros, J.F. How to use in practice a simplified HLDN linear equation for surfactant mixtures. In Proceedings of the Proceedings of the 2022 AOCS annual meeting; AOCS Press: Atlanta, 2022.

211. Antón, R.E.; Mosquera, F.; Oduber, M. Anionic-nonionic surfactant mixture to attain emulsion insensitivity to temperature. Trends Colloid Interface Sci. IX 1995, 98, 85-88, doi:10.1007/bfb0115213.

212. Kunieda, H.; Shinoda, K. Phase Behavior In Systems Of Nonionic Surfactant/Water/Oil Around The HydrophileLipophile-Balance-Temperature (Hlb-Temperature). J. Dispers. Sci. Technol. 1982, 3, 233-244, doi:10.1080/01932698208943639.

213. Shinoda, K.; Kunieda, H. Phase properties of emulsions: PIT and HLB; Marcel Dekker, Inc: New York, USA, 1983;

214. Antón, R.E.; Gómez, D.; Graciaa, A.; Gómez, D.; Salager, J.-L. Surfactant-Oil-Water Systems Near the Affinity Inversion Part ix: Optimum Formulation and Phase Behavior of Mixed Anionic-Cationic Systems. J. Dispers. Sci. Technol. 1993, 14, 401-416, doi:10.1080/01932699308943413.

215. Koukounis, C.; Wade, W.H.; Schechter, R.S. Phase Partitioning of Anionic and Nonionic Surfactant Mixtures. Soc. Pet. Eng. J. 1983, 23, 301-310, doi:10.2118/8261-PA.

216. Wade, W.; Morgan, J.C.; Schechter, R.S.; Jacobson, J.K.; Salager, J.-L. Interfacial tension and phase behavior of surfactant systems. Soc. Pet. Eng. J. 1978, 18, 242-252, doi:10.2118/6844-PA.

217. Shinoda, K.; Arai, H. The Correlation between Phase Inversion Temperature in Emulsion and Cloud Point in Solutions of Nonionic Emulsifier. J. Phys. Chem. 1964, 68, 3485-3490, doi:10.1021/j100794a007.

218. Arandia, M.A.; Forgiarini, A.; Salager, J.-L. Resolving an Enhanced Oil Recovery Challenge: Optimum Formulation of a Surfactant-Oil-Water System Made Insensitive to Dilution. J. Surfactants Deterg. 2010, 13, 119-126, doi:10.1007/s11743-009-1171-1.

219. Becher, P. Encyclopedia of Emulsion Technology. Vol. 3. Basic Theory Measurement Applications; Becher, P., Ed.; Marcel Dekker: New York, USA, 1988;

220. Becher, P. Encyclopedia of Emulsion Technology. Vol. 2. Applications; Becher, P., Ed.; Marcell Dekker, Inc: New York, USA, 1985;

221. Becher, P. Encyclopedia of Emulsion Technology. Vol. 4.; CRC Press: Boca Raton, USA, 1996;

222. Salager, J.-L.; Anton, R.; Aubry, J.M. Formulation des émulsions par la méthode du HLD, Techniques de l'Ingénieur, J2158, 2006 Available online: https://www.techniques-ingenieur.fr/base-documentaire/procedes-chimie-bio-agroth2/principes-de-formulation-42489210/formulation-des-emulsions-par-la-methode-du-hld-j2158/.

223. Salager, J.-L.; Bullón, J.; Pizzino, A.; Rondón-González, M.; Tolosa, L.; Somasundaran, P. Emulsion formulation engineering for the practitioner. In Encyclopedia of surface and colloid science; Somasundaran, P., Ed.; Taylor \& Francis New York, 2010; Vol. 1, pp. 1-6.

224. Kahlweit, M.; Salager, J.-L. Microemulsions. In Handbook of Detergents, Part A: Properties; Broze, G., Ed.; CRC Press: Boca Raton, 1999; pp. 89-115.

225. Salager, J.-L.J.-L. Formulation concepts for the emulsion maker. In Pharmaceutical Emulsions and Suspensions; Nielloud, F., Marti-mestres, G., Eds.; Marcel Dekker: New York, 2000; pp. 18-71 ISBN 1420001515. 
226. Salager, J.-L. Emulsion properties and related know-how to attain them. In Pharmaceutical emulsions and suspensions; Nielloud, F., Marti-Mestres, G., Eds.; Marcel Dekker: New Jersey, USA, 2000; Vol. 1, pp. 73-125 ISBN 978-0-8247-0304-2.

227. Marquez, N.; Anton, R.E.; Graciaa, A.; Lachaise, J.; Salager, J.L. Partitioning of ethoxylated alkylphenol surfactants in microemulsion-oil-water systems. Colloids Surfaces A Physicochem. Eng. Asp. 1995, 100, 225-231, doi:10.1016/09277757(95)03184-F.

228. Márquez, N.; Graciaa, A.; Lachaise, J.; Salager, J.L. Partitioning of ethoxylated alkylphenol surfactants in microemulsion-oil-water systems: Influence of physicochemical formulation variables. Langmuir 2002, 18, 6021-6024, doi:10.1021/la020199o.

229. Pizzino, A.; Molinier, V.; Catté, M.; Salager, J.-L.J.L.; Aubry, J.M. Bidimensional analysis of the phase behavior of a well-defined surfactant (C10e4)/Oil (n -Octane)/water-temperature system. J. Phys. Chem. B 2009, 113, 16142, doi:10.1021/jp907261u.

230. Shinoda, K.; Saito, H. The Stability of O/W type emulsions as functions of temperature and the HLB of emulsifiers: The emulsification by PIT-method. J. Colloid Interface Sci. 1969, 30, 258-263, doi:10.1016/S0021-9797(69)80012-3.

231. Kunieda, H.; Shinoda, K. Evaluation of the hydrophile-lipophile balance (HLB) of nonionic surfactants. I. Multisurfactant systems. J. Colloid Interface Sci. 1985, 107, 107-121, doi:10.1016/0021-9797(85)90154-7.

232. Antón, R.E.; Castillo, P.; Salager, J.-L. Surfactant-Oil-Water Systems near the Affinity Inversion. Part IV: Emulsion Inversion Temperature. J. Dispers. Sci. Technol. 1986, 7, 319, doi:10.1080/01932698608943463.

233. Boyd, J.; Parkinson, C.; Sherman, P. Factors affecting emulsion stability, and the HLB concept. J. Colloid Interface Sci. 1972, 41, 359-370, doi:10.1016/0021-9797(72)90122-1.

234. Jones, T.J.; Neustadter, E.L.; Whittingham, K.P. Water-in-Crude Oil Emulsion Stability and Emulsion Destabilization By Chemical Demulsifiers. J. Can. Pet. Technol. 1978, 17, 100-108, doi:10.2118/78-02-08.

235. Bourrel, M.; Graciaa, A.; Schechter, R.S.; Wade, W.H. The relation of emulsion stability to phase behavior and interfacial tension of surfactant systems. J. Colloid Interface Sci. 1979, 72, 161, doi:10.1016/0021-9797(79)90198-X.

236. Salager, J.-L.; Quintero, L.; Ramos, E.; Anderez, J.M. Properties of surfactant/oil/water emulsified systems in the neighborhood of the three-phase transition. J. Colloid Interface Sci. 1980, 77, doi:https://doi.org/10.1016/00219797(80)90447-6.

237. Vinatieri, J.E. Correlation of emulsion stability with phase behavior in surfactant systems for tertiary oil recovery. Soc. Pet. Eng. J. 1980, 20, 402-406, doi:10.2118/6675-PA.

238. Milos, F.S.; Wasan, D.T. Emulsion stability of surfactant systems near the three phase region. Colloids and Surfaces 1982, 4, 91-96, doi:10.1016/0166-6622(82)80092-9.

239. Antón, R.E.; Salager, J.-L. Emulsion instability in the three-phase behavior region of surfactant-alcohoi-oil-brine systems. J. Colloid Interface Sci. 1986, 111, 54-59, doi:10.1016/0021-9797(86)90006-8.

240. Wasan, D.T.; McNamara, J.J.; Shah, S.M.; Sampath, K.; Aderangi, N. The role of coalescence phenomena and interfacial rheological properties in enhanced oil recovery: an overview. J. Rheol. (N. Y. N. Y). 1979, 23, 181-207, doi:10.1122/1.549524.

241. Maru, H.C.; Wasan, D.T. Dilational viscoelastic properties of fluid interfaces-II. Experimental study. Chem. Eng. Sci. 1979, 34, 1295-1307, doi:10.1016/0009-2509(79)80021-4.

242. Tambe, D.; Paulis, J.; Sharma, M.M. Factors controlling the stability of colloid-stabilized emulsions. IV. evaluating the effectiveness of demulsifiers. J. Colloid Interface Sci. 1995, 171, 463-469, doi:10.1006/jcis.1995.1203.

243. Kim, Y.H.; Nikolov, A.D.; Wasan, D.T.; Diaz-Arauzo, H.; Shetty, C.S. Demulsification of water-in-crude oil emulsions: Effects of film tension, elasticity, diffusivity and interfacial activity of demulsifier individual components and their blends. J. Dispers. Sci. Technol. 1996, 17, 33-53, doi:10.1080/01932699608943487.

244. Goldszal, A.; Bourrel, M. Demulsification of crude oil emulsions: Correlation to microemulsion phase behavior. Ind. 
Eng. Chem. Res. 2000, 39, 2746-2751, doi:10.1021/ie990922e.

245. Kabalnov, A.; Weers, J. Macroemulsion stability within the Winsor III region: theory versus experiment. Langmuir 1996, 12, 1931-1935, doi:10.1021/la951053a.

246. Kabalnov, A.; Wennerström, H. Macroemulsion stability: the oriented wedge theory revisited. Langmuir 1996, 12, 276292, doi:10.1021/la950359e.

247. Dinh, H.-H.-Q.; Santanach-Carreras, E.; Lalanne-Aulet, M.; Schmitt, V.; Panizza, P.; Lequeux, F. Effect of a Surfactant Mixture on Coalescence Occurring in Concentrated Emulsions: The Hole Nucleation Theory Revisited. Langmuir 2021, 37, 8726-8737, doi:10.1021/acs.langmuir.1c00975.

248. Dinh, H.-H.-Q.; Santanach-Carreras, E.; Schmitt, V.; Lequeux, F. Coalescence in concentrated emulsions: theoretical predictions and comparison with experimental bottle test behaviour. Soft Matter 2020, 16, 10301-10309, doi:10.1039/D0SM01459A.

249. Zamora, J.M.; Marquez, R.; Forgiarini, A.; Langevin, D.; Salager, J.L. Interfacial rheology of low interfacial tension systems using a new oscillating spinning drop method. J. Colloid Interface Sci. 2018, 519, 27-37, doi:10.1016/j.jcis.2018.02.015.

250. Marquez, R.; Forgiarini, A.M.; Fernández, J.; Langevin, D.; Salager, J.-L. New Interfacial Rheology Characteristics Measured using a Spinning-Drop Rheometer at the Optimum Formulation of a Simple Surfactant-Oil-Water System. J. Surfactants Deterg. 2018, 21, 611-623, doi:10.1002/jsde.12163.

251. Marquez, R.; Forgiarini, A.; Langevin, D.; Salager, J.-L.J.-L. Instability of Emulsions Made with Surfactant-Oil-Water Systems at Optimum Formulation with Ultralow Interfacial Tension. Langmuir 2018, 34, 9252-9263, doi:10.1021/acs.langmuir.8b01376.

252. Marquez, R.; Meza, L.; Alvarado, J.G.; Bullón, J.; Langevin, D.; Forgiarini, A.M.; Salager, J.-L.J.J.-L. Interfacial Rheology Measured with a Spinning Drop Interfacial Rheometer: Particularities in More Realistic Surfactant-Oil-Water Systems Close to Optimum Formulation at HLDN = 0. J. Surfactants Deterg. 2021, 24, 587-601, doi:10.1002/jsde.12502.

253. Salager, J.-L. Fundamental basis for the action of a chemical dehydrant. Influence of the physical and chemical formulation on the stability of an emulsion. Int. Chem. Eng. 1990, 30, 103-116.

254. Salager, J.-L.; Marquez, R.; Delgado-Linares, J.G.; Rondon, M.; Forgiarini, A.; Forgiarin, A.; I Fundamental Basis for Action of a Chemical Demulsifier Revisited after 30 Years: HLDN as the Primary Criterion for Water-in-Crude Oil Emulsion Breaking. Energy \& Fuels 2022, 36, 711-730, doi:10.1021/acs.energyfuels.1c03349.

255. Acosta, E.J.; Harwell, J.H.; Sabatini, D.A. Self-assembly in linker-modified microemulsions. J. Colloid Interface Sci. 2004, 274, 652-664, doi:10.1016/j.jcis.2004.03.037.

256. Salager, J.L.; Antón, R.E.; Sabatini, D.A.; Harwell, J.H.; Acosta, E.J.; Tolosa, L.I. Enhancing solubilization in microemulsions - State of the art and current trends. J. Surfactants Deterg. 2005, 8, 3-21, doi:10.1007/s11743-005-0328-4.

257. Kahlweit, M.; Strey, R.; Firman, P.; Haase, D. Phase Behavior of Ternary Systems: H2O-Oil-Nonionic Surfactant as a Near-Tricritical Phenomenon. Langmuir 1985, 1, 281-288, doi:10.1021/la00063a004.

258. shinoda, K.; Lindman, B. Organized Surfactant Systems: Microemulsions. Langmuir 1987, 3, 135-149, doi:10.1021/la00074a001.

259. Kahlweit, M.; Strey, R.; Haase, D.; Firman, P. Properties of the three-phase bodies in H2O-oil-nonionic amphiphile mixturest. Langmuir 1988, 4, 785-790, doi:10.1021/la00082a001.

260. Stubenrauch, C. Microemulsions: Background, New Concepts, Applications, Perspectives; Stubenrauch, C., Ed.; John Wiley \& Sons Ltd: Oxford, UK, 2009; ISBN 9781405167826.

261. Solans, C.; Kunieda, H. Industrial Applications of Microemulsions; Solans, C., Kunieda, H., Eds.; Surfactant.; Marcell Dekker, Inc: New York, USA, 1997;

262. Kunieda, H.; Ishikawa, N. Evaluation of the hydrophile-lipophile balance (HLB) of nonionic surfactants. II. 
Commercial-surfactant systems. J. Colloid Interface Sci. 1985, 107, 122-128, doi:10.1016/0021-9797(85)90155-9.

263. Kunieda, H.; Ishikawa, N.; Shinoda, K. Evaluation of the Hydrophile-Lipophile-Balance (HLB) of Long-chain Nonionic Surfactant. J. Japan Oil Chem. Soc. 1985, 107, 122-128, doi:10.1016/0021-9797(85)90155-9.

264. Kunieda, H.; Hanno, K.; Yamaguchi, S.; Shinoda, K. The Three Phase Behavior of a Brine/Ionic Surfactant/Nonionic Surfactant/Oil System: Evaluation of the Hydrophile-Lipophile Balance (HLB) of Ionic Surfactant. J. Colloid Interface Sci. 1985, 107, 129, doi:10.1016/0021-9797(85)90156-0.

265. Levison, M.I. Surfactant production: present realities and future perspectives. In Handbook of detergents part F: production; Zoller, U., Sosis, A., Eds.; Taylor \& Francis Group, LLC Boca Raton, FL, 2009; Vol. 142, pp. 1-38.

266. Zoller, U.; Sosis, P. Handbook of Detergents, Part F: Production; Uri Zoller, Ed.; CRC Press: Boca Raton, USA, 2008;

267. Showell, M. Handbook of Detergents, Part D: Formulation; Showell, M., Ed.; CRC Press: Boca Raton, USA, 2005;

268. Uri Zoller Handbook of Detergents, Part E: Surfactants; Uri Zoller, Ed.; CRC Press: Boca Raton, USA, 2008;

269. Phaodee, P.; Harwell, J.H.; Sabatini, D.A. Correlation between Detergency of Different Oily and Solid Non-Particulate Soils and Hydrophilic-Lipophilic Deviation. J. Surfactants Deterg. 2020, 23, 953-962, doi:10.1002/jsde.12441.

270. Phaodee, P.; Attaphong, C.; Sabatini, D.A. Cold Water Detergency of Triacylglycerol Semisolid Soils: The Effect of Salinity, Alcohol Type, and Surfactant Systems. J. Surfactants Deterg. 2019, 22, 1175-1187, doi:10.1002/jsde.12234.

271. Tolosa, L.-I.I.; Forgiarini, A.; Moreno, P.; Salager, J.L.J.-L. Combined effects of formulation and stirring on emulsion drop size in the vicinity of three-phase behavior of surfactant-oil water systems. Ind. Eng. Chem. Res. 2006, 45, 38103814, doi:10.1021/ie060102j.

272. Shinoda, K. The correlation between the dissolution state of nonionic surfactant and the type of dispersion stabilized with the surfactant. J. Colloid Interface Sci. 1967, 24, 4, doi:10.1016/0021-9797(67)90270-6.

273. Shinoda, K. The Comparison between the PIT System and the HLB-Value System to Emulsifier Selection. Proceedings, 5th Int. Congr. Surf. Act. Barcelona, Spain 1968, 3, 275.

274. Shinoda, K.; Arai, H. The effect of phase volume on the phase inversion temperature of emulsions stabilized with nonionic surfactants. J. Colloid Interface Sci. 1967, 25, 429-431, doi:10.1016/0021-9797(67)90051-3.

275. Shinoda, K.; Sagitani, H. Emulsifier selection in water/oil type emulsions by the hydrophile-lipophile balancetemperature system. J. Colloid Interface Sci. 1978, 64, 68-71, doi:10.1016/0021-9797(78)90335-1.

276. Dickinson, E. Interpretation of Emulsion Phase Inversion as a Cusp Catastrophe. J. Colloid Interface Sci. 1981, 84, 284287, doi:10.1016/0021-9797(81)90290-3.

277. Dickinson, E. Thermodynamic Aspects of Emulsion Phase Inversion. J. Colloid Interface Sci. 1982, 87, 416-423, doi:10.1016/0021-9797(82)90338-1.

278. Salager, J.-L. Phase behavior of amphiphile-oil-water systems related to the butterfly catastrophe. J. Colloid Interface Sci. 1985, 105, 21-26, doi:10.1016/0021-9797(85)90342-X.

279. Salager, S.E.; Tyrode, E.C.; Celis, M.T.; Salager, J.-L. Influence of the Stirrer Initial Position on Emulsion Morphology. Making Use of the Local Water-to-Oil Ratio Concept for Formulation Engineering Purpose. Ind. Eng. Chem. Res. 2001, 40, 4808-4814, doi:10.1021/ie010196r.

280. Salager, J.-L.; Moreno, N.; Antón, R.E.; Marfisi, S. Apparent Equilibration Time Required for a Surfactant-Oil-Water System to Emulsify into the Morphology Imposed by the Formulation. Langmuir 2002, 18, 607-611, doi:10.1021/la010582d.

281. Alvarez, G.; Antón, R.E.; Marfisi, S.; Márquez, L.; Salager, J.-L. Apparent Equilibration Time Required for SurfactantOil- Water Systems to Emulsify into the Morphology Imposed by the Formulation. Part 2: Effect of s ec-Butanol Concentration and Initial Location. Langmuir 2004, 20, 5179-5181, doi:10.1021/la049727h.

282. Salager, J.-L. Phase Transformation and Emulsion Inversion on the Basis of Catastrophe Theory. In Encyclopedia of Emulsion Technology. Vol. 3. Basic theory, measurement, applications; Becker, P., Ed.; Marcell Dekker, Inc: New York, 1988; 
Vol. 3, pp. 79-134.

283. Stegemeier, G.L. Mechanisms of Entrapment and Mobilization of Oil in Porous Media. Improv. Oil Recover. by Surfactant Polym. Flooding 1977, 55-91, doi:10.1016/b978-0-12-641750-0.50007-4.

284. Taber, J.J. Research on Enhanced Oil Recovery: Past, Present and Future. In Surface Phenomena in Enhanced Oil Recovery; Shah, D.O., Ed.; Springer US: Boston, MA, 1981; pp. 13-52 ISBN 978-1-4757-0337-5.

285. Hirasaki, G.J.; Miller, C.A.; Puerto, M. Recent advances in surfactant EOR. SPE J. 2011, 16, 889-907, doi:10.2118/115386PA.

286. Soontravanich, S.; Scamehorn, J.F. Use of a Nonionic Surfactant to Inhibit Precipitation of Anionic Surfactants by Calcium. J. Surfactants Deterg. 2009, 13, 13, doi:10.1007/s11743-009-1149-z.

287. Salager, J.-L.; Forgiarini, A.; Rondón, M.J. How to Attain Ultralow Interfacial Tension and Three-Phase Behavior with a Surfactant Formulation for Enhanced Oil Recovery: a Review - Part 3. Practical Procedures to Optimize the Laboratory Research According to the Current State of the Art in Surfactant. J. Surfactants Deterg. 2017, 20, 3-19, doi:10.1007/s11743-016-1883-y.

288. Levitt, D.B.; Jackson, A.C.; Heinson, C.; Britton, L.N.; Malik, T.; Dwarakanath, V.; Pope, G.A. Identification and evaluation of high-performance EOR surfactants. SPE Reserv. Eval. Eng. 2009, 12, 243-253, doi:10.2118/100089-PA.

289. Barakat, Y.; Fortney, L.N.; LaLanne-Cassou, C.; Schechter, R.S.; Wade, W.H.; Weerasooriya, U.; Yiv, S. Phase Behavior of Simple Salt-Tolerant Sulfonates. Soc. Pet. Eng. J. 1983, 23, 913-918, doi:10.2118/10679-PA.

290. Osterloh, W.T.; Jante, M.J. Surfactant-polymer flooding with anionic PO/EO surfactant microemulsions containing polyethylene glycol additives. Eighth Symp. Enhanc. Oil Recover. 1992, 485-494, doi:10.2118/24151-ms.

291. Adkins, S.; Liyanage, P.J.; Pinnawala Arachchilage, G.W.P.; Mudiyanselage, T.; Weerasooriya, U.; Pope, G.A. A new process for manufacturing and stabilizing high-performance EOR surfactants at low cost for high-temperature, highsalinity oil reservoirs. SPE - DOE Improv. Oil Recover. Symp. Proc. 2010, 2, 1233-1241, doi:10.2118/129923-ms.

292. Barnes, J.R.; Dirkzwager, H.; Smit, J.R.; Smit, J.P.; Navarrete, R.C.; Ellison, B.H.; Buijse, M.A. Application of internal olefin sulfonates and other surfactants to EOR. Part 1: Structure - Performance relationships for selection at different reservoir conditions. SPE - DOE Improv. Oil Recover. Symp. Proc. 2010, 1, 663-678, doi:10.2118/129766-ms.

293. Wu, Y.; Iglauer, S.; Shuler, P.; Tang, Y.; Goddard, W.A. Branched alkyl alcohol propoxylated sulfate surfactants for improved oil recovery. Tenside, Surfactants, Deterg. 2010, 47, 152-161, doi:10.3139/113.110064.

294. Aoudia, M.; Al-Shibli, M.N.; Al-Kasimi, L.H.; Al-Maamari, R.; Al-Bemani, A. Novel surfactants for ultralow interfacial tension in a wide range of surfactant concentration and temperature. J. Surfactants Deterg. 2006, 9, 287-293, doi:10.1007/s11743-006-5009-9.

295. Bourrel, M.; Chambu, C. The Rules for Achieving High Solubilization of Brine and Oil by Amphiphilic Molecules. Soc. Pet. Eng. J. 1983, 23, 327, doi:10.2118/10676-PA.

296. Sahni, V.; Dean, R.M.; Britton, C.; Kim, D.H.; Weerasooriya, U.; Pope, G.A. The role of co-solvents and co-surfactants in making chemical floods robust. Proc. - SPE Symp. Improv. Oil Recover. 2010, 2, 1515-1532, doi:10.2523/130007-ms.

297. Salager, J.-L.; Antón, R.E.; Arandia, M.A.; Forgiarini, A.M. How to Attain Ultralow Interfacial Tension and ThreePhase Behavior with Surfactant Formulation for Enhanced Oil Recovery: A Review. Part 4: Robustness of the Optimum Formulation Zone Through the Insensibility to Some Variables and the Occurrence of Compl. J. Surfactants Deterg. 2017, 20, 987-1018, doi:10.1007/s11743-017-2000-6.

298. Hirasaki, G.J.; van Domselaar, H.R.; Nelson, R.C. Evaluation of the Salinity Gradient Concept in Surfactant Flooding. Soc. Pet. Eng. J. 1983, 23, 486-500, doi:10.2118/8825-PA.

299. Salager, J.L.; Márquez, N.; Antón, R.E.; Graciaa, A.; Lachaise, J. Retrograde Transition in the Phase Behavior of Surfactant-Oil-Water Systems Produced by an Alcohol Scan. Langmuir 1995, 11, 37-41, doi:10.1021/la00001a010.

300. Ysambertt, F.; Anton, R.; Salager, J.-L. Retrograde transition in the phase behaviour of surfactant-oil-water systems 
produced by an oil equivalent alkane carbon number scan. Colloids Surfaces A Physicochem. Eng. Asp. 1997, 125, 131-136, doi:https://doi.org/10.1016/S0927-7757(96)03841-1.

301. Arandia, M.A. Microemulsiones de formulación robusta a cambios de dilución y/o composición, Universidad de Los Andes, Merida, Venezuela, 2011.

302. Sasol Alcohol Ethoxylates Available online: http://www.sasoltechdata.com/MarketingBrochures/Alcohol_Ethoxylates.pdf (accessed on Oct 24, 2021).

303. BASF Care Chemicals Available online: https:/www.basf.com/global/en/investors/calendar-andpublications/factbook/business-segments/nutrition-and-care/care-chemicals.html (accessed on Oct 24, 2021).

304. Evonik Biosurfactants Available online: https://corporate.evonik.com/misc/micro/biosurfactants/index.en.html (accessed on Oct 24, 2021).

305. Tisler, S.; Liang, C.; Carvalho, P.N.; Bester, K. Identification of more than 100 new compounds in the wastewater: Fate of polyethylene/polypropylene oxide copolymers and their metabolites in the aquatic environment. Sci. Total Environ. 2021, 761, 143228, doi:https://doi.org/10.1016/j.scitotenv.2020.143228.

306. Smith, G.A.; Hand, K. Enhanced solubilization using extended chain surfactants. US Patent 20060211593. Huntsman Corporation 2006.

307. Witthayapanyanon, A.; Acosta, E.; Harwell, J.H.; Sabatini, D.A. Formulation of ultralow interfacial tension systems using extended surfactants. J. Surfactants Deterg. 2006, 9, 331-339, doi:10.1007/s11743-006-5011-2.

308. Do, L.; Withayyapayanon, A.; Harwell, J.H.; Sabatini, D.A. Environmentally friendly vegetable oil microemulsions using extended surfactants and linkers. J. Surfactants Deterg. 2009, 12, 91-99, doi:10.1007/s11743-008-1096-0.

309. Attaphong, C.; Sabatini, D.A. Optimized Microemulsion Systems for Detergency of Vegetable Oils at Low Surfactant Concentration and Bath Temperature. J. Surfactants Deterg. 2017, 20, 805-813, doi:10.1007/s11743-017-1962-8.

310. Chanwattanakit, J.; Scamehorn, J.F.; Sabatini, D.A.; Chavadej, S. Laundry Detergency of Solid Non-particulate Soil or Waxy Solids: Part I. Relation to Oily Soil Removal Above the Melting Point. J. Surfactants Deterg. 2017, 20, 815-830, doi:10.1007/s11743-017-1963-7.

311. Benita, S.; Levy, M. Submicron Emulsion as Colloidal Drug Carrier for Intravenous Administration: Comprehensive Physicochemical Characterization. J. Pharm. Sci. Vol. 82, Issue 11, Novemb. 1993, Pages 1069-1079 1993, 82, 1069-1079, doi:10.1002/jps.2600821102.

312. Benita, S. Microencapsulation: Methods and Industrial Applications; 2nd ed.; CRC Press, Taylor \& Francis, 2005;

313. Floyd, A.G. Top ten considerations in the development of parenteral emulsions. Pharm. Sci. Technolo. Today 1999, 2, 134-143, doi:https://doi.org/10.1016/S1461-5347(99)00141-8.

314. Jumaa, M.; Müller, B.W. The effect of oil components and homogenization conditions on the physicochemical properties and stability of parenteral fat emulsions. Int. J. Pharm. 1998, 163, 81-89, doi:10.1016/S0378-5173(97)00369-4.

315. Márquez, R.; Bullón, J.; Márquez, L.; Cárdenas, A.; Briceño, M.I.I.; Forgiarini, A. Rheological changes of parenteral emulsions during phase-inversion emulsification. J. Dispers. Sci. Technol. 2008, 29, 621-627, doi:10.1080/01932690801945998.

316. Cuéllar, I.; Bullón, J.; Forgarini, A.M.; Cárdenas, A.; Briceño, M.I. More efficient preparation of parenteral emulsions or how to improve a pharmaceutical recipe by formulation engineering. Chem. Eng. Sci. 2005, 60, 2127-2134, doi:10.1016/j.ces.2004.11.013.

317. Collins-Gold, L.C.; Lyons, R.T.; Bartholow, L.C. Parenteral emulsions for drug delivery. Adv. Drug Deliv. Rev. 1990, 5, 189-208, doi:10.1016/0169-409X(90)90016-L.

318. Santana, R.C.; Perrechil, F.A.; Cunha, R.L. High- and Low-Energy Emulsifications for Food Applications: A Focus on Process Parameters. Food Eng. Rev. 2013, 5, 107-122, doi:10.1007/s12393-013-9065-4.

319. Ostertag, F.; Weiss, J.; McClements, D.J. Low-energy formation of edible nanoemulsions: Factors influencing droplet 
size produced by emulsion phase inversion. J. Colloid Interface Sci. 2012, 388, 95-102, doi:10.1016/j.jcis.2012.07.089.

320. Yang, Y.; Marshall-Breton, C.; Leser, M.E.; Sher, A.A.; McClements, D.J. Fabrication of ultrafine edible emulsions: Comparison of high-energy and low-energy homogenization methods. Food Hydrocoll. 2012, 29, 398-406, doi:10.1016/j.foodhyd.2012.04.009.

321. Forgiarini, A.; Esquena, J.; González, C.; Solans, C. The Relation Between Phase Behavior and Formation of Narrow Size Distribution W/O Emulsions. J. Dispers. Sci. Technol. 2002, 23, 209-217, doi:10.1080/01932690208984201.

322. Sajjadi, S. Effect of mixing protocol on formation of fine emulsions. Chem. Eng. Sci. 2006, 61, 3009-3017, doi:10.1016/j.ces.2005.10.071.

323. Rao, J.; McClements, D.J. Stabilization of phase inversion temperature nanoemulsions by surfactant displacement. J. Agric. Food Chem. 2010, 58, 7059-7066, doi:10.1021/jf100990r.

324. Perazzo, A.; Preziosi, V.; Guido, S. Phase inversion emulsification: Current understanding and applications. Adv. Colloid Interface Sci. 2015, 222, 581-599, doi:10.1016/j.cis.2015.01.001.

325. Hörmann, K.; Zimmer, A. Drug delivery and drug targeting with parenteral lipid nanoemulsions - A review. J. Control. Release 2016, 223, 85-98, doi:10.1016/j.jconrel.2015.12.016.

326. Forgiarini, A.; Esquena, J.; González, C.; Solans, C. Studies of the relation between phase behavior and emulsification methods with nanoemulsion formation - Trends in Colloid and Interface Science XIV. In Proceedings of the Prog. Colloid Polym. Sci.; Buckin, V., Ed.; Springer Berlin Heidelberg: Berlin, Heidelberg, 2000; Vol. 115, pp. 36-39.

327. Maruno, M.; Rocha-Filho, P.A. da; da Rocha-Filho, P.A. O/W Nanoemulsion After 15 Years of Preparation: A Suitable Vehicle for Pharmaceutical and Cosmetic Applications. J. Dispers. Sci. Technol. 2009, 31, 17-22, doi:10.1080/01932690903123775.

328. Erramreddy, V.V.; Ghosh, S. Influence of droplet size on repulsive and attractive nanoemulsion gelation. Colloids Surfaces A Physicochem. Eng. Asp. 2015, 484, 144-152, doi:10.1016/j.colsurfa.2015.07.027.

329. Zhou, H.; Yue, Y.; Liu, G.; Li, Y.; Zhang, J.; Gong, Q.; Yan, Z.; Duan, M. Preparation and Characterization of a Lecithin Nanoemulsion as a Topical Delivery System. Nanoscale Res. Lett. 2010, 5, 224-230, doi:10.1007/s11671-009-9469-5.

330. Klaus, A.; Tiddy, G.J.T.; Solans, C.; Harrar, A.; Touraud, D.; Kunz, W. Effect of salts on the phase behavior and the stability of nano-emulsions with rapeseed oil and an extended surfactant. Langmuir 2012, 28, 8318-8328, doi:10.1021/la300435t.

331. Forgiarini, A.; Pietrangeli, G.; Arandia, M.; Guédez, V.; Celis, M.-T.; Márquez, L. Influencia del tipo de alcohol sobre la formación de nanoemulsiones de aceite de soja-en-agua. Cienc. e Ing. 2009, 30, 115-120.

332. Forgiarini, A.; Marquez, L.; Salager, J.L. Nanoemulsiones-Formación con baja energía. In Nanopartículas: Fundamentos y Aplicaciones; Universidad de Los Andes, Ed.; Merida, Venezuela, 2015; pp. 273-293.

333. Bullón, J.; Molina, J.; Márquez, R.; Véjar, F.; Scorzza, C.; Forgiarini, A. Nano-emulsionación de aceites triglicéridos para uso parenteral mediante un método de baja energía. Rev. Tec. la Fac. Ing. Univ. del Zulia 2007, 30, 428-437.

334. Villarreal, A.M.; Fernandez, C.; Forgiarini, A.; Marquez, L.; Nielloud, F.; Salager, J. Nanoencapsulation de filtres solaires via nanoémulsions. In Procédés et formulations au service de la santé; Durand, A., Canselier, J.-P., Eds.; EDP Sciences, 2011; pp. 1-14.

335. Salager, J.-L.; Forgiarini, A.; Lopez, J.C.; Marfisi, S.; Alvarez, G. Dynamics of Near-zero Energy Emulsification. In Proceedings of the 6th World Surfactant Congress CESIO; Berlin, 2004; Vol. 203, pp. 1-11.

336. Thakur, N.; Garg, G.; Sharma, P.K.; Kumar, N. Nanoemulsions: A Review on Various Pharmaceutical Application. Glob. J. Pharmacol. 2012, 6, 222-225, doi:10.5829/idosi.gjp.2012.6.3.65135.

337. Le Guenic, S.; Chaveriat, L.; Lequart, V.; Joly, N.; Martin, P. Renewable Surfactants for Biochemical Applications and Nanotechnology. J. Surfactants Deterg. 2019, 22, 5-21, doi:10.1002/jsde.12216.

338. Hayes, D.G. Oils and Their Use Beyond the Food Industry. In Oil and Oilseed Processing: Opportunities and Challenges; 
Lafarga, T., Bobo, G., Aguiló-Aguayo, I., Eds.; John Wiley \& Sons Ltd.: Hoboken, New Jersey, US., 2021; pp. 119-148 ISBN 9781119575313.

339. Marti-Mestres, G.; Nielloud, F. Emulsions in health care applications - An overview. J. Dispers. Sci. Technol. 2002, 23, 419-439, doi:10.1081/DIS-120003329.

340. Leal-Calderon, F.; Cansell, M. The design of emulsions and their fate in the body following enteral and parenteral routes. Soft Matter 2012, 8, 10213-10225, doi:10.1039/c2sm26215k.

341. Thakur, R.K.; Villette, C.; Aubry, J.M.; Delaplace, G. Formulation-composition map of a lecithin-based emulsion. Colloids Surfaces A Physicochem. Eng. Asp. 2007, 310, 55-61, doi:10.1016/j.colsurfa.2007.05.066.

342. Thakur, R.K.; Villette, C.; Aubry, J.M.; Delaplace, G. Spectrophotometric method associated with formulation scans for application of hydrophilic-lipophilic deviation concept in food emulsions. Colloids Surfaces A Physicochem. Eng. Asp. 2007, 301, 469-474, doi:10.1016/j.colsurfa.2007.01.028.

343. Aboofazeli, R.; Patel, N.; Thomas, M.; Lawrence, M.J. Investigations into the formation and characterization of phospholipid microemulsions. IV. Pseudo-ternary phase diagrams of systems containing water-lecithin-alcohol and oil; The influence of oil. Int. J. Pharm. 1995, 125, 107-116, doi:10.1016/0378-5173(95)00125-3.

344. Weschayanwiwat, P.; Scamehorn, J.F.; Reilly, P.J. Surfactant properties of low molecular weight phospholipids. J. Surfactants Deterg. 2005, 8, 65-72, doi:10.1007/s11743-005-0332-8.

345. Yu, L.; Li, C.; Xu, J.; Hao, J.; Sun, D. Highly stable concentrated nanoemulsions by the phase inversion composition method at elevated temperature. Langmuir 2012, 28, 14547-14552, doi:10.1021/la302995a.

346. Schwartzberg, L.S.; Navari, R.M. Safety of Polysorbate 80 in the Oncology Setting. Adv. Ther. 2018, 35, 754-767, doi:10.1007/s12325-018-0707-z.

347. Hosmer, J.; Reed, R.; Bentley, M.V.L.B.; Nornoo, A.; Lopes, L.B. Microemulsions containing medium-chain glycerides as transdermal delivery systems for hydrophilic and hydrophobic drugs. AAPS PharmSciTech 2009, 10, 589-596, doi:10.1208/s12249-009-9251-0.

348. Hategekimana, J.; Chamba, M.V.M.; Shoemaker, C.F.; Majeed, H.; Zhong, F. Vitamin E nanoemulsions by emulsion phase inversion: Effect of environmental stress and long-term storage on stability and degradation in different carrier oil types. Colloids Surfaces A Physicochem. Eng. Asp. 2015, 483, 70-80, doi:10.1016/j.colsurfa.2015.03.020.

349. Ismail, Z.; Kassim, A.; Suhaimi, H.; Ahmad, S. Physicochemical properties of a ternary system based on medium chain triglycerides/water/mixed nonionic sugar-based surfactants. J. Dispers. Sci. Technol. 2001, 22, 261-268, doi:10.1081/DIS100105213.

350. Kogan, A.; Garti, N. Microemulsions as transdermal drug delivery vehicles. Adv. Colloid Interface Sci. 2006, 123-126, 369-385, doi:10.1016/j.cis.2006.05.014.

351. Fernandez, P.; André, V.; Rieger, J.; Kühnle, A. Nano-emulsion formation by emulsion phase inversion. Colloids Surfaces A Physicochem. Eng. Asp. 2004, 251, 53-58, doi:10.1016/j.colsurfa.2004.09.029.

352. Solè, I.; Pey, C.M.; Maestro, A.; González, C.; Porras, M.; Solans, C.; Gutiérrez, J.M. Nano-emulsions prepared by the phase inversion composition method: Preparation variables and scale up. J. Colloid Interface Sci. 2010, 344, 417-423, doi:10.1016/j.jcis.2009.11.046.

353. Komaiko, J.; McClements, D.J. Low-energy formation of edible nanoemulsions by spontaneous emulsification: Factors influencing particle size. J. Food Eng. 2015, 146, 122-128, doi:10.1016/j.jfoodeng.2014.09.003.

354. Mohlin, K.; Holmberg, K.; Esquena, J.; Solans, C. Study of low energy emulsification of alkyl ketene dimer related to the phase behavior of the system. Colloids Surfaces A Physicochem. Eng. Asp. 2003, 218, 189-200, doi:10.1016/S09277757(02)00585-X.

355. López-Montilla, J.C.; James, M.A.; Crisalle, O.D.; Shah, D.O. Surfactants and protocols to induce spontaneous emulsification and enhance detergency. J. Surfactants Deterg. 2005, 8, 45-53, doi:10.1007/s11743-005-0329-3. 
356. López-Montilla, J.C.; Herrera-Morales, P.E.; Pandey, S.; Shah, D.O.; Lapez-Montilla, J.C.; Herrera-Morales, P.E.; Pandey, S.; Shah, D.O. Spontaneous emulsification: Mechanisms, physicochemical aspects, modeling, and applications. J. Dispers. Sci. Technol. 2002, 23, 219-268, doi:10.1080/01932690208984202.

357. Solè, I.; Maestro, A.; Pey, C.M.; González, C.; Solans, C.; Gutiérrez, J.M. Nano-emulsions preparation by low energy methods in an ionic surfactant system. Colloids Surfaces A Physicochem. Eng. Asp. 2006, 288, 138-143, doi:10.1016/j.colsurfa.2006.02.013.

358. Solans, C.; Izquierdo, P.; Nolla, J.; Azemar, N.; Garcia-Celma, M.J. Nano-emulsions. Curr. Opin. Colloid Interface Sci. 2005, 10, 102-110, doi:10.1016/j.cocis.2005.06.004.

359. Guzey, D.; McClements, D.J. Formation, stability and properties of multilayer emulsions for application in the food industry. Adv. Colloid Interface Sci. 2006, 128-130, 227-248, doi:10.1016/j.cis.2006.11.021.

360. Ghosh, S.; Hornby, S.; Grove, G.; Zerwick, C.; Appa, Y.; Blankschtein, D. Ranking of aqueous surfactant-humectant systems based on an analysis of in vitro and in vivo skin barrier perturbation measurements. J. Cosmet. Sci. 2007, 58, 599-620.

361. Sousa, G.D.; De Souza Dantas, I.M.; De Santana, D.P.; Leal, L.B. New Oils for Cosmetic O/W Emulsions: In Vitro/In Vivo Evaluation. Cosmetics 2018, 5, doi:10.3390/cosmetics5010006.

362. Adejokun, D.A.; Dodou, K. Quantitative Sensory Interpretation of Rheological Parameters of a Cream Formulation. Cosmetics 2020, 7, doi:10.3390/cosmetics7010002.

363. Walters, K.A.; Brain, K.R. Dermatological formulation and transdermal systems. Dermatological Transdermal Formul. 2002, 319-400, doi:10.1201/9780824743239-10.

364. Haq, A.; Dorrani, M.; Goodyear, B.; Joshi, V.; Michniak-Kohn, B. Membrane properties for permeability testing: Skin versus synthetic membranes. Int. J. Pharm. 2018, 539, 58-64, doi:10.1016/j.ijpharm.2018.01.029.

365. Harwansh, R.K.; Patra, K.C.; Pareta, S.K.; Singh, J.; Rahman, M.A. Nanoemulsions as vehicles for transdermal delivery of glycyrrhizin. Brazilian J. Pharm. Sci. 2011, 47, 769-778, doi:10.1590/S1984-82502011000400014.

366. Bouwstra, J.A. The skin barrier, a well-organized membrane. Colloids Surfaces A Physicochem. Eng. Asp. 1997, 124, 403413, doi:10.1016/S0927-7757(96)03819-8.

367. Peña-Juárez, M.C.; Guadarrama-Escobar, O.R.; Escobar-Chávez, J.J. Transdermal Delivery Systems for Biomolecules. J. Pharm. Innov. 2021, doi:10.1007/s12247-020-09525-2.

368. Van Bocxlaer, K.; McArthur, K.-N.; Harris, A.; Alavijeh, M.; Braillard, S.; Mowbray, C.E.; Croft, S.L. Film-Forming Systems for the Delivery of DNDI-0690 to Treat Cutaneous Leishmaniasis. Pharmaceutics 2021, 13, doi:10.3390/pharmaceutics13040516.

369. Demisli, S.; Mitsou, E.; Pletsa, V.; Xenakis, A.; Papadimitriou, V. Development and Study of Nanoemulsions and Nanoemulsion-Based Hydrogels for the Encapsulation of Lipophilic Compounds. Nanomaterials 2020, 10, doi:10.3390/nano10122464.

370. Uchida, T.; Kadhum, W.R.; Kanai, S.; Todo, H.; Oshizaka, T.; Sugibayashi, K. Prediction of skin permeation by chemical compounds using the artificial membrane, Strat-M ${ }^{\mathrm{TM}}$. Eur. J. Pharm. Sci. 2015, 67, 113-118, doi:https://doi.org/10.1016/j.ejps.2014.11.002.

371. Bullón, J.; Márquez, L.; Fernández, J.A.; Scorzza, C.; Scorza, J.V.; Rodríguez, J.; Cordero, A.; Vejar, F.; Khatib, S.K.; Forgiarini, A. A Promising Cutaneous Leishmaniasis Treatment with a Nanoemulsion-Based Cream with a Generic Pentavalent Antimony (Ulamina) as the Active Ingredient. Cosmetics 2021, 8, doi:10.3390/cosmetics8040115.

372. Xing, H.; Krogmann, A.R.; Vaught, C.; Chambers, E. Understanding the Global Sensory Landscape for Facial Cleansing/Makeup Remover Wipes. Cosmetics 2019, 6, doi:10.3390/cosmetics6030044.

373. Krasodomska, O.; Jungnickel, C. Viability of fruit seed oil O/W emulsions in personal care products. Colloids Surfaces A Physicochem. Eng. Asp. 2015, 481, 468-475, doi:10.1016/j.colsurfa.2015.06.022. 
374. Tchakalova, V.; Fieber, W. Classification of fragrances and fragrance mixtures based on interfacial solubilization. J. Surfactants Deterg. 2012, 15, 167-177, doi:10.1007/s11743-011-1295-y.

375. Bouton, F. Influence of terpenes and terpenoids on the phase behavior of micro- and macro-emulsions, Universite de Lille, 2010.

376. Sajinčič, N.; Gordobil, O.; Simmons, A.; Sandak, A. An Exploratory Study of Consumers' Knowledge and Attitudes about Lignin-Based Sunscreens and Bio-Based Skincare Products. Cosmetics 2021, 8, doi:10.3390/cosmetics8030078.

377. Ghosh, S.; Blankschtein, D. Why is sodium cocoyl isethionate (SCI) mild to the skin barrier? - An in vitro investigation based on the relative sizes of the SCI micelles and the skin aqueous pores. J. Cosmet. Sci. 2007, 58, 229-244, doi:10.1111/j.1468-2494.2007.00405_3.x.

378. Frézard, F.; Demicheli, C.; Ribeiro, R.R. Pentavalent Antimonials: New Perspectives for Old Drugs. Molecules 2009, 14, doi:10.3390/molecules14072317.

379. Buffet, P.A.; Morizot, G. Cutaneous leishmaniasis in France: towards the end of injectable therapy? Bull. Soc. Pathol. Exot. 2003, 96, 383-388.

380. Shmulsky, R.; P. David Jones Durability and Protection. In Forest Products and Wood Science: An Introduction; Shmulsky, R., Jones, P.D., Eds.; Wiley Online Books; Wiley, 2019; pp. 231-255 ISBN 9781119426400.

381. Gardner, D.J.; Generalla, N.C.; Gunnells, D.W.; Wolcott, M.P. Dynamic wettability of wood. Langmuir 1991, 7, 24982502, doi:10.1021/la00059a017.

382. Gindl, M.; Reiterer, A.; Sinn, G.; Stanzl-Tschegg, S.E. Effects of surface ageing on wettability, surface chemistry, and adhesion of wood. Holz als Roh - und Werkst. 2004, 62, 273-280, doi:10.1007/s00107-004-0471-4.

383. Bullon, J. Technical Report FIRP 1308. Development of a Product, for the Preservation of Sawn Wood of Caribbean Pine and other Plantation Species; Merida, Venezuela. Report of the project funded by the National Center for Chemical Technology CNTQ, 2013;

384. Homayuni, F.; Hamidi, A.A.; Vatani, A.; Shaygani, A.A.; Faraji Dana, R. The viscosity reduction of heavy and extra heavy crude oils by a pulsed magnetic field. Pet. Sci. Technol. 2011, 29, 2407-2415, doi:10.1080/10916461003645443.

385. Less, S.; Hannisdal, A.; Bjørklund, E.; Sjöblom, J. Electrostatic destabilization of water-in-crude oil emulsions: Application to a real case and evaluation of the Aibel VIEC technology. Fuel 2008, 87, 2572-2581, doi:10.1016/j.fuel.2008.03.004.

386. Dudek, M.; Vik, E.A.; Aanesen, S.V.; Øye, G. Colloid chemistry and experimental techniques for understanding fundamental behaviour of produced water in oil and gas production. Adv. Colloid Interface Sci. 2020, 276, 102105, doi:10.1016/j.cis.2020.102105.

387. Olajire, A.A. Recent advances on the treatment technology of oil and gas produced water for sustainable energy industry-mechanistic aspects and process chemistry perspectives. Chem. Eng. J. Adv. 2020, 4, 100049, doi:10.1016/j.ceja.2020.100049.

388. Jiménez, S.; Micó, M.M.; Arnaldos, M.; Medina, F.; Contreras, S. State of the art of produced water treatment. Chemosphere 2018, 192, 186-208, doi:10.1016/j.chemosphere.2017.10.139.

389. Abdulredha, M.M.; Siti Aslina, H.; Luqman, C.A. Overview on petroleum emulsions, formation, influence and demulsification treatment techniques. Arab. J. Chem. 2020, 13, 3403-3428, doi:10.1016/j.arabjc.2018.11.014.

390. ASTM ASTM D-7678 Standard Test Method for Total Petroleum Hydrocarbons (TPH) in Water and Wastewater with Solvent Extraction using Mid-IR Laser Spectroscopy 2017.

391. Eaton, A.D.; Clesceri, L.S.; Greenberg, A.E.; Franson, M.A.H. Standard Methods for the Examination of Water and Wastewater; 23th ed.; American Water Works Association: Washington, USA, 1995;

392. Duan, M.; Wang, C.; Song, X.; Fang, S.; Ma, Y.; Tao, T. A block polyether designed quantitatively by HLD concept for recovering oil from wastewater. Chem. Eng. J. 2016, 302, 44-49, doi:10.1016/j.cej.2016.05.036. 
393. Ghasemi, H.; Eslami, F. Design of industrial wastewater demulsifier by HLD-NAC model. Sci. Rep. 2021, 11, 16111, doi:10.1038/s41598-021-95485-7.

394. Babak, V.G.; Stébé, M.-J. Highly Concentrated Emulsions: Physicochemical Principles of Formulation. J. Dispers. Sci. Technol. 2002, 23, 1-22, doi:10.1080/01932690208984184.

395. Solans, C.; Pons, R.; Zhu, S.; Davis, H.T.; Evans, D.F.; Nakamura, K.; Kunieda, H. Studies on Macro- and Microstructures of Highly Concentrated Water-in-Oil Emulsions (Gel Emulsions). Langmuir 1993, 9, 1479-1482, doi:10.1021/la00030a009.

396. Mahadevan, E.G. Ammonium Nitrate Explosives for Civil Applications; Wiley Online Books; Wiley-VCH Verlag GmbH \& Co. KGaA: Weinheim, Germany, 2013; ISBN 9783527645688.

397. Das, A.K.; Ghosh, P.K. Concentrated Emulsions. Investigation of Polydispersity and Droplet Distortion and Their Effect on Volume Fraction and Interfacial Area1. Langmuir 1990, 6, 1668-1675, doi:10.1021/la00101a008.

398. Rámirez, M.; Bullón, J.; Andérez, J.; Mira, I.; Salager, J.L. Drop size distribution bimodality and its effect on O/W emulsion viscosity. J. Dispers. Sci. Technol. 2002, 23, 309-321, doi:10.1081/DIS-120003322.

399. Hancsók, J.; Bartha, L.; Baladincz, J.; Kocsis, Z. Relationship between the properties of polyisobutenyl succinic anhydrides and their additive derivatives. Lubr. Sci. 1999, 11, 297-310, doi:https://doi.org/10.1002/1s.3010110307.

400. Foudazi, R.; Masalova, I.; Malkin, A.Y. The rheology of binary mixtures of highly concentrated emulsions: Effect of droplet size ratio. J. Rheol. (N. Y. N. Y). 2012, 56, 1299, doi:10.1122/1.4736556.

401. Bengtsson, L.A.; Frostemark, F.; Holmberg, B. Speciation, structural characteristics and proton dynamics in the systems NH4NO3. $1.5 \mathrm{H} 2 \mathrm{O}$ and $\mathrm{NH} 4 \mathrm{NO} 3 \cdot 1.5 \mathrm{H} 2 \mathrm{O}-(\mathrm{HNO} 3, \mathrm{NH} 4 \mathrm{~F}, \mathrm{NH} 3)-\mathrm{H} 2 \mathrm{O}$ at $50{ }^{\circ} \mathrm{C}$. J. Chem. Soc. Faraday Trans. 1994, 90, 559-570, doi:10.1039/FT9949000559.

402. Masalova, I.; Foudazi, R.; Malkin, A.Y. The rheology of highly concentrated emulsions stabilized with different surfactants. Colloids Surfaces A Physicochem. Eng. Asp. 2011, 375, 76-86, doi:10.1016/j.colsurfa.2010.11.063.

403. Foudazi, R.; Masalova, I.; Malkin, A.Y. Flow behaviour of highly concentrated emulsions of supersaturated aqueous solution in oil. Rheol. Acta 2011, 50, 897-907, doi:10.1007/s00397-010-0505-2.

404. Masalova, I.; Taylor, M.; Kharatiyan, E.; Malkin, A.Y. Rheopexy in highly concentrated emulsions. J. Rheol. (N. Y. N. Y). 2005, 49, 839-849, doi:10.1122/1.1940641.

405. Yaron, P.N.; Scott, A.J.; Reynolds, P.A.; Mata, J.P.; White, J.W. High Internal Phase Emulsions under Shear. CoSurfactancy and Shear Stability. J. Phys. Chem. B 2011, 115, 5775-5784, doi:10.1021/jp2005919.

406. Ortiz, M.; Alvarado, J.G.; Zambrano, F.; Marquez, R. Surfactants produced from carbohydrate derivatives. A review of the biobased building blocks used in their synthesis. J. Surfactants Deterg. 2022, doi:10.1002/jsde.12581. 